TÂNIS MOREIRA RODRIGUES DE MOURA

O RESULTADO FONOAUDIOLÓGICO DA AUDIÇÃO E DA LINGUAGEM ASSOCIA-SE COM A PERCEPÇÃO DO RESULTADO DOS PAIS E DOS PROFESSORES DE CRIANÇAS USUÁRIAS DO IMPLANTE COCLEAR? 


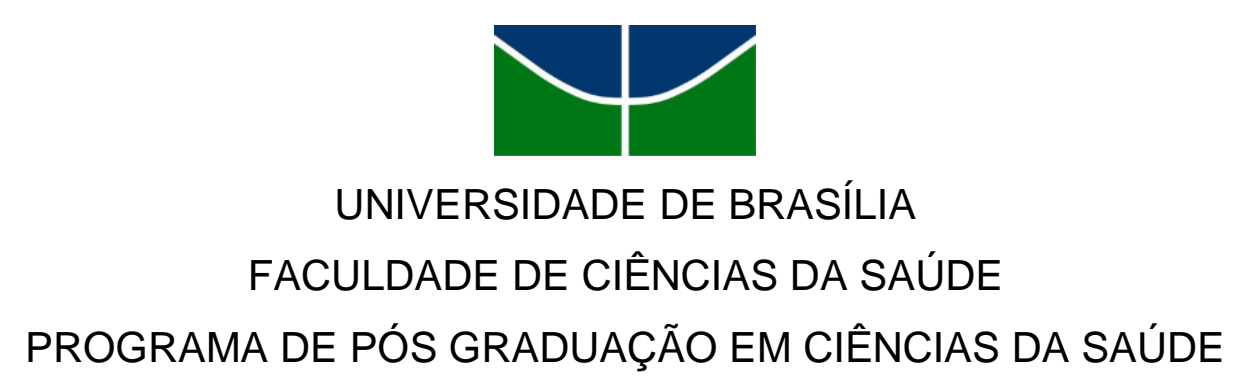

TÂNIS MOREIRA RODRIGUES DE MOURA

O RESULTADO FONOAUDIOLÓGICO DA AUDIÇÃO E DA LINGUAGEM ASSOCIA-SE COM A PERCEPÇÃO DO RESULTADO DOS PAIS E DOS PROFESSORES DE CRIANÇAS USUÁRIAS DO IMPLANTE COCLEAR?

Dissertação apresentada como requisito parcial para a obtenção do Título de Mestre em Ciências da Saúde pelo Programa de Pós Graduação em Ciências da Saúde da Universidade de Brasília.

Orientador: Prof. Dr. Carlos Augusto Costa Pires Oliveira Co-orientador: Prof. Dr. André Luiz Lopes Sampaio

Brasília - DF 2016 


\title{
O RESULTADO FONOAUDIOLÓGICO DA AUDIÇÃO E DA LINGUAGEM ASSOCIA-SE COM A PERCEPÇÃO DO RESULTADO DOS PAIS E DOS PROFESSORES DE CRIANÇAS USUÁRIAS DO IMPLANTE COCLEAR?
}

\author{
Dissertação apresentada como requisito parcial para a \\ obtenção do Título de Mestre em Ciências da Saúde pelo \\ Programa de Pós Graduação em Ciências da Saúde da \\ Universidade de Brasília.
}

Aprovado em: 20/07/2016.

\section{Banca Examinadora}

$1^{\circ}$ Membro (presidente): Professor Doutor Carlos Augusto Costa Pires Oliveira Pesquisador Associado Sênior do Programa de Pós Graduação da Faculdade de Medicina e da Faculdade de Ciências da Saúde da Universidade de Brasília

$2^{\circ}$ Membro: Professora Doutora Alessandra da Rocha Arrais Professora da Escola Superior de Ciências da Saúde - ESCS

$3^{\circ}$ Membro: Professora Doutora Amaralina Miranda de Souza

Professora da Faculdade de Educação - Departamento de Teoria e Fundamentos da Universidade de Brasília

Suplente: Professora Doutora Valéria Reis do Canto Pereira Professora da Faculdade de Fonoaudiologia da Universidade de Brasília 


\section{AGRADECIMENTOS}

Agradeço a Deus porque tem me dado o fôlego de vida e força para viver, produzir e reproduzir (Ester nasceu!), apesar dos dilemas do dia-a-dia.

À minha família, por ter me mostrado o quanto sou forte. Especialmente à minha mãe, Ana Maria, pelo exemplo de vida e força que me ajuda e me encoraja a prosseguir.

Ao meu pai, Antônio Xepa, que embora em poucos encontros, é sempre especial e sábio em seus ensinamentos, é forte sem perder a doçura.

Ao meu "fibrinho", Diogo Igor, a quem muito amo, pois mesmo passando por momentos difíceis, continua de pé.

Ao meu marido, Adilson, que acredita no meu potencial e aos meus filhos, João Lucas e Ester, que me enchem o coração de alegria.

À Gabriela Moreira que chegou na nossa família em um tempo turbulento para acalmar os nossos corações.

Ao Dr. Carlos Augusto por se arriscar em investir em mim.

Ao Dr. André Luís Lopes Sampaio pelo incentivo, ajuda e exemplo de garra, força e simplicidade.

Ao Dr. Elioenai (in memoriam) pelo acolhimento, encorajamento, suporte, simpatia e motivação. Sua presença foi de extrema relevância. Fiquei encantada por conhecer alguém tão rico e inspirador, com tanta força mesmo em tempo de fragilidade.

Ao Centro Educacional de Audição e Linguagem Ludovico Pavoni - CEAL - na pessoa do Pe. José Rinaldi, pela abertura, confiança, liberalidade e gentileza. Pude ver o amor que há pelas crianças e o cuidado dispensado a elas.

Às fonoaudiólogas Flávia, Cristiane e suas equipes pela ajuda, presteza e apoio no transcorrer da coleta de dados.

Aos pais das crianças usuárias de implante coclear que participaram da pesquisa e foram fundamentais para a realização deste trabalho.

Aos professores das escolas regulares que também participaram e puderam contribuir para o aperfeiçoamento do olhar frente aos implantados.

À Universidade de Brasília que me abriu as portas para o estudo e o aprimoramento da minha formação. 
Ao Hospital Universitário de Brasília que me mostrou um novo campo de atuação e refinou a minha vivência frente à surdez.

Às pessoas raras que conheci e que me encantaram pela sabedoria, coragem, vigor, esperança, força, alegria, criatividade, presteza, adaptação e amor. Especialmente às mães de crianças surdas que lutam para que seus filhos aprendam, se superem, se adaptem, se coloquem no mundo e, acima de tudo, sejam felizes. 


\section{RESUMO}

INTRODUÇÃO: O implante coclear (IC) em crianças pré-linguais tem obtido resultados diversificados. Este estudo tem como objetivo investigar se o resultado fonoaudiológico auditivo e linguístico associa-se com a percepção dos resultados dos pais e professores de crianças usuárias de IC. MÉTODO: Participaram do estudo 40 pais, selecionados em um centro de reabilitação auditiva, e 39 professores de escolas regulares do Distrito Federal, Brasil. Aos pais foi aplicado o questionário "Crianças com implante coclear: perspectivas dos pais", validado para o Brasil. Desenvolveu-se um questionário de acordo com as categorias de audição e linguagem a partir da literatura pesquisada, que foi aplicado aos pais e aos professores. Aos últimos acrescentou-se duas questões fechadas sobre o desempenho escolar do estudante. As fonoterapeutas das crianças classificaram cada uma de acordo com as categorias de audição e de linguagem. RESULTADOS: Os resultados mostram que os pais tem uma concepção positiva sobre o IC e esta percepção torna-se mais positiva com o passar dos anos, apontando ganhos significativos relacionados à linguagem, relações sociais e educação dos seus filhos, contudo, a idade de implantação não correlacionase de forma ainda mais positiva com os resultados. Os pais e professores concordam mais com os resultados na esfera da linguagem que na audição, e que quanto maior o desempenho da audição e da linguagem, melhor é a comunicação e a educação da criança. CONCLUSÃO: Sugere-se que a avaliação clínica fonoaudiológica seja enriquecida com questões parentais e acadêmicas dos implantados com o objetivo de sinalizar problemas que necessitem ser ajustados ao longo do processo de reabilitação.

PALAVRAS-CHAVE: Implante Coclear; crianças; pais; professores; comunicação; educação; audição; linguagem. 


\begin{abstract}
INTRODUCTION: Cochlear implants in prelingual children have achieved mixed results. The aim of this study was to investigate the gains obtained by cochlear implant users indicated by their parents and teachers. METHOD: The study included 40 parents, selected in a hearing rehabilitation center, and 39 teachers from regular schools of the Federal District of Brasilia, Brazil. Parents completed the Children with cochlear implants: parental perspectives questionnaire validated for Brazil. Another questionnaire was developed according to the hearing and language categories in the research literature and completed by parents and teachers. Two closed questions about the academic performance of the student were added to the end. The speechlanguage therapists of the children classified each child according to the categories of hearing and language. RESULTS: The results show that parents have a positive conception of cochlear implants and this perception becomes more positive over time, pointing to significant gains related to the language, social relationships, and education of their children, however, age of implantation does not correlate even more favorably to the results. Agreement between parents and teachers was greater for gains in language than for hearing. In addition, the higher the hearing and language performance, the better the communication and education of the child. CONCLUSION: Findings indicate that the phonoaudiological clinical evaluation needs to be enriched with parental and academic questions to signal problems that need to be adjusted over the rehabilitation process.
\end{abstract}

Keywords: cochlear implant; children; parents; teachers; communication; education; hearing; language. 


\section{LISTA DE TABELAS}

Tabela 1 - Matriz de correlação CCIPP - Rho de Spearman e p-valor........................49

Tabela 2 - Avaliação fonoaudilógica da audição e linguagem..................................52

Tabela 3 - Questionário elaborado para pais e professores - Correlação tau-b de

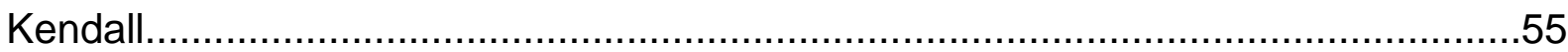

Tabela 4 - Avaliação fonoaudiológica e escalas do CCIPP - Rho de Spearman e pvalor. 


\section{LISTA DE FIGURAS}

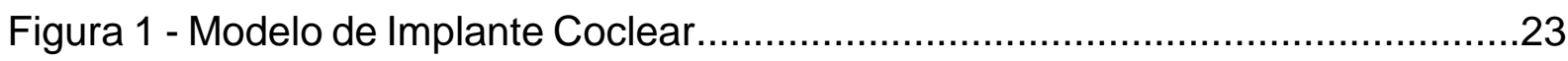

Figura 2 - Funcionamento do Implante Coclear ...................................................24

Figura 3 - Ranking da percepção dos pais por escalas do CCIPP ............................48

Figura 4 - Percepção do resultado dos pais de crianças com menos e mais de 5 anos de uso nas escalas do CCIPP .50

Figura 5 - Percepção dos pais de crianças implantadas até aos 2 anos, de 2 aos 5 anos e com mais de 5 anos nas escalas do CCIPP 51

Figura 6 - Proporção de classificação da linguagem por tempo de uso do IC...............53

Figura 7 - Proporção de classificação da audição por tempo de uso do IC...................53

Figura 8 - Proporção de classificação da linguagem por idade no implante..................54

Figura 9 - Proporção de classificação da audição por idade no implante......................54 


\section{LISTA DE ABREVIATURAS}

DANS Deficiência Auditiva Neurossensorial

IRDA Indicadores de Risco para Deficiência Auditiva

IBGE Instituto Brasileiro de Geografia e Estatística

DA Deficiência Auditiva

TANU Triagem Auditiva Neonatal Universal

SUS S Sistema Único de Saúde

IC Implante Coclear

SNC Sistema Nervoso Central

MBP Muito Baixo Peso

UTI Unidade de Tratamento Intensivo

PAC Processamento Auditivo Central

CEAL Centro Educacional de Audição e Linguagem Ludovico Pavoni

AASI Aparelho de Amplificação Sonora Individual

FM Frequência Modulada 


\section{SUMÁRIO}

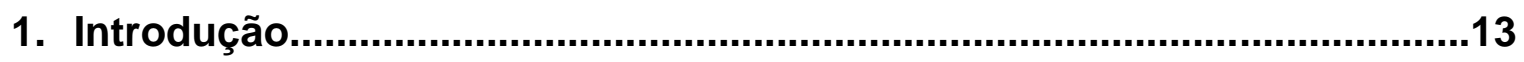

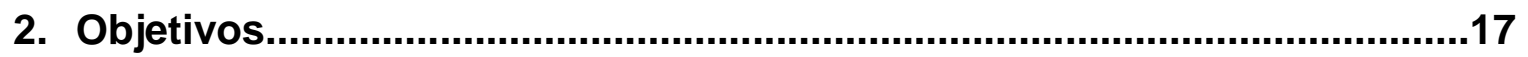

3. Revisão de literatura

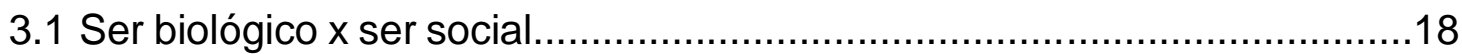

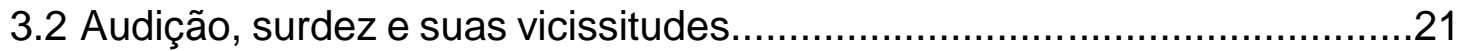

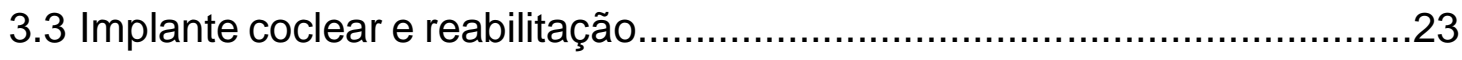

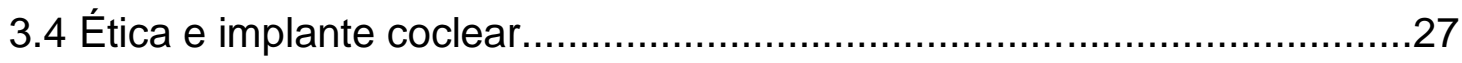

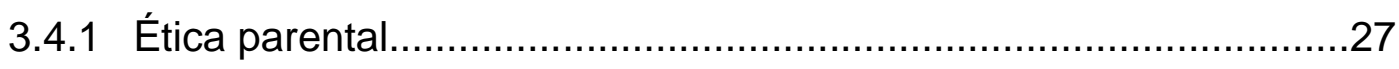

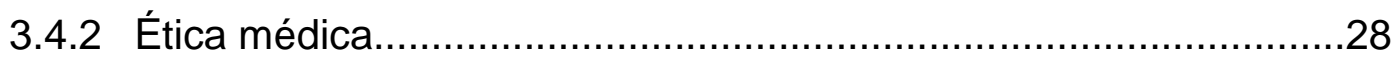

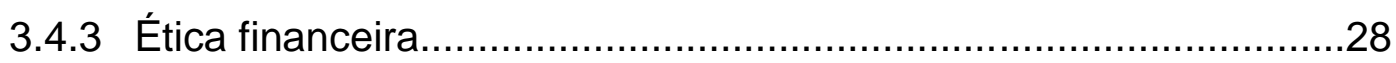

3.5 Implante coclear e Libras...........................................................

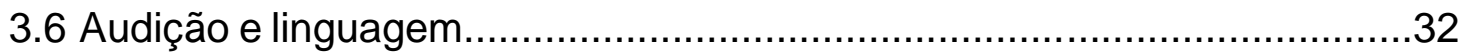

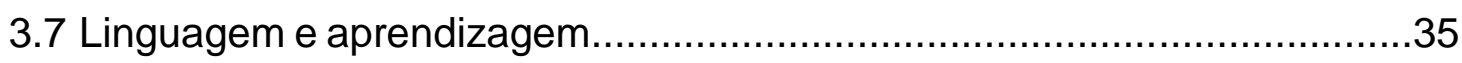

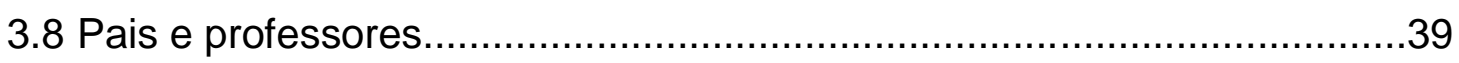

3.9 Resultados de longo prazo com uso do IC ..........................................42

4. Metodologia

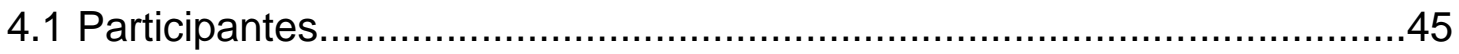

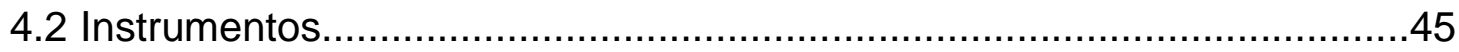

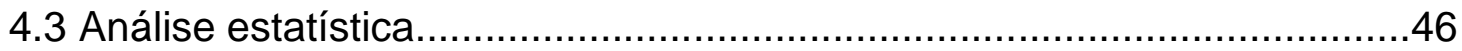

5. Resultados

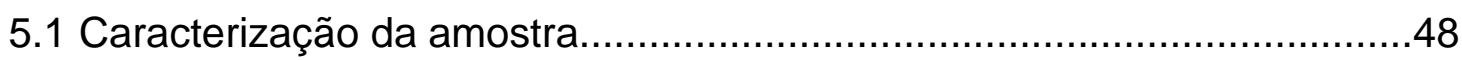

5.2 Percepção dos pais avaliados pelo instrumento "Crianças com implante

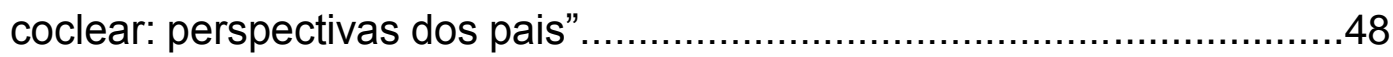

5.3 Avaliação das crianças usuárias de IC de acordo com as categorias de audição e linguagem.........................................................................

5.4 Associação entre a avaliação dos pais e dos professores...........................55

5.5 Correlação entre a perspectiva dos pais e a avaliação fonoaudiológica da

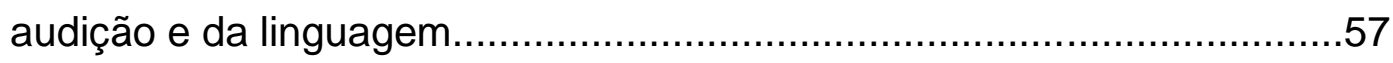

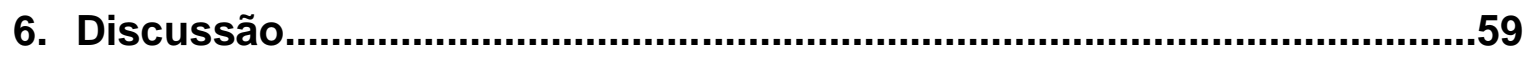

6.1 Percepção dos pais sobre os resultados do IC avaliadas pelo CCIPP.........59 
6.2 Avaliação fonoaudilógica da audição e da linguagem de crianças usuárias de

IC.

6.3 Associação entre avaliação de pais e professores de crianças usuárias de IC 62

6.4 Correlação entre a percepção dos pais e a avaliação da audição e da linguagem realizada pelos fonoaudiólogos. .66

7. Conclusão. .68

8. Referências Bibliográficas. 69

9. Apêndice

A - Termo de Consentimento Livre e Esclarecido - Pais............................81

B - Termo de Consentimento Livre e Esclarecido - Professores.....................82

$\mathrm{C}-$ Questionário dos professores.................................................... 83

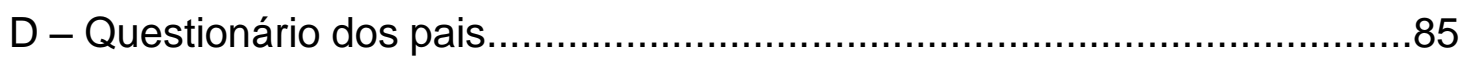

10. ANEXOS

I - Termo de Concordância da Instituição Co-participante.............................88

II - Parecer do Comitê de Ética em Pesquisa...............................................89

V - Questionário “Crianças com implante coclear: perspectivas dos pais”.......91 


\section{1- INTRODUÇÃO}

A audição é o sentido basilar para o desenvolvimento da língua falada. É por meio da linguagem que introjetamos o conhecimento, a cultura, as regras sociais e a interação humana mais refinada, mediada pela linguagem simbólica ${ }^{1 ; 2}$. É por seu intermédio que aprendemos a estrutura dos significantes e significados, damos sentido às coisas. É através da linguagem que ocorre a constituição/subjetivação do indivíduo enquanto pessoa e por ela a possibilidade de apreensão e compreensão do mundo ${ }^{2}$.

Por estarmos dentro de um modelo social oralizado, a deficiência auditiva (DA) inscreve dificuldades sociais, linguísticas e escolares na pessoa que tem DA ${ }^{3}$.

As dificuldades de comunicação advindas da perda auditiva podem gerar no indivíduo tanto problemas internos, como insegurança, dependência, inibição, irritação, diminuição da auto-estima, quanto também sociais, como a diminuição da escolarização e de oportunidades trabalhistas, consequentemente ${ }^{4 ; 5}$.

A surdez pode estar presente em vários graus. A perda auditiva leve $\mathrm{e}$ moderada são tipos que apresentam bons ganhos com o Aparelho de Amplificação Sonora Individual (AASI). A perda severa nem sempre é bem ajustada com o uso de AASI e a profunda, mesmo com a amplificação, não apresenta ganhos auditivos nas ondas da fala. Ou seja, os tipos mais debilitantes são esses dois últimos, pois captam poucas ou nenhuma das frequências da fala humana, o que ocasiona dificuldade e/ou impossibilidade de aprendizagem da língua ${ }^{6}$.

A deficiência auditiva é altamente prevalente. Seu índice em neonatos aumenta em $10 \%$ devido a fatores de risco associados ao pré termo $7 ; 8 ; 9$. No Brasil estima-se que $5,1 \%$ da população em geral tenha algum tipo de DA ${ }^{10}$.

Devido à alta incidência da surdez é que tem se consolidado os serviços de Triagem Auditiva Neonatal Universal (TANU) e os programas de Saúde Auditiva e Implante Coclear através da Política Nacional de Atenção à Saúde Auditiva, do Ministério da Saúde ${ }^{11}$. A reabilitação auditiva por meio do Implante Coclear (IC), disponibilizado pelo Sistema Único de Saúde (SUS), surge a partir da implementação desta Política.

O implante coclear (IC) é um dispositivo implantado cirurgicamente na cóclea que possibilita a retomada progressiva da habilidade de ouvir, após treino 
fonoaudiológico e ajustes através dos mapeamentos realizados ao longo de 3-5 anos 12; 13. Os mapeamentos visam ajustar os estímulos elétricos e as frequências sonoras gradualmente, para possibilitar a adaptação neurológica através do ouvido interno do usuário ${ }^{7}$.

O implante coclear pode possibilitar a audição e, com isso, a aquisição da linguagem oral. Contudo, outros fatores, como a qualidade das interações sociais, são também significativos e têm um papel crucial na constituição do indivíduo como sujeito de linguagem $2 ; 5 ; 14$.

Como a linguagem se ramifica para todos os contextos da vida, é natural pensar na complexidade da questão do implante coclear, embora seja difícil apreendê-la em toda a sua dinâmica e profundidade.

A criança encontra-se em fase de desenvolvimento e vincular pais e professores como informantes do quanto a melhora da capacidade auditiva, advinda do uso do IC, interfere no desenvolvimento global da criança é essencial para vermos os reais benefícios do uso dessa tecnologia para o indivíduo. É importante averiguar se os ganhos obtidos com o uso do IC em crianças se estendem aos seus ambientes mais frequentados, para além da avaliação clínica fonoaudiológica da audição e da linguagem que ocorre em situações ideais para comunicação e que nem sempre são reproduzidas nas situações da vida real, por exemplo no ambiente escolar.

Estudos apontam que os pais são bons informantes e várias pesquisas tem se utilizado das informações fornecidas pelos pais, pela dificuldade de coleta com as crianças, seja pela idade ou pela dificuldade de compreensão devido à privação auditiva $15 ; 16 ; 17$.

A literatura tem mostrado alguns preditores de sucesso do implante coclear realizado em crianças: o curto tempo de privação auditiva, o maior tempo de uso do IC, a idade de implantação antes dos 12 meses, o uso de linguagem oral, o resíduo auditivo, os ajustes no dispositivo, a tecnologia do IC, o estilo parental, a capacidade cognitiva da criança e o uso de implantes bilaterais, tem sido cada vez mais consolidados neste campo 18; 19; 20 21; 22; 23; 24; 2526.

No entanto, outros fatores são controversos e desafiadores quando tratamos de crianças implantadas. A questão da qualidade das relações sociais, da aprendizagem escolar e da comunicação da criança são discutidos a fim de se expor quais os reais ganhos possibilitados pelo uso deste aparelho nos infantes 27; 28; 29; 30; 31; 32 . 
Não se questiona que o IC pediátrico melhora a habilidade de fala em crianças surdas ${ }^{33} ; 34$. E estudos tem mostrado que se alcança um valor médio de linguagem depois de 6-8 anos de uso do IC, em crianças implantadas antes dos 2 anos de idade 26; 35. Isto significa que os atrasos linguísticos devido a surdez infantil persistem durante toda a pré-escola e seus anos iniciais para muitas crianças, o que ocasiona consequências negativas para seu contexto educacional e seu desenvolvimento psicossocial $^{22 ; 27 ; 28 .}$

Estudos recentes mostram que as crianças que experimentam um vocabulário mais diversificado, desenvolvem maior quantidade e diversidade vocabular. Isto se entrelaça com a questão socioeconômica, o vocabulário dos pais e o uso de gestos na comunicação inicial. Tais habilidades de linguagem oral nas crianças trazem consigo uma forte relação com seu sucesso mais tarde na escola. Ou seja, as taxas de crescimento iniciais do vocabulário refina a predição de habilidade do vocabulário mais tarde. As intervenções que aceleram o crescimento do vocabulário cedo na vida, têm o potencial para aumentar o tamanho do vocabulário de uma criança ao ingressar na escola e, por sua vez, melhorar a preparação para a escola ${ }^{24 ; 36}$.

Muitos estudos comprovam a eficácia do implante coclear em diferentes aspectos $4 ; 37 ; 38 ; 39$. Outros, no entanto, relatam o baixo desempenho escolar, a dificuldade do processo de aquisição da linguagem e do processamento de padrões acústicos e equívocos relacionados ao domínio da língua oral e da escrita em crianças usuárias de IC 27; 40. A preocupação instaurada não se relaciona apenas com os ganhos obtidos com o uso do IC, mas como estes se configuram em potencialidades para a melhora da comunicação, desempenho escolar e relacionamento social.

A reabilitação auditiva através do IC gera uma série de discussões de ordem biopsicossocioculturais, pedagógicas, familiares e organizacionais ${ }^{29 ; 41}$. A deficiência auditiva se inscreve em várias esferas e o trabalho não deve ser realizado apenas no indivíduo surdo, mas em toda a sua comunidade relacional. Ressalta-se que 0 sucesso do IC depende da estimulação dos pais, pares e professores, por isso, é essencial um trabalho com a família e a escola no sentido de promover o estabelecimento de uma comunicação adequada na busca da adaptação sócio-afetiva e lingüística do sujeito ${ }^{42}$. Além disso, destaca-se também a importância de se investigar as mudanças emocionais e familiares ocorridas ao longo de todo o percurso de avaliação, preparação e de reabilitação do usuário de IC ${ }^{38}$. 
Portanto, o presente estudo faz-se necessário para averiguar se os resultados fonoaudiológicos da audição e da linguagem dos implantados correlacionam-se com as percepções dos principais atores sociais que circundam as crianças usuárias de IC, a saber, pais e professores. 


\section{1- OBJETIVOS}

Investigar se o resultado fonoaudiológico da audição e da linguagem associa-se com a percepção do resultado dos pais e dos professores de crianças usuárias do implante coclear multicanal que realizam reabilitação fonoterápica no Centro Educacional da Audição e Linguagem Ludovico Pavoni - CEAL-LP.

Objetivos específicos:

1- Averiguar a percepção dos pais avaliados pelo instrumento "Crianças com implante coclear: perspectivas dos pais";

2- Avaliar as crianças usuárias de IC de acordo com as categorias de audição e linguagem;

3- Verificar se há associação entre a avaliação dos pais e dos professores;

4- Investigar se existe correlação entre a perspectiva dos pais e a avaliação fonoaudiológica da audição e da linguagem. 


\section{3 - REVISÃO DE LITERATURA}

\section{1 - SER BIOLÓGICO X SER SOCIAL}

Adentrar no campo da deficiência é algo delicado. Existem multifacetas que precisam ser analisadas e colocadas em pauta. Isto porque necessariamente a deficiência se atrela ao indivíduo e, cabalmente, falamos de pessoas.

A deficiência aloca características diferentes em quem convive com ela e pode destruir a possibilidade de atenção para outros atributos, dificultando a relação e a interação social do indivíduo ${ }^{43}$. Assim, a deficiência corporal é facilmente apreendida pelo meio social e por ele estigmatizada, a percepção do corpo é maximizada em detrimento de outras características pessoais do indivíduo deficiente.

Para além do pensamento dicotômico e cartesiano entre corpo e mente, sabemos das interações e interferências mútuas nesses campos. Por isso, outros modelos pós-modernistas tem entrado em voga na constituição de um pensamento mais múltiplo, pluralista, tolerante, complexo, de instabilidade, e não baseado na imutabilidade causa-efeito ${ }^{44}$.

Dessa forma, abordagens pluralistas e paradigmas ecológicos sugerem que 0 corpo é muito mais do que um fenômeno fisiológico, o humano se evidencia como um sujeito desejante, socializado e em construção discursiva, tanto da linguagem quanto do pensamento ${ }^{45}$. Neste ponto de vista, a incapacidade física não é vista apenas como uma questão biológica, de déficit sensório-corporal, mas sim o entrelaçamento das interações entre biologia, estrutura psicossocial e institucional. Portanto, abarca o sujeito corpóreo que sente e se relaciona com o outro dentro de uma estrutura organizacional/cultural ${ }^{45}$.

O desafio posto é entender a relação complexa entre fatores fisiológicos e sócio históricos, refinando a análise da relação entre deficiência e incapacidade, a partir da percepção do corpo como fenômeno biossocial.

O pensamento simplista da normalidade como matriz de interpretação significa partir da premissa de que tal padrão é definido pelo saber médico. Dessa forma, a deficiência é qualificada como desvio da norma ou doença no indivíduo. O resultado em última análise é delegado à pessoa, ou seja, o problema é do sujeito portador de determinada moléstia. Isto acaba por contribuir para a segregação das pessoas e o 
preconceito entre os seres, porque o desviante é visto com desvantagem em relação aos demais. A crença subjacente é de que não são capazes, já que não são classificadas como pessoas normais ${ }^{46}$.

O modelo médico considera a incapacidade como um problema da pessoa, causado diretamente pela doença, trauma ou outro problema de saúde, que requer assistência especializada sob a forma de tratamento individual por profissionais qualificados. Os cuidados são direcionados para a cura ou a adaptação do indivíduo e mudança de comportamento para a devida adequação na sociedade. A assistência médica é considerada como a questão principal e para a sua melhora, em termos políticos, a principal resposta é a modificação ou reforma da Política de Saúde ${ }^{47}$.

Como ciência milenar, a medicina tem oferecido o alívio e superação de inúmeros males que assolam a humanidade. Seu progresso e constante aperfeiçoamento acarretam evoluções na maneira como se é visto determinados problemas e sua forma de lidar com eles. Tal evolução tem proporcionado inúmeras vantagens para o sujeito adoecido ou deficiente. No entanto, a evolução na medicina não significa evolução social e/ou educacional necessariamente. Há que se considerar o modelo social da deficiência onde as estruturas sociais potencializam ou bloqueiam as capacidades da pessoa deficiente ${ }^{47}$.

Por sua vez, o modelo social considera a incapacidade como um problema criado pela sociedade e, basicamente, como uma questão de integração plena do indivíduo neste contexto. A incapacidade não é um atributo de um indivíduo, mas sim um conjunto complexo de condições, muitas das quais criadas pelo ambiente social. Assim, a solução do problema requer uma ação social e é de responsabilidade coletiva da sociedade fazer as modificações ambientais necessárias para a participação plena das pessoas com incapacidades em todas as áreas da vida social. Portanto, é uma questão atitudinal ou ideológica que requer mudanças sociais que, a nível político, se transforma numa questão de direitos humanos. Neste modelo a incapacidade é encarada como uma questão política ${ }^{48}$.

Sabemos que socialmente o respaldo médico é legítimo, comprovatório do diagnóstico e dele depende até mesmo a consolidação do direito social do indivíduo. Ou seja, para se fazer uso dos direitos delegados aos deficientes, é necessário o diagnóstico médico. Contudo, ainda que haja reabilitação física, a pessoa se depara com condições, inadequações e estigmas que são sociais, para além da problemática corporal. Assim, a discussão do modelo médico x social da deficiência acaba por ter 
pontos de entrelaçamento que por um lado facilitam e por outro dificultam a entrada e/ou permanência nesse social.

Na tentativa de integrar a dialética do modelo médico x social da deficiência, a Classificação Internacional de Funcionalidade, Incapacidade e Saúde (CIF), proposta pela Organização Mundial da Saúde (OMS), traz um modelo de função e incapacidade e um sistema de classificação.

MORETTIN (2012), em sua tese, elaborou um checklist da CIF-CJ para crianças e jovens usuários de implante coclear, a partir das dimensões clínicoterapêuticas e familiares dos implantados e elencou 71 códigos $^{49}$.

O modelo proposto baseia-se na junção dos modelos médico e social. Uma abordagem biopsicossocial é usada para se obter uma integração das várias dimensões da saúde, a saber, biológica, individual e social. A funcionalidade e a incapacidade humanas são concebidas como uma interação dinâmica entre as condições de saúde, seja doença, trauma, lesões, distúrbios, e os fatores contextuais, tanto os pessoais quanto os ambientais ${ }^{50}$.

Quando lidamos com a deficiência auditiva devemos ter em mente toda essa dimensão de fatores. Assim, teremos claro que a reabilitação auditiva através do IC é bem mais complexa do que o procedimento cirúrgico em si, mas entrelaça diversas questões, é processual, cheia de desafios e obstáculos socioculturais e pedagógicos. 


\section{2 - AUDIÇÃO, SURDEZ E SUAS VICISSITUDES}

A audição é um sentido que compreende não apenas a questão auditiva, mas está intrinsicamente relacionada com a linguagem. Esta, por sua vez, é a que abrange a cultura, o conhecimento e a comunicação entre os seres humanos ${ }^{1}$. Portanto, a audição e a sua estreita ligação com a linguagem representa uma magnitude de importância para o sujeito, visto que o conecta com a estrutura dos significantes e significados, dando sentido às coisas, ao mundo ${ }^{2}$.

Sabemos que o desenvolvimento auditivo é complexo e para se chegar à aquisição da linguagem são necessários vários processos, a saber, de detecção, localização, discriminação, memorização, reconhecimento e compreensão de sons ${ }^{51}$. Qualquer falha numa dessas etapas representa prejuízo para o indivíduo. Por isso, busca-se através da Triagem Auditiva Neonatal Universal (TANU) o diagnóstico precoce, para o possível tratamento da criança com o objetivo de minimizar os danos causados pela surdez ${ }^{9 ; 51}$.

As causas conhecidas da surdez são: hereditariedade, muito baixo peso (MBP) no neonato (abaixo de 1500g), ocorrência da hiperbilirrubinemia, infecções congênitas (rubéola, toxoplasmose, citomegalovírus, herpes e sífilis), meningite, rubéola materna durante a gestação, uso de drogas ototóxicas no período neonatal, permanência em Unidade de Tratamento Intensivo (UTI), uso de ventilação mecânica por mais de 5 dias no neonato, baixo índice de Apgar, hipóxia, mal formação craniofacial, fenda palatina, lábio leporino, hemorragia intracraniana, crises convulsivas neonatais, icterícia, síndromes que podem apresentar a deficiência auditiva como uma de suas características, acidentes e traumas cranianos 7;8;9;52. Além dessas causas, há as desconhecidas, de natureza idiopática $8 ; 9$.

Nos países desenvolvidos, a deficiência auditiva neurossensorial (DANS) acomete um em cada 1000 recém nascidos, sendo que $40 \%$ dos casos podem ser atribuídos a fatores hereditários, $30 \%$ às diversas etiologias adquiridas e $20 \%$ ainda apresentam etiologia desconhecida $7 ; 8$. Embora sejam poucos os estudos de base populacional com a participação de neonatos, sabemos que a surdez está entre as morbidades de recém nascidos de maior incidência no Brasil, de acordo com os dados do Ministério da Saúde publicados nos programas de triagem auditiva neonatal. A prevalência de perda auditiva neonatal é de aproximadamente 1-6 por 1.000 recém- 
nascidos e entre 1-4 para cada 100 bebês nascidos a partir de unidades de terapia intensiva neonatal 7;8;9. Estima-se que 10\% dos neonatos apresentam indicadores de risco para deficiência auditiva (Irda) ${ }^{9}$.

Em 2010, pesquisa realizada pelo Instituto Brasileiro de Geografia e Estatística (IBGE), aponta que cerca de 9,7 milhões de brasileiros possuem deficiência auditiva (DA), o que representa $5,1 \%$ da população brasileira em geral. Sendo que mais de 344 mil são surdos ${ }^{10}$.

Há alta prevalência da surdez em neonatos, se comparados com outras patologias passíveis de triagem na infância, tais como: a fenilcetonúria 1:10.000, a anemia falciforme 2:10.000 e a surdez 30:10.000 9. Por isso, instituiu-se a Política Nacional de Atenção à Saúde Auditiva, através da Portaria GM n.ำ 2.073/04, de 28 de setembro de 2004, do Ministério da Saúde. Assim, ficou estabelecido a distribuição de um serviço de saúde auditiva para cada um milhão e meio de habitantes e a implantação de novos serviços a partir de dois milhões de habitantes ${ }^{11}$.

A privação sensorial auditiva severa ou profunda pode impor grandes prejuízos na socialização, linguagem e escolarização, visto que há a tendência cultural de que estejamos sob controle das propriedades acústicas da fala nos mais variados contextos. Isto porque é através da interação humana, mediada pela linguagem, que ocorre a constituição/subjetivação do indivíduo enquanto pessoa e, por meio dela, a possibilidade de apreensão e compreensão do mundo 2; 53.

Alguns fatores negativos advém das dificuldades de comunicação ocasionadas pela perda auditiva, a saber: diminuição do senso de segurança pessoal, aumento do isolamento social, da irritação e inibição, a diminuição das oportunidades escolares e trabalhistas, da confiança em si mesmo e da independência do sujeito devido à perda da noção de localização sonora 4 . Além disso, as consequências a longo prazo de perda auditiva neonatal e infantil são agora bem reconhecidas. Tornou-se evidente que a surdez na infância afeta não apenas a comunicação, mas também a cognição, comportamento, desenvolvimento social e emocional, os resultados acadêmicos e, mais tarde, as oportunidades profissionais. Ou seja, a pessoa é afetada não apenas na sua aprendizagem, mas no seu desenvolvimento integral ${ }^{11}$.

O diagnóstico tardio coloca as crianças em desvantagem acadêmica. Por isso a relevância da TANU. Afinal, a presença de perda auditiva nos primeiros anos de vida pode ter efeitos negativos adicionais sobre o Processamento Auditivo Central (PAC) e o funcionamento intelectual da criança ${ }^{7}$. 


\section{3- IMPLANTE COCLEAR E REABILITAÇÃO}

O Implante Coclear (IC) é um dispositivo tecnológico inserido cirurgicamente na cóclea, para substituir as células ciliadas e possibilitar a audição no usuário (Fig. 1). O componente interno possui um feixe de eletrodos, um fio e a antena receptora. A parte externa do aparelho é composta por microfone, processador de fala e pela antena transmissora, que envia os estímulos sonoros codificados eletricamente para a antena receptora (Fig.2) ${ }^{12 ; 13}$. O seu funcionamento possibilita a sensação sonora gradualmente. Isto porque a reabilitação auditiva se dá ao longo de aproximadamente três anos. Tempo em que se espera que o dispositivo já esteja em pleno ajustamento audiológico e que a pessoa surda, após treino fonoaudiológico, esteja apta a distinguir os vários sons que a circundam.

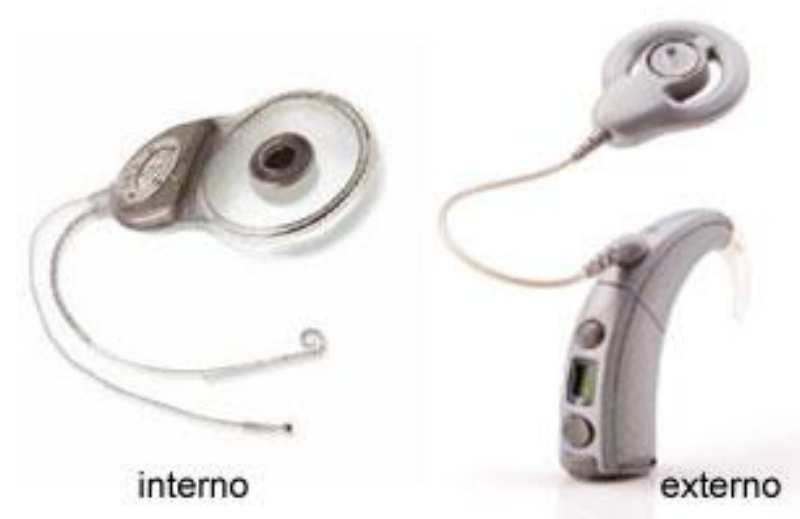

Figura 1 - Modelo de Implante coclear http://diariodosurdo.com.br/category/surdez/implante-coclear/ 


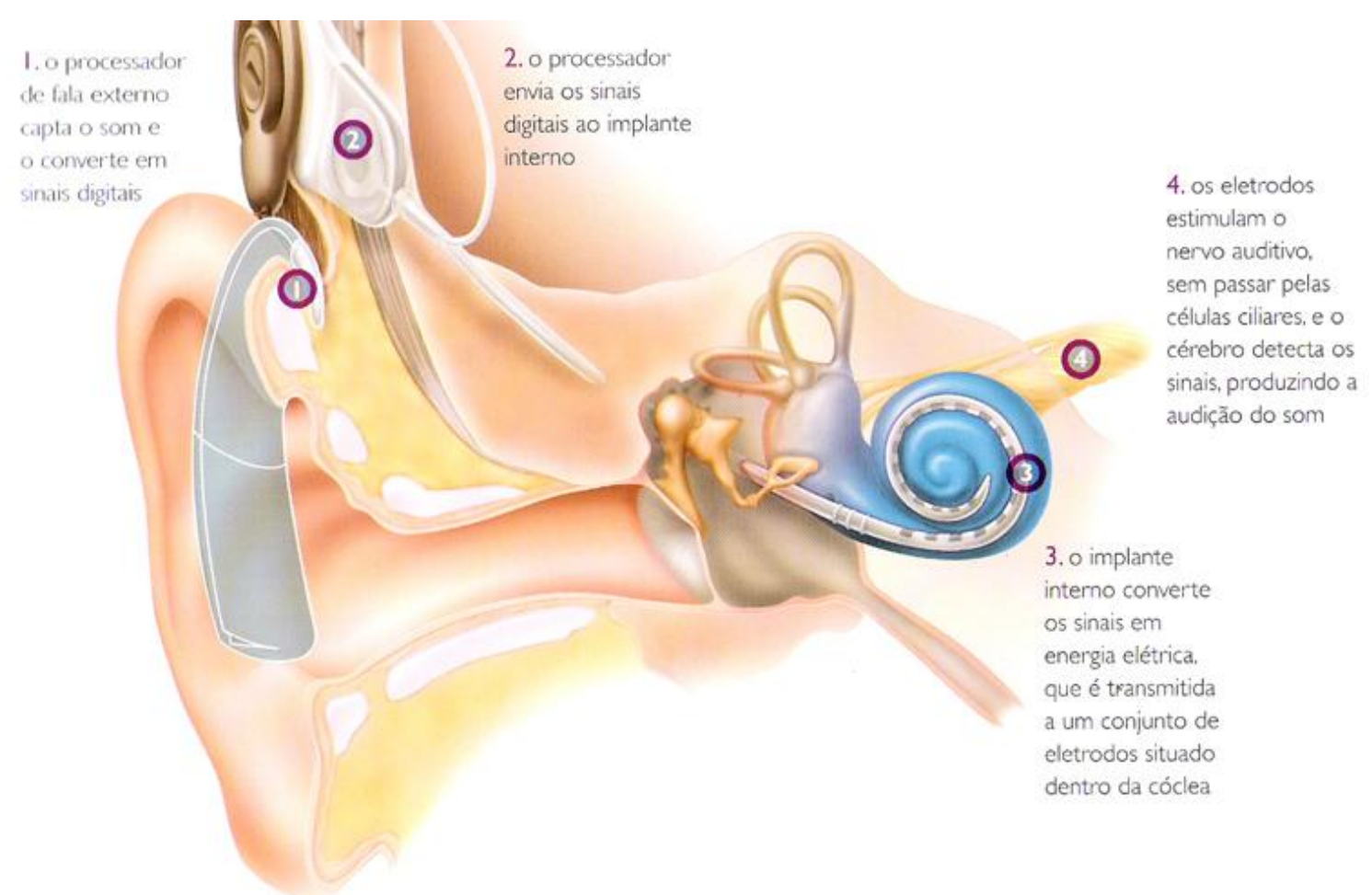

Figura 2 - Funcionamento do Implante Coclear.

http://www.implantecoclear.org.br/textos.asp?id=3

A demora para o pleno ajustamento do dispositivo se dá devido ao que chamamos de mapeamento. Os mapeamentos são realizados por um programa de computador que ajusta as frequências sonoras gradualmente, possibilitando conforto ao usuário e acomodação neurológica ponderal dos novos estímulos que chegam ao Sistema Nervoso Central (SNC) ${ }^{7}$.

Ressaltamos que este dispositivo é disponibilizado pelo Sistema Único de Saúde (SUS) de acordo com os critérios da portaria ํㅡ 2.776, de 18 de dezembro de 2014, que descreve os parâmetros dos Centros de Implante Coclear e dos possíveis candidatos ao IC 9;54. Tais questões incluem uma equipe interdisciplinar que avalia o candidato em vários aspectos, a saber, médico, fonoaudiológico, psicológico e social. Busca-se apreender uma globalidade do indivíduo com a finalidade de assegurar o bom andamento da reabilitação 4;13; 54 .

Contudo, o processo de reabilitação é bem diferenciado quando tratamos com surdos pré-linguais e pós-linguais. O primeiro é portador de surdez antes da aquisição da fala e o segundo após sua aquisição. Isto significa que o pré-lingual terá que aprender a língua, no nosso caso, o Português. O pós-lingual terá que reforçar seu 
treino auditivo para lembrar os fonemas, ritmos e modulações sonoras do idioma. Ou seja, para o último a reabilitação ocorre mais rapidamente pela existência de uma língua estabelecida previamente. Além disso, o paciente pós-lingual pode relatar como está ouvindo e aprimorar mais adequadamente os ajustes realizados nos mapeamentos, o que acarreta uma melhora bem mais rápida em termos audiológicos 55 .

Há grandes diferenças na reabilitação entre pré-linguais e pós-linguais. Isto porque a reabilitação auditiva entrelaça várias outras questões. A pessoa que já sabe falar, geralmente o adulto, provavelmente tem um círculo social estabelecido com o qual se relaciona, já foi alfabetizado e tem uma vida laboral. Pensar no pré-lingual, geralmente criança que não desenvolveu a fala por falta da audição, significa dizer que a reabilitação se dá não apenas no campo audiológico, mas social, educacional e até laboral. Isto porque se espera uma total reabilitação do infante para que ele se torne um adulto sociável e produtivo ${ }^{5}$.

Por isso, a criança é mais cobrada e precisa se sujeitar a todo um treinamento comportamental, de atenção auditiva, de aprendizagem, de reestruturação cognitiva e neurológica. Ou seja, é uma mudança gigantesca para o sujeito e sua família. Visto que a família é quem oferece o suporte necessário para que a reabilitação aconteça 56 .

O que no adulto se ajusta em até um ano no processo de reabilitação, na criança esse tempo é acrescido de 5 a 10 anos. É mais dispendioso, mais desgastante e, obviamente, mais problemático.

Além disso, temos que considerar algumas questões que advém com o tempo de uso do IC, a saber, manutenções, defeitos técnicos, perdas do componente externo, dentre outros ${ }^{57}$. Em se tratando de crianças tais problemas se intensificam não apenas na frequência ou gravidade, mas também nos desdobramentos que isto acarreta. O tempo gasto em manutenções e consertos ocasiona o não uso do aparelho e, especialmente para os que estão em processo de aprendizagem da língua, representa uma grande perda sensorial que, inevitavelmente, atrapalha 0 desenvolvimento linguístico, social e neurológico ${ }^{7}$.

Como a criança está em fase de crescimento, mudanças físicas e psíquicas, próprias dos estágios desenvolvimentais, também interferem na reabilitação ${ }^{58}$. Assim, esse processo é flutuante, não linear, não previsível, por mais que todos os esforços 
sejam para torná-lo o mais estável possível, com passos pré-estabelecidos e resultados esperados definidos.

A reabilitação realizada através do IC traz inúmeros ganhos audiológicos, sociais e emocionais, bem como, nos aspectos relacionados com a qualidade de vida, na melhora da autoestima, comunicação e autonomia do indivíduo ${ }^{59}$. Vemos, porém, que há que se ter flexibilidade, paciência, perseverança e metodologias variadas para lograr êxito com a reabilitação infantil no IC, pois além das questões próprias da infância, há de se vislumbrar todo o contexto sócio familiar e educacional do infante, para que os ajustes se deem em todas as esferas e possibilite uma readaptação adequada e global. Afinal, é todo um conjunto que precisa se reorganizar e se readaptar juntamente com a reabilitação da criança, especialmente. Temos o IC não apenas como um aparelho utilizado em surdos para retomar progressivamente a habilidade de ouvir. O sucesso do implante interliga multifatores e depende do bom ajuste de variados atores sociais que circundam a pessoa implantada. Isto para otimizar a adaptação sócio afetiva e linguística do sujeito ${ }^{3}$. 


\section{4 - ÉTICA E IMPLANTE COCLEAR}

O IC é um artefato tecnológico atualmente reconhecido para o tratamento da surdez severa/profunda. Porém, como a surdez traz comprometimentos exacerbados para o indivíduo e a sociedade, se apresenta como uma questão multifatorial e complexa. Tamanha complexidade se entrelaça com diversos fatores e coloca em xeque questões éticas que precisam ser analisadas.

\subsection{1 - ÉTICA PARENTAL}

A realização do IC em crianças coloca questões éticas em pauta. Por ser um procedimento eletivo, onde a decisão tomada pelos pais/responsáveis é que definirá o futuro linguístico da criança e o caminho que deverá ser seguido em termos de reabilitação, podemos pensar até que ponto é cabível a responsabilidade parental.

A criança se encontra numa situação de vulnerabilidade, tanto pela incapacidade de tomar decisão quanto pela surdez que impossibilita a comunicação da sua vontade ${ }^{60}$.

Considerar a igualdade de oportunidades como um princípio da Justiça, a utilização do IC em candidatos, dentro dos critérios de implantação ${ }^{9 ; 11}$, demonstra o cuidado para o alcance da proteção da oportunidade igualitária do cidadão ${ }^{60}$. Isto porque a linguagem em crianças implantadas antes de 1 ano de idade se aproxima a de crianças ouvintes ${ }^{56 ; 61}$. Sendo assim, a escolha dos pais/responsáveis pelo infante se justifica moralmente não apenas pela vulnerabilidade social da criança, como também pelo oferecimento de oportunidade igualitária para que a mesma possa vislumbrar um futuro mais inclusivo.

Dessa forma, aos pais e aos médicos que cuidam da criança é dado poder discricionário para tomar decisões sobre o que é lhe melhor ${ }^{62}$. Legal e eticamente, aceita-se que os pais podem dar o seu consentimento ou não para o tratamento médico de condições envolvendo seus filhos, pois são esses que detém a responsabilidade sobre a criança, arcam com seus cuidados e despesas ${ }^{63}$. 


\subsection{2 - ÉTICA MÉDICA}

Devemos ponderar se a realização do IC é segura ou oferece risco aceitável para o paciente, se essa tecnologia é eficaz, se traz benefícios atuais e futuros aos seus usuários.

Temos que o tratamento com a utilização do IC é considerado seguro na medida em que não está associado com qualquer mortalidade e que as taxas de complicações médico-cirúrgica são consideradas baixas ${ }^{56 ; 61 ; 64}$. Os riscos giram em torno de infecção, paralisia do nervo facial, dificuldade cirúrgica pelo pequeno tamanho do crânio, pouco desenvolvimento da mastóide, movimento do eletrodo ou extrusão causado pelo crescimento do crânio, possibilidade de otite média, maior risco de falha do dispositivo, em parte por causa do alto nível de atividade motora da criança, com a possibilidade de lesão traumática do receptor e estimulador interno ${ }^{56}$; 65 .

De igual modo, o tratamento é considerado como eficaz, pois estudos comprovam a melhora nos resultados da audição, fala, linguagem, maior qualidade de vida global, aumento da performance escolar, maior senso de segurança e rebaixamento do sentimento de frustração ${ }^{38 ; 52 ; 56 ; 59 ; 65 .}$

\subsection{3 - ÉTICA FINANCEIRA}

É preciso fazer bom uso dos recursos disponibilizados pelo governo, especialmente em países em desenvolvimento como o Brasil. O implante coclear é um aparelho caro para ser disponibilizado para indivíduos que não usufruirão dos seus benefícios. Por isso, a equipe interdisciplinar deve ter critérios claros de avaliação, embasados nas disposições governamentais que a regem ${ }^{9 ; 11}$. O IC deve ser potencialmente benéfico para o paciente que o utilizará. As questões pessoais, sociais, financeiras, emocionais e culturais devem ser avaliadas em termos de custobenefício para que o investimento seja frutífero e próspero.

É necessário fazer análise dos custos de intervenção, do tratamento ao longo do tempo e, também, dos elementos de custos indiretos, como a Educação, por exemplo. A lógica por trás da inclusão de tais custos é que, se uma intervenção gerar 
poupanças em outros lugares, estes são pertinentes para a consideração de ganhos financeiros numa perspectiva social 66 .

O IC é um tratamento eletivo de último recurso para uma condição crônica. Reduz a deficiência auditiva, mas não restaura a função normal do ouvido. Como tal, é suscetível de ser classificado com menor prioridade para as despesas governamentais do que muitos tratamentos que salvam vidas, são curativos ou preventivos. Por isso, medidas de custo-eficácia são necessárias a fim de avaliar os benefícios de tal tratamento e justificar os seus custos em relação a outras alternativas de manejo ${ }^{55}$.

Os implantes cocleares são fornecidos às crianças com base na hipótese de que os resultados de curto prazo de melhora das habilidades auditivas irão traduzir a médio prazo uma maior independência, aprimoramento social e escolar do usuário 62 .

Tais resultados incluem: maior envolvimento e integração no ensino primário, levando ao maior desempenho escolar; maior versatilidade social e cognitiva permitindo uma transição bem sucedida para o ensino médio; e, com a maior qualificação educacional, maiores oportunidades na educação adicional e no emprego 62 .

Como a deficiência auditiva na infância tem consequências de longo alcance sobre a comunicação, o grau de escolaridade e oportunidades de vida, incorre em um custo social elevado para o Estado 56; 60; 62. O custo estimado com um surdo nos Estados Unidos ao longo de sua vida é de 1 milhão de dólares, devido aos gastos com educação especial, serviço social e de suporte e à sua baixa produtividade na vida adulta ${ }^{61}$.

O implante coclear é uma alternativa mais barata, pois visa a reabilitação e inclusão do indivíduo na sociedade produtiva. Embora não tenha sido encontrada na literatura uma estimativa dos gastos financeiros com a pessoa surda no Brasil, alguns estudos tem demonstrado que o IC em termos econômicos representa um ganho de recursos a longo prazo, pela melhora no desempenho acadêmico, aumento da probabilidade das crianças frequentarem o ensino regular e possibilidade de melhores conquistas laborais futuras. Tais benefícios são derivados da implantação precoce, com pouco tempo de privação auditiva. As análises de limiares probabilísticos sugerem que, quando medido em um horizonte de tempo de vida e em comparação com qualquer apoio não tecnológico ou aparelhos auditivos acústicos, os implantes cocleares unilaterais são altamente suscetíveis de serem rentáveis ${ }^{55 ; 67 .}$ 


\section{5 - IMPLANTE COCLEAR E LIBRAS}

A reabilitação com o IC é uma intervenção que altera a comunicação e consequentemente as opções educacionais. Para que a audição alcance um uso funcional com o IC, temos que considerar que tal opção limita o paciente ao acesso à Língua Brasileira de Sinais (LIBRAS) e à cultura surda, visto que sua reabilitação se fomentará em termos de melhoras audiológicas e linguísticas ${ }^{56}$.

Não se pode negligenciar a relevância da LIBRAS para os surdos. Antigamente ela era um excelente recurso que possibilitava a comunicação. Ainda hoje se configura como uma alternativa de ajustamento diante da deficiência auditiva e deve ser considerada e divulgada $63 ; 68$.

O uso do IC pode ser encarado como uma negação da língua, dos valores culturais e da identidade surda como uma diversidade de apresentação do humano. A possibilidade de etnocídio é vislumbrada pela comunidade surda frente a crescente utilização do IC nos últimos 10 anos, principalmente com o advento da TANU ${ }^{63}$.

Nos Estados Unidos, no ano de 2000 , cerca de $10 \%$ das crianças com surdez profunda foram implantadas e, em 2005, este número estava compreendido entre $50 \%$ e $60 \%$. No Reino Unido, a taxa de implantação se apresenta em torno de $73 \%$. A taxa na Austrália e Suécia gira em torno de $80 \%$. Parece provável que a taxa de implantação é igualmente elevada na maioria das nações desenvolvidas, embora os dados sejam difíceis de serem obtidos com precisão e não terem sido encontrados dados sobre o Brasil ${ }^{63}$.

As discordâncias e entraves existentes se configuram em métodos de lidar com a surdez, a saber, oral ou gestual, e abrange visões de mundos discrepantes e, até mesmo, divergentes. Sabemos que existe uma cultura surda que teme ser extinta com o passar do tempo com a utilização da "correção" da surdez possibilitada pelo IC. Isto porque, para esta comunidade, a surdez é encarada como uma diferença cultural e linguística, em vez de uma condição médica que requer tratamento 56; 63; 68. Neste sentido, vemos claramente os entraves do modelo médico $x$ social da surdez ${ }^{50}$. $\mathrm{E}$, também, nos deparamos com a condição familiar e individual, onde se pondera sobre a decisão parental de escolha ou não pelo IC ${ }^{3}$.

Se tivéssemos uma Educação realmente inclusiva o uso de LIBRAS nas escolas seria frequente, como postulado pela legislação, mas não na práxis escolar 
69. Destarte, infelizmente, o sistema educacional brasileiro não está adaptado para esta realidade e necessidade de intérprete de LIBRAS. Não há escolas plenamente habilitadas para lidar com os diversos tipos de deficiência e incluí-las em sua rotina 69 . Em relação ao Distrito Federal, o que temos são escolas mais focadas em algum tipo de deficiência específica, como a Escola Bilíngue Libras e Português-Escrito de Taguatinga e outras conveniadas, como o CEAL, por exemplo.

Pensar nesse arranjo sócio educativo no nosso país é complicado. A Lei oo 10.436, de 24 de abril de $2002{ }^{70}$ que determina a presença de tradutores de LIBRAS em todos os órgãos públicos não está plenamente em uso, assim como para os pais conseguir um professor de apoio para seus filhos ainda é uma conquista. No entanto, a decisão de renunciar o implante coclear para uma criança, longe de condená-la a um mundo de silêncio sem sentido, abre um outro leque: o de adesão da comunidade surda, que tem uma rica história, linguagem e sistema de valores próprios ${ }^{63 ; 71}$. 


\section{6 - AUDIÇÃO E LINGUAGEM}

Em termos neurológicos o uso do IC cada vez mais precoce em crianças se justifica pelo período sensível da efetivação da audição. Mas, tem se visto que, semelhantemente, há período mais sensível para a aquisição da linguagem.

O período mais sensível para aprendizagem e desenvolvimento da linguagem, seja ela gestual ou falada, são os primeiros anos de vida da criança. O déficit sensorial que ocasiona a falta de experiência auditiva em crianças com DA durante este período crítico da infância inibe diretamente o crescimento morfológico e a capacidade funcional do caminho auditivo central, e limita severamente a eficácia da correção com o uso de amplificadores mais tarde na vida $7 ; 72 ; 73$.

Em crianças com privação auditiva, outros sentidos, como a visão, tornam-se mais funcionais que o córtex auditivo, através de um processo de reorganização crossmodal do cérebro ${ }^{74 ; 75}$. Estudos apontam que o plano temporal cerebral pode ser sensível ao movimento visual tanto em surdos quanto ouvintes, mas quando a audição está ausente no início do desenvolvimento, o papel do processamento visual desta região é reforçado ${ }^{75 ; 76}$. Depois de uma etapa de maturação crítica, as áreas auditivas de associação já não podem ser recrutadas pela estimulação auditiva, embora regiões primárias geralmente respondam a estimulação elétrica do nervo auditivo. Portanto, é importante minimizar o tempo de privação auditiva entre o início da surdez bilateral e a intervenção com o uso de aparelhos auditivos e/ou do implante coclear ${ }^{74}$.

Muito se pensou que a exposição da linguagem de sinais era prejudicial para a aquisição da fala por distorcer a função do córtex auditivo e impactar negativamente a eficácia do IC. No entanto, novas pesquisas tem demonstrado que a língua de sinais, adquirida por uma criança surda como uma primeira língua em um ambiente de usuários dessa modalidade de comunicação, é corticalmente organizada como uma língua falada para um ouvinte $77 ; 78$. A aquisição da língua materna, ou ao menos um primeiro idioma, parece ser uma importante condição para a plasticidade cerebral posterior ${ }^{78 ; 79}$.

Por conseguinte, as crianças surdas que não tem contato com nenhum tipo de linguagem efetiva estão em risco de possuírem estruturas neurais ineficientes para apoiar o processamento linguístico, dado ao fato de que apenas $10 \%$ dos deficientes 
auditivos tem pais que também são DA e usam efetivamente a língua gestual em sua comunicação ${ }^{74 ; 77 ; 78 .}$

Apesar dos pressupostos vigentes, não há nenhuma evidência de ligação entre o uso de uma língua visual com o resultado insatisfatório do IC. Isto porque a reorganização crossmodal do córtex auditivo ocorre independentemente de estratégias compensatórias, como a língua de sinais, usados pela pessoa surda ${ }^{74 ; 75}$; 77. Em contraste, a privação auditiva durante o período sensível do desenvolvimento infantil, especialmente na primeira infância, tem sido repetidamente ligada a resultados pobres de linguagem. Contudo, os períodos sensíveis linguísticos têm sido largamente ignorados quando se considera a variação no resultado do IC, levando a recomendações infundadas relativas a língua visual na reabilitação ${ }^{74}$.

Foi amplamente preconizado que as crianças surdas só poderiam ser expostas a uma língua de sinais depois de não conseguirem adquirir uma língua falada. Esta exposição tardia a uma primeira língua acessível, geralmente, resulta em déficits de linguagem de longo prazo. É importante para a criança que está aguardando o IC que ela tenha uma língua de entrada que permita o desenvolvimento cognitivo adequado para continuação da aquisição da linguagem ${ }^{75 ; 77}$. Isto porque o sucesso do implante coclear parece depender de habilidades de integração audiovisuais, competências linguísticas e do desenvolvimento cognitivo ${ }^{74}$.

Por isso, ao invés de privar o bebê da comunicação visual, tanto pela pista visual quanto pela linguagem gestual, sugere-se que a criança surda que aguarda o IC tenha acesso a qualquer entrada de linguagem para facilitar sua aquisição oral futura $74 ; 77$.

O IC parece ser um avanço notável para a aquisição da audição nas crianças que nasceram surdas, mas o seu sucesso deve ser avaliado além de seu impacto auditivo. Para além da audição, novas evidências sugerem que a boa aquisição de uma primeira língua dentro dos primeiros anos de vida pode ser o melhor preditor de bom resultado linguístico para a criança que nasce surda 77 .

Temos ainda a necessidade da reabilitação fonoaudiológica para fomentar o funcionamento eficaz do IC, pois não há evidência convincente de que a reabilitação da audição por si só engendre um discurso satisfatório e o progresso do idioma no usuário. Contudo, estudos recentes sugerem que a reabilitação audiovisual pode ser tão eficaz como a reabilitação somente auditiva $77 ; 80$. Ademais, melhores resultados linguísticos foram relacionados a estimulação contralateral e a participação dos pais 
no incentivo da comunicação oral. A presença de uma deficiência de aprendizagem adicional teve uma influência negativa no desenvolvimento da linguagem ${ }^{73}$.

Assim, vemos que o IC precoce garante que as crianças com deficiência auditiva recebam o máximo de estímulos auditivos, e, por conseguinte, reduza o efeito adverso da privação auditiva. A realização do IC antes de 12 meses de idade reduz 0 fosso entre as disparidades de desempenho entre idade auditiva e idade cronológica 19. 


\section{7 - LINGUAGEM E APRENDIZAGEM}

A linguagem é determinada por questões anatomofuncionais e também pelos estímulos do meio ${ }^{81}$. Ela está intrinsicamente relacionada com a cognição e com as funções superiores do pensamento, regula a conduta da pessoa e lhe dá ferramentas simbólicas para que a mesma se coloque no mundo ${ }^{2}$.

A aquisição da linguagem oral também é um preditor para o desenvolvimento ortográfico, isto porque existe uma estreita relação entre o desenvolvimento fonológico e o domínio da escrita e da leitura, indicando que a desorganização fonológica pode persistir ainda como uma desorganização da linguagem escrita ${ }^{34 ; 81}$.

Pesquisas mostram que as habilidades metalinguísticas, a saber, de consciência fonológica, lexical e morfossintática exercem múltiplas influências no processo de aquisição da escrita na fase alfabética e, depois, na ortográfica, demonstrando que os atrasos linguísticos estão relacionados com o desenvolvimento vocabular e gramatical ${ }^{34 ; 40}$.

A dificuldade auditiva nos usuários de IC causa perda de informação linguística (forma, conteúdo e uso), o que ocasiona atraso no desenvolvimento da linguagem e dificuldades sociais (emissor e receptor) ${ }^{34}$.

Tais dificuldades são reveladas no convívio escolar e nos objetivos pedagógicos de fluência na leitura e na escrita. Dessa forma, a escola surge como um fator decisivo sobre a questão do sucesso do IC em crianças.

Daí surge uma série de discussões sobre a reabilitação auditiva e a adequação escolar frente ao implantado, visto que ele pode ser considerado como ouvinte ou surdo em potencial. Além das questões de ajustes escolares, como sala de apoio, classe reduzida ou intérprete. Assim, a educação formal pode ser baseada numa comunicação oral ou em LIBRAS. E o modo de comunicação usado no cenário educacional da criança também desempenha um papel importante no resultado pósimplante.

As crianças que receberam serviços de reabilitação baseado na oralidade durante os anos pré-escolares demonstraram maior potencial para desenvolver habilidades de fala. A falta de desenvolvimento da linguagem falada pode induzir restrição na aprendizagem e na alfabetização, comprometendo substancialmente oportunidades educacionais e laborais mais tarde na vida ${ }^{82}$. Pesquisas apontam que 
os dois primeiros anos de vida do infante são primordiais para o bom desenvolvimento linguístico e que o IC precoce está associado com o aumento significativo da taxa de compreensão e expressão ${ }^{83}$.

Embora haja boas evidências quanto aos resultados da oralização dos surdos usuários do IC, ainda não se conseguiu encontrar provas conclusivas quanto ao melhor método e seus resultados ${ }^{78}$. Pesquisas de revisão sistemática estão sendo feitas para embasar as decisões clínicas quanto a isso. É o que veremos a seguir.

O método da comunicação oral (CO) compreende sessões intensivas de intervenção precoce com foco na audição, gestão tecnológica e envolvimento dos cuidadores da criança em sessões de terapia. É embasada apenas na oralização, excluindo-se o uso de gestos ou pistas visuais. O principal objetivo da CO é que a criança fale apropriadamente à sua idade e que seja o método principal ou exclusivo de comunicação. Programas de CO estão se expandindo em todo o mundo. No entanto, por vezes, não se alcança os resultados esperados e poucas evidências são encontradas sobre a eficácia da intervenção devido à falta de estudos bem controlados ${ }^{84}$.

A abordagem da comunicação total (CT), desenvolvida no início dos anos 1970, foi originalmente destinada a promover o uso de qualquer método de comunicação que fosse necessário para desenvolver a competência linguística em uma criança. Ao longo do tempo, no entanto, a definição de CT se tornou sinônimo de "comunicação simultânea ou interpretação", ou seja, o uso combinado de expressão e sinal em todas as situações. A insistência na comunicação simultânea em todos os momentos foi feita para garantir que a criança tenha pleno acesso aos modelos de linguagem. No entanto, a experiência clínica sugere que um aluno visual matriculado em um programa de CT que não reforça as competências auditivas e orais continua a ser um aprendiz visual, apesar do uso do implante coclear ${ }^{85}$.

Destarte, afirma-se que o grupo de comunicação total é frequentado por alunos pré-linguais, que receberam seus implantes cocleares quando mais velhos, que não conseguiram avançar em programas orais e aqueles com menos audição residual préimplante. Este último pode sugerir empobrecimento dos estímulos nervosos, menor desenvolvimento da fala e menor experiências auditivas antes da implantação, o que representa piores resultados ${ }^{85}$.

Embora não haja evidências de que crianças matriculadas em programas de CO demonstrem melhor percepção da fala e linguagem pós-implante do que nos de 
$\mathrm{CT}$, outros estudos indicam maior vocabulário nas crianças matriculadas em programas de $\mathrm{CT}{ }^{86}$.

Mesmo que a quantidade de treinamento de fala, preparação do professor e expectativas dos pais para o uso da fala possa ser melhorado na CT, o desenvolvimento da fala inteligível ainda pode ocorrer mais frequentemente em crianças que usam apenas a voz para se comunicar do que aquelas que se utilizam também de sinais na comunicação. Se os sinais são o aspecto mais saliente da comunicação, as informações auditivas e da fala, muitas vezes, recebem atenção secundária. Pode ser que as crianças que usam CT não atinjam seu potencial no desenvolvimento da fala por causa da natureza do seu método de comunicação ${ }^{87}$.

Apesar disso, os pais e professores dos pacientes implantados tardiamente têm comentado sobre a utilidade do sinal para apoiar a transição da criança para a comunicação oral, esclarecer ideias complexas ou novos conteúdos dentro da sala de aula regular e acompanhar trocas rápidas de conversação entre vários falantes ${ }^{87}$.

A integração de sinais auditivos e visuais carrega implicações importantes para o desenvolvimento da aprendizagem em períodos sensíveis. Embora a sensação auditiva seja restaurada após o IC, estes processos co-ativados em crianças surdas demonstram um viés em direção visual ao invés de estímulos auditivos. A persistência de um viés visual sugere que a integração multissensorial pode não se desenvolver normalmente quando um único sentido domina durante o desenvolvimento precoce. A estimulação auditiva no início dos períodos sensíveis do desenvolvimento linguístico pode, portanto, ser necessária para garantir a influência adequada na integração multissensorial de circuitos neurológicos. O IC no primeiro ano de vida pode resgatar a capacidade funcional destes circuitos e ativar a correspondência de pistas auditivas e visuais ${ }^{82 ; 8}$.

Como vários estudos têm mostrado que em média a criança implantada aprende aproximadamente um ano de linguagem em um ano de tempo, os profissionais devem estar preocupados com a criança cujo progresso linguístico seja significativamente mais lento do que este. Para os profissionais que lidam com a criança implantada a meta, independentemente da modalidade da comunicação, continua a mesma: estabelecer altos níveis de competência comunicativa, embora a educação oral pareça ser uma escolha educacional mais adequada para os sujeitos que receberam o IC antes dos 5 anos de idade ${ }^{85 ; 89 .}$ 
Ainda que as crianças variem nos padrões de seu crescimento linguístico, ambos os programas CO e CT deveriam ter pré-estabelecido "bandeiras vermelhas", ou seja, sinais de alerta para aquelas que não estejam progredindo adequadamente.

O profissional deve manter um olhar atento sobre a forma como funciona a metodologia escolhida para uma determinada criança. Se o progresso não estiver ocorrendo, os professores e os pais devem se reunir e discutir estratégias.

O uso do IC atrelado com a fonoterapia potencializa a aquisição da fala, mas não a define completamente. É necessário entender por que algumas crianças mais precocemente implantadas não conseguem adquirir a linguagem apropriada para a idade e por que algumas crianças implantadas mais tardiamente adotam trajetórias que diminuem as lacunas.

É sabido que o desempenho pós-implante interliga multifatores, tais como: idade da criança na ativação, tempo de privação sensorial, cognição, motivação da criança/família, nível socioeconômico e cultural da família, tempo de uso do dispositivo, fatores individuais, como resíduo auditivo, tipo de processador, longo período de reabilitação, exposição constante a comunicação oral em sua educação e frequência em pré-escolas regulares $34 ; 83 ; 90$.

A análise desses multifatores objetivam fornecer informação que permita pais e educadores fazerem escolhas assertivas para maximizar o potencial auditivo, de fala e de linguagem do implantado 20.

Em particular, recomenda-se uma avaliação da fala e da linguagem, de componentes específicos do desenvolvimento, tais como questionários de idades e estágios. Há uma necessidade de um "padrão-ouro" para a definição de atrasos da fala e da linguagem e critérios de referência adequados ${ }^{91}$. 


\section{8 - PAIS E PROFESSORES}

A "surdez social" refere-se às dificuldades de interações sociais que envolvem grupos de pessoas ou ambientes ruidosos, em contraste com as interações um-a-um, que são geralmente mais fáceis para as pessoas que são surdas ou com deficiência auditiva gerirem. No contexto escolar, por ser um ambiente sonoro difícil, a surdez social pode impedir interações como as brincadeiras e conversas entre pares e, assim, dificultar o sentimento de pertença e inclusão social. Até certo ponto, a capacidade que muitas crianças tem em situações de comunicação um-a-um parece mascarar as dificuldades que elas encontram dentro do grupo e em contextos de múltiplos participantes ${ }^{30}$.

Por isso, a importância de avaliar a forma como as crianças se relacionam e se comunicam no dia-a-dia por meio de pais e professores, o que pode refletir mais de perto os resultados funcionais de crianças em situações da vida cotidiana ao invés de avaliações feitas em ambientes clínicos ${ }^{29}$. Além de que, apenas uma pequena fração dos implantados alcança altas pontuações nos testes clínicos e os resultados em geral são bem variáveis ${ }^{92}$.

Como o ambiente cotidiano é envolto a ruídos, múltiplas interações e o envolvimento familiar no processo terapêutico afeta diretamente o desenvolvimento do usuário de IC, é essencial averiguar como as crianças implantadas evoluem ao longo do tempo, não apenas na questão da oralização, mas em seu desenvolvimento pessoal, social e educacional, bem como, perceber como as famílias gerenciam tantos desafios ${ }^{93}$.

Pesquisas também mostram que os pais são bons informantes e podem perceber melhor os resultados e o impacto do IC na vida de seus filhos ${ }^{34 ; 94}$.

Temos a fase inicial do diagnóstico de surdez da criança e a tomada de decisão pelo implante como um momento desgastante vivenciado pelos pais, em que as expectativas devem ser manejadas adequadamente com informações pontuais dos riscos, desafios, vantagens e desvantagens do IC 29; 95; 96 .

Uma pesquisa realizada com 60 pais que tinham filhos candidatos ao IC, revelou que suas expectativas pós-cirurgia eram: desenvolvimento de linguagem falada (97\%), habilidades auditivas (100\%) e educação em escolas regulares para 
seus filhos (92\%). Os pais perceberam a decisão pelo implante coclear como a melhor que poderiam fazer para a criança $(98,3 \%)^{97}$.

Embora as expectativas geralmente sejam altas e a maioria dos pais relatem satisfação com o IC, entre 5-20\% deles referem insatisfação com as habilidades de comunicação, sociais e acadêmicas de seus filhos ${ }^{29 ;} 98$.

Quanto aos professores, $48 \%$ relataram que a criança não poderia acompanhar uma conversa falada com um grupo de pessoas, além de pontuarem sobre as dificuldades que as crianças com IC tem de fazer amigos ouvintes, de não serem aceitos pelos colegas e terem baixas habilidades sociais, dificultadas pelo ambiente escolar ruidoso e com múltiplas interações 29; 99; 100 . Referem que seus alunos implantados tem menor desempenho esperado pela idade em relação a escrita, leitura e matemática, que necessitam de maior apoio para a aprendizagem e que os conteúdos são mais desafiadores a cada ano ${ }^{29 ;} 40$.

Estudos apontam que 74\% dos alunos implantados apresentam desempenho escolar abaixo do esperado, com maior dificuldade para a escrita e desempenho verbal inferior aos seus pares ouvintes ${ }^{27 ; 33}$.

Na pesquisa de Brazorotto, os pais referiram que suas principais preocupações são quanto à aprendizagem da leitura e da escrita, ao acompanhamento das atividades de sala de aula com os colegas ouvintes e preocupações quanto à quebra do dispositivo do IC de seus filhos. Quanto aos professores, as conclusões foram que os mesmos têm poucas informações a respeito do IC, expectativas na média ou abaixo da média quanto ao desempenho acadêmico do aluno implantado, mas expectativas positivas em relação ao potencial de aprendizado dessas crianças, especialmente as mais jovens ${ }^{28}$.

Outra pesquisa, realizada com 90 mães de surdos, sinalizou que a maioria delas sofre estigma por ter um filho deficiente auditivo. No total, 72,2\% considerava a surdez infantil como um sinal de retribuição divina e 33,3\% sentiam vergonha da surdez de seu filho ${ }^{101}$.

Um estudo com 153 pais de crianças usuárias de IC (111 mães e 42 pais), revelou que as mães expressam significativamente mais sintomas de ansiedade e insônia em comparação com as mães de crianças com desenvolvimento típico, enquanto os pais destas crianças mostram a tendência para o aumento do nível de sintomas de depressão em comparação com os pais do grupo controle. No grupo de crianças surdas as mães relacionam mais sintomas somáticos e substancialmente 
mais ansiedade do que os pais, ao passo que o nível de sintomas de depressão é semelhante em mães e pais. Não houve relação entre a duração do uso do IC da criança e a saúde mental dos pais ${ }^{102}$.

Outro estudo apontou que as crianças geralmente se viam (e os pais percebiam seus filhos) como competentes e bem ajustadas, na maioria dos aspectos da vida diária. Os pais expressaram uma opinião geral positiva do implante coclear e seus efeitos sobre a vida familiar. Nenhuma das medidas de ajustamento sócio emocional foram significativamente relacionadas com a percepção de fala, de produção de fala ou habilidades de linguagem alcançados pós-implante. No entanto, a satisfação dos pais com o IC da criança foi significativamente relacionada com a fala e linguagem de seus filhos ${ }^{103}$.

Outra pesquisa demonstrou que há crianças na escola regular, usuárias de IC, que adquiriram os níveis educacionais e de linguagem comparáveis aos dos seus colegas com audição normal e mostraram habilidades de percepção de fala similares. Contudo, o desenvolvimento da linguagem em crianças em cenários auditivos difíceis revela um atraso significativo. Além disso, a percepção de fala, linguagem e nível educacional das crianças na educação especial permaneceu extremamente pobres. O estudo ainda mostrou que a maioria dos pais dessas crianças não relatam preocupações sociais e emocionais com seus filhos ${ }^{104}$.

Vemos que as preocupações psicossociais e pedagógicas preocupam os professores dos implantados e que os pais apresentam diversos desafios frente a surdez, tanto pessoalmente quanto socialmente. Contudo, não há receitas para manejos de todas as problemáticas oriundas desse contexto. Pais e professores precisam encontrar formas de potencializar os resultados dentro da situação vivenciada. Embora haja recomendações para manejo de ruído e maiores benefícios com uso de IC bilateral ${ }^{100}$. 


\section{9 - RESULTADOS DE LONGO PRAZO COM O USO DO IC}

A idade de implantação, o tempo de privação auditiva, o resíduo auditivo, o uso contínuo, a reabilitação auditiva baseada na oralidade, a frequência em escola regular e o envolvimento adequado da família são aspectos favoráveis para o sucesso do IC 93; 105. Além disso, estudos tem mostrado os benefícios a longo prazo com o uso do IC. É o que veremos a seguir.

TANAMATI, BEVILACQUA \& COSTA(2012), em pesquisa brasileira realizada com 10 jovens usuários de IC há mais de 10 anos, os escores médios foram de $73 \%$ para o reconhecimento de sentenças no silêncio e de $40 \%$ no ruído. A pontuação média para inteligibilidade da fala foi de $92 \%$. Não houve nenhum caso de falha do dispositivo. Em relação ao estado educacional e vocacional, três indivíduos se formaram na Universidade. Cinco pararam de estudar após concluir o ensino médio. Oito indivíduos apresentavam uma atividade profissional ${ }^{106}$.

UZIEL et al. (2007), em estudo internacional semelhante realizado com 82 usuários de IC há 10 anos identificou que 79 crianças (96\%) sempre usavam o dispositivo; 79\% (65 de 82 crianças) poderia usar o telefone. Os escores médios foram de $72 \%$ para o reconhecimento de fala, $44 \%$ para o reconhecimento de palavras no ruído. Trinta e três crianças (40\%) desenvolveram discurso inteligível para o ouvinte médio, e 22 (27\%) desenvolveram fala inteligível a um ouvinte com pouca experiência no discurso de pessoa surda. As medidas de vocabulário mostraram que a maioria (76\%) das crianças que receberam implantes marcaram abaixo do valor médio de seus colegas com audição normal. Em relação ao estado educacional e vocacional, 6 indivíduos faziam universidades, três já tinham uma atividade profissional, 14 estavam cursando o ensino médio, 32 estavam no ensino fundamental, 6 crianças frequentavam ensino especial, e 3 crianças ainda estavam frequentando escolas de educação infantil. Dezessete estavam no ensino profissionalizante ${ }^{107 .}$

BEADLE et al. (2005), avaliou 30 usuários após 10 anos de experiência com o IC. Concluiu que 26 indivíduos (87\%) relataram que sempre usavam o dispositivo; 2 indivíduos (7\%), com frequência; e um sujeito (3\%), ocasionalmente. Apenas uma criança tinha interrompido o uso do seu dispositivo. Após 10 anos de uso do implante, $26(87 \%)$ das crianças compreenderam uma conversa sem leitura labial e 18 (60\%) faziam uso do telefone, 23 (77\%) dos indivíduos utilizavam fala inteligível a um ouvinte 
médio ou a um ouvinte com pouca experiência em discurso de uma pessoa surda. Um terço das crianças implantadas continuaram a demonstrar melhorias em 5 e 10 anos de uso do implante. Das 30 crianças implantadas, 8 (26,7\%) tiveram falhas no dispositivo e foram reimplantadas com sucesso. O período de tempo desde a identificação do primeiro eletrodo defeituoso e a cirurgia de reimplante variou de 2 semanas a 5,5 anos. Ao final do estudo, 19 indivíduos estavam na escola: 6 estavam em escolas regulares, 7 frequentavam unidades regulares com apoio especial e 6 estavam em escolas para surdos. Dos restantes 11 indivíduos: 4 estavam em cursos profissionalizantes, 2 na universidade, 3 estavam trabalhando em tempo integral, 1 trabalhava e estudava em universidade, e uma era mãe em tempo integral ${ }^{108}$.

Embora haja poucos estudos longitudinais que averiguam tais características de vida, as evidências mostram a variabilidade de resultados, mas apontam também fatores bem positivos de integração social, escolar e laboral na maioria dos casos, sinalizando que o IC é um dispositivo tecnológico que possibilita a melhora do sujeito surdo em vários aspectos da vida. 


\section{MÉTODO}

Trata-se de estudo prospectivo, descritivo, de caráter exploratório, incluindo técnicas quantitativas na coleta e análise dos dados, por meio de questionários com questões fechadas.

Foram recrutados para este estudo 40 pais e 40 professores de 40 crianças usuárias de implante coclear de um mesmo centro de reabilitação da audição e linguagem do Distrito Federal, Brasília, Brasil. Um professor não participou da pesquisa por ser novato com a criança $(n=39)$. Os pacientes, em idade escolar (de 7 a 14 anos), foram implantados com dispositivo multicanal, unilateralmente, com os processadores de fala: Nucleus Freedom BTE $(n=7)$, Nucleos Freedom Bodyworn $(n=13)$, Opus $1(n=3)$, Opus $2(n=6)$, Nucleus $5(n=6)$ e Harmony $(n=5)$.

O Centro de Reabilitação foi contatado para apoio na coleta de dados (Anexo I). Após a aprovação do Comitê de Ética e Pesquisa em Seres Humanos da Faculdade de Ciências da Saúde (Anexo II), da Universidade de Brasília (número de parecer do CAAE: 35335214.0.0000.0030), foi realizado o convite de participação, esclarecimento da pesquisa e assinatura do termo de consentimento livre e esclarecido (Apêndice A e B), no período de novembro de 2014 à junho de 2015. Os pais responderam aos questionários no centro de reabilitação. Como cada criança estudava em escolas e cidades diferentes, foi pedido aos pais que levassem o outro instrumento para os professores das escolas regulares, que também assinaram o termo de livre consentido direcionado aos professores. Posteriormente os pais devolveram o questionário dos professores já respondidos para os pesquisadores.

Foi realizada a avaliação fonoaudiológica da audição e da linguagem pelas fonoterapeutas, na qual cada criança foi classificada de acordo com as categorias propostas por Bevilacqua (1996) $)^{109}$ e Geers $(1994)^{110}$. A categorização da audição se dá em um escore de 0-6, onde: 0 - Não detecção dos sons de fala; 1 - Detecção dos sons da fala; 2 - Iniciando padrão de percepção de palavras; 3 - Iniciando a identificação de palavras; 4 - Identificação de palavras por reconhecimento da vogal; 5 - Identificação de palavras por meio do reconhecimento da consoante; 6 Reconhecimento de palavras em conjunto aberto. A categorização da linguagem é feita em um sistema de pontuação de 1-5, sendo: 1 - Não fala; 2 - Emissão de palavras isoladas; 3 - Emissão de palavras simples; 4 - Emissão de frases completas; 5 - Fluência. 


\section{1- PARTICIPANTES:}

\section{CRITÉRIOS DE INCLUSÃO:}

Pais e professores de crianças usuárias de implante coclear em idade escolar (de 7 a 14 anos de idade), com ativação do aparelho realizada há pelo menos um ano, que realizam fonoterapia no CEAL-LP - Centro Educacional de Audição e Linguagem Ludovico Pavoni, que tiveram a inserção total dos eletrodos na cóclea.

\section{CRITÉRIOS DE EXCLUSÃO:}

Pais e professores de crianças que possuam outras morbidades, síndromes e/ou outras deficiências associadas à surdez. Usuários do implante coclear que não tiveram inserção total dos eletrodos na cóclea.

\section{2- INSTRUMENTOS:}

Para avaliar o resultado do IC sob as perspectivas dos pais que acompanham os implantados na fonoterapia foi utilizado o instrumento "Crianças com implante coclear: perspectivas dos pais"111 (CCIPP - Anexo III), validado para o Brasil, por Tavares et al. (2012) ${ }^{112}$. Este questionário é composto por 74 frases afirmativas e negativas, em escala Likert de 1 a 5 pontos, sendo 1 - concordo plenamente; 2 concordo; 3 - nem concordo nem discordo; 4 - discordo; 5 -discordo plenamente. As frases estão dispostas de maneira a compor 11 escalas, a saber: (1) Ansiedades sobre a decisão de implantar; (2) Atitudes no processo de implante; (3) Uso do implante pela criança; (4) Comunicação atual; (5) Educação; (6) Funcionamento da criança antes do implante; (7) Adaptação imediata; (8) $O$ apoio dos pais para a criança; (9) Autoconfiança atual; (10) Relações sociais; (11) Bem-estar e felicidade. Cada escala refere-se a amplitude do conjunto de questões por ela abordada, de acordo com as considerações e inversões de valores das frases negativas propostas por Nunes et al $(2005)^{113}$.

Aos professores aplicou-se um instrumento com 11 questões fechadas (Apêndice C), em escala Likert de 1 a 4 pontos: 1 - nunca; 2 - as vezes; 3 - quase 
sempre; 4 - sempre, proposto pelos pesquisadores, com questões baseadas nas categorias de desenvolvimento da audição e da linguagem, propostos por Bevilacqua 109 e Geers 114. Foram incluídas duas outras questões sobre o desempenho acadêmico da criança. Este instrumento tem o objetivo de caracterizar a percepção dos professores sobre a audição, a linguagem e o desempenho acadêmico dos seus alunos.

O mesmo questionário (Apêndice D) também foi aplicado aos pais, com exceção das duas perguntas sobre o desempenho acadêmico da criança implantada. Este instrumento foi construído para verificar se há associação entre a avaliação dos pais e dos professores.

\section{3- ANÁLISE ESTATÍSTICA}

Para verificar se a percepção dos pais que responderam ao CCIPP é de concordância com as escalas, foi utilizado o teste Wilcoxon para uma única amostra, em que a hipótese nula $(\mathrm{Ho})$ é que a mediana da dimensão é igual a 0 , isto é indiferente (nem concorda nem discorda), e a hipótese alternativa de concordância dos pais, de que a mediana da dimensão é maior que 0\% (Teste unicaudal). Para verificar a correlação entre as escalas do CCIPP entre si utilizou-se o coeficiente de Sperman. As escalas foram classificadas percentualmente de $-100 \%$ a $100 \%$, em que valores negativos referem-se à discordância, o 0 nem concorda nem discorda e os positivos à concordância. Quanto mais perto de 100 mais forte a correlação. Para o valor 0 não existe correlação. Se o valor for negativo, a correlação é negativa.

Para investigar se há diferença nas percepções dos pais de crianças implantadas há menos de cinco anos e aquelas dos pais de usuários há mais de cinco anos comparou-se os resultados das diferentes escalas do CCIPP pelo teste estatístico de Wilcoxon (signed-rank test) para amostras pareadas. Nesse teste a hipótese nula $(\mathrm{Ho})$ é que a diferença das medianas dos pais de usuários de IC há menos e há mais de 5 anos é igual a zero e a hipótese alternativa (Ha) é que as medianas das percepções dos pais de crianças implantadas há mais de 5 anos é maior do que as medianas das percepções dos pais implantadas há menos de 5 anos (unicaudal). O teste foi realizado para cada escala e em âmbito geral (todos as escalas). 
Já para a comparação dos resultados na perspectiva dos pais das crianças que foram implantadas com idade até os 2 anos, de 2 a 5 anos e mais de 5 anos foi utilizado teste de Kruskal Wallis, em que a hipótese nula (Ho) é de não existir diferença na avaliação do resultado do IC com a idade para o implante contra a hipótese alternativa $(\mathrm{Ha})$ de que existe diferença. $\mathrm{O}$ teste foi realizado para cada escala.

Para verificar se há associação entre a avaliação dos pais e dos professores realizou-se o teste de correlação de Kendall (tau-b) que é indicado para medir a associação de duas variáveis que estão na escala ordinal, em tabelas de contingência.

Utilizou-se o coeficiente de Sperman Rho para verificar a correlação entre as escalas do CCIPP e a avaliação da audição e da linguagem realizada pelas fonoterapeutas. A hipótese nula (Ho) é que a avaliação da audição e da linguagem não correlaciona-se significativamente com as escalas do CCIPP e a hipótese alternativa $(\mathrm{Ha})$ é que esta avaliação correlaciona-se significativamente com as escalas estudas $(p<0.05)$.

Usaremos o tempo de uso do IC e a idade de implantação como variáveis independentes. O critério do intervalo de confiança considerado foi de $95 \%$, sendo o valor de significância considerado quando o p-valor for menor ou igual a 0,05. 


\section{RESULTADOS}

\section{1 - CARACTERIZAÇÃO DA AMOSTRA}

Foram sujeitos do estudo 40 pais e 39 professores de 40 crianças usuárias de IC. As idades dos implantados variam entre 7 e 14 anos $(M=9,63$; $D P=1,97)$, dos quais 26 são femininos (65\%) e 14 (35\%) são masculinos, com tempo de privação sensorial auditiva variando entre 1 ano e 8 meses a 7 anos e 4 meses $(M=3,6$; $D P=1,51)$, e tempo de uso do IC variando entre 3 a 9 anos $(M=6,03 ; D P=1,49)$.

\section{2 - PERCEPÇÃO DOS PAIS AVALIADOS PELO INSTRUMENTO “CRIANÇAS COM IMPLANTE COCLEAR: PERSPECTIVAS DOS PAIS"}

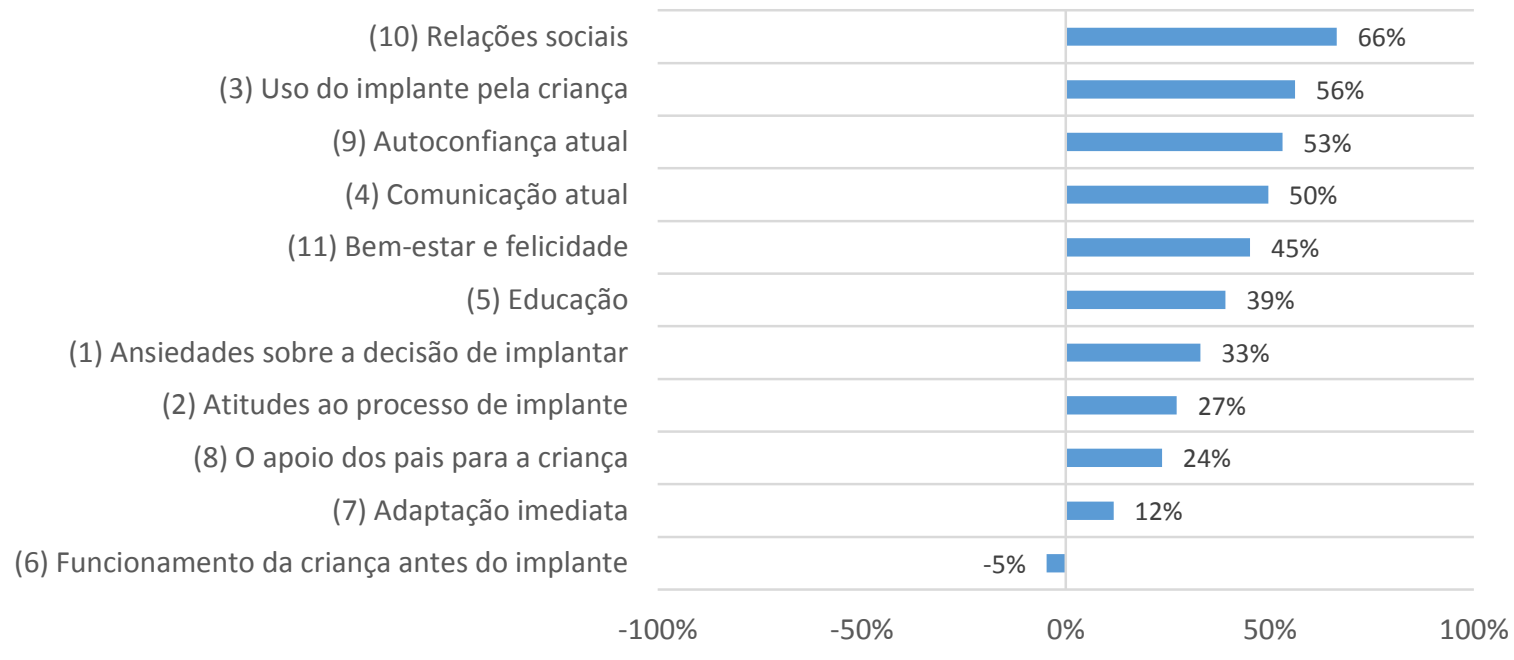

Figura 3: Ranking da percepção dos pais por escalas do CCIPP

Foi constatado que na perspectiva dos pais, o resultado foi positivo para 10 das 11 escalas. A escala de maior concordância foi a de (10) Relações sociais. Apenas para a escala de (6) funcionamento da criança antes do implante os pais apresentaram discordância em relação as frases abordadas. 
Tabela 1: Matriz de correlação do CCIPP - Rho de Spearman e p-valor

\begin{tabular}{|c|c|c|c|c|c|c|c|c|c|c|}
\hline Blocos & 1 & 2 & 3 & 4 & 5 & 6 & 7 & 8 & 9 & 10 \\
\hline 1 & - & & & & & & & & & \\
\hline 2 & $\begin{array}{c}0,233 \\
(0,154)\end{array}$ & - & & & & & & & & \\
\hline 3 & $\begin{array}{l}-0,008 \\
(0,959)\end{array}$ & $\begin{array}{c}0,126 \\
(0,446)\end{array}$ & - & & & & & & & \\
\hline 4 & $\begin{array}{c}0,093 \\
(0,573)\end{array}$ & $\begin{array}{c}0,341 \\
(0,033)^{*}\end{array}$ & $\begin{array}{c}0,368 \\
(0,021)\end{array}$ & - & & & & & & \\
\hline 5 & $\begin{array}{c}0,164 \\
(0,318)\end{array}$ & $\begin{array}{c}0,223 \\
(0,172)\end{array}$ & $\begin{array}{c}0,117 \\
(0,478)\end{array}$ & $\begin{array}{c}0,574 \\
(0,001)^{* *}\end{array}$ & - & & & & & \\
\hline 6 & $\begin{array}{c}0,076 \\
(0,644)\end{array}$ & $\begin{array}{c}0,111 \\
(0,5)\end{array}$ & $\begin{array}{l}-0,082 \\
(0,618)\end{array}$ & $\begin{array}{c}0,065 \\
(0,694)\end{array}$ & $\begin{array}{c}0,546 \\
(0,001)^{* *}\end{array}$ & - & & & & \\
\hline 7 & $\begin{array}{c}0,059 \\
(0,721)\end{array}$ & $\begin{array}{c}0,025 \\
(0,878)\end{array}$ & $\begin{array}{c}0,076 \\
(0,645)\end{array}$ & $\begin{array}{c}0,177 \\
(0,281)\end{array}$ & $\begin{array}{c}0,249 \\
(0,127)\end{array}$ & $\begin{array}{c}0,288 \\
(0,075)\end{array}$ & - & & & \\
\hline 8 & $\begin{array}{l}-0,056 \\
(0,734)\end{array}$ & $\begin{array}{c}0,11 \\
(0,505)\end{array}$ & $\begin{array}{c}0,144 \\
(0,381)\end{array}$ & $\begin{array}{l}-0,086 \\
(0,604)\end{array}$ & $\begin{array}{l}-0,094 \\
(0,568)\end{array}$ & $\begin{array}{l}-0,075 \\
(0,649)\end{array}$ & $\begin{array}{l}-0,228 \\
(0,162)\end{array}$ & - & & \\
\hline 9 & $\begin{array}{c}0,064 \\
(0,699)\end{array}$ & $\begin{array}{c}0,105 \\
(0,524)\end{array}$ & $\begin{array}{c}0,176 \\
(0,283)\end{array}$ & $\begin{array}{c}0,133 \\
(0,421)\end{array}$ & $\begin{array}{c}0,244 \\
(0,134)\end{array}$ & $\begin{array}{c}0,23 \\
(0,159)\end{array}$ & $\begin{array}{l}-0,132 \\
(0,423)\end{array}$ & $\begin{array}{c}0,391 \\
(0,014)^{*}\end{array}$ & - & \\
\hline 10 & $\begin{array}{l}-0,072 \\
(0,664)\end{array}$ & $\begin{array}{l}-0,055 \\
(0,74)\end{array}$ & $\begin{array}{c}0,434 \\
(0,006)^{\star *}\end{array}$ & $\begin{array}{c}0,01 \\
(0,953)\end{array}$ & $\begin{array}{c}0,048 \\
(0,773)\end{array}$ & $\begin{array}{c}0,215 \\
(0,188)\end{array}$ & $\begin{array}{c}0,109 \\
(0,509)\end{array}$ & $\begin{array}{c}-0,19 \\
(0,248)\end{array}$ & $\begin{array}{c}0,162 \\
(0,324)\end{array}$ & - \\
\hline 11 & $\begin{array}{c}0,321 \\
(0,046)^{*}\end{array}$ & $\begin{array}{c}0,334 \\
(0,038)^{\star}\end{array}$ & $\begin{array}{c}0,046 \\
(0,779)\end{array}$ & $\begin{array}{l}-0,018 \\
(0,912)\end{array}$ & $\begin{array}{c}0,113 \\
(0,495)\end{array}$ & $\begin{array}{c}0,037 \\
(0,821)\end{array}$ & $\begin{array}{c}0,085 \\
(0,608)\end{array}$ & $\begin{array}{c}0,307 \\
(0,057)\end{array}$ & $\begin{array}{c}0,252 \\
(0,122)\end{array}$ & $\begin{array}{c}-0,022 \\
(0,894)\end{array}$ \\
\hline
\end{tabular}

Quando avaliada a correlação entre as escalas do CCIPP (Tabela 1) foi observado que existe correlação positiva entre a escala (4)Comunicação atual com as escalas de (5)Educação ( $p=0,001$ Rho 0,574$)$ e (2)Atitudes ao processo de implante $(p=0,033$ Rho 0,341$)$. Desta forma quanto mais positiva a percepção do resultado dos pais nas escalas relacionadas com a comunicação atual, mais positiva também a percepção do resultado relacionado à escala de educação e de atitudes ao processo de implante. As escalas (3) Uso do implante pela criança e (10)Relações sociais também correlacionaram-se positivamente ( $\mathrm{p}=0,006$, Rho 0,434$)$, assim, a percepção da melhora da audição e da linguagem da criança com o uso do implante correlacionou-se com a percepção de uma melhora nas relações sociais. A escala de (8)Apoio dos pais para a criança correlacionou-se positivamente com a (9)Autoconfiança atual ( $p=0,014$ Rho 0,391 ), ou seja, quanto melhor avaliado o apoio dos pais, mais positiva a sua avalição na autoconfiança da criança. 
A Figura 4 apresenta a comparação das perspectivas dos pais das crianças que usam o IC há menos e há mais de 5 anos.

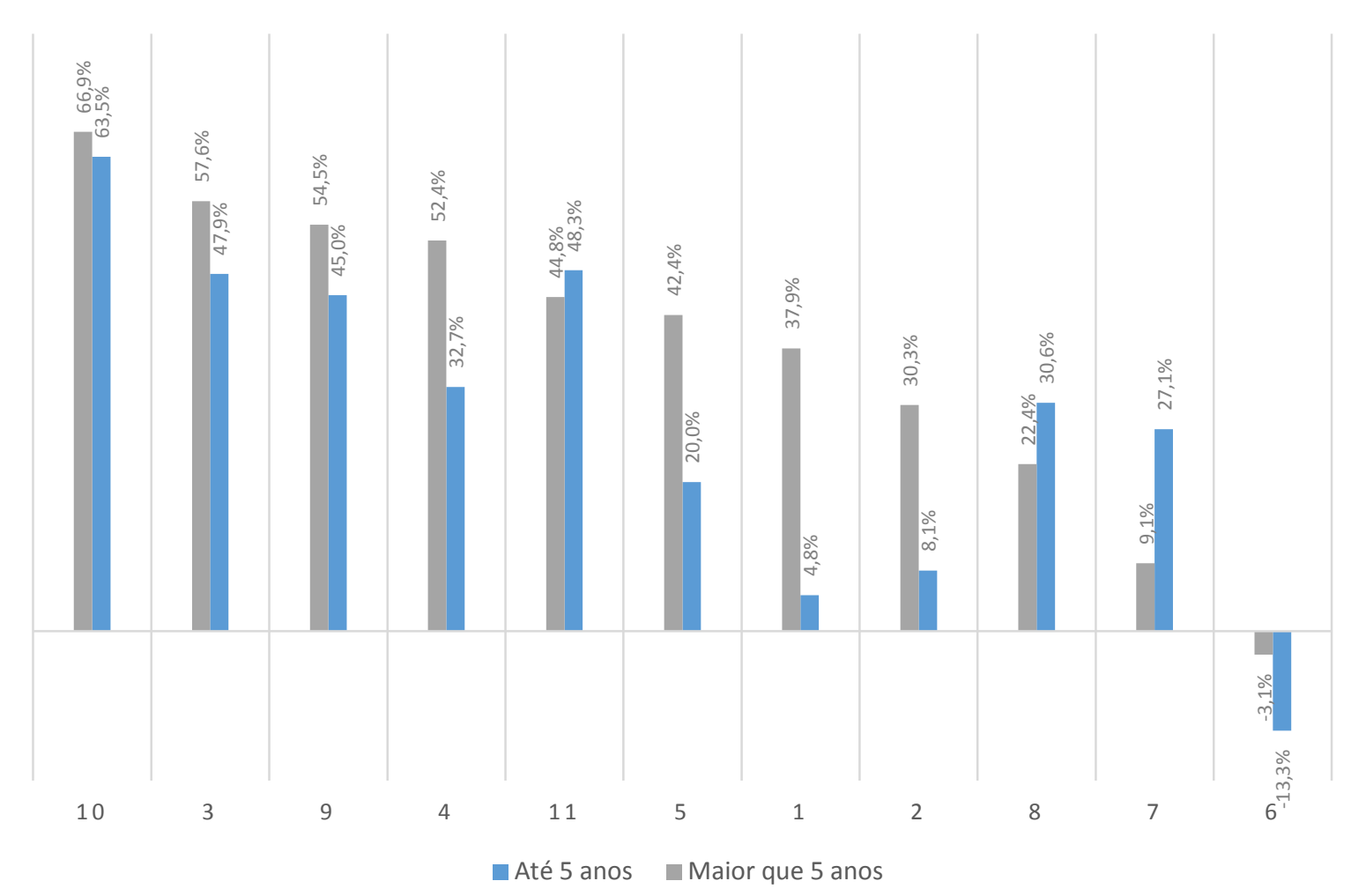

Figura 4: Percepção do resultado dos pais de crianças com menos e mais de 5 anos de uso nas escalas do CCIPP

Foi constatado que a percepção do resultado dos pais de crianças implantadas há mais de 5 anos é diferente da percepção dos pais de crianças implantadas há menos de 5 anos (Figura 4), isto é, a percepção do resultado dos pais de crianças implantadas há mais de 5 anos é mais positiva do que a percepção dos pais de crianças implantas há menos de 5 anos para as seguintes escalas: (10) Relações sociais, (3)Uso do implante pela criança, (9)Autoconfiança atual, (4)Comunicação atual, (5)Educação, (1)Ansiedades sobre a decisão de implantar, (2)Atitudes ao processo de implante e (6) Funcionamento da criança antes do implante. Houve significância estatística apenas para a escala (1)Ansiedade sobre a decisão de 
implantar $(p=0,03)$ para as outras escalas não foi evidenciada diferença significativa para $p<0,05$.

A Figura 5 mostra a comparação das perspectivas dos pais das crianças que foram implantadas com idade até aos 2 anos, de 2 aos 5 anos e mais de 5 anos, separados em cada escala.

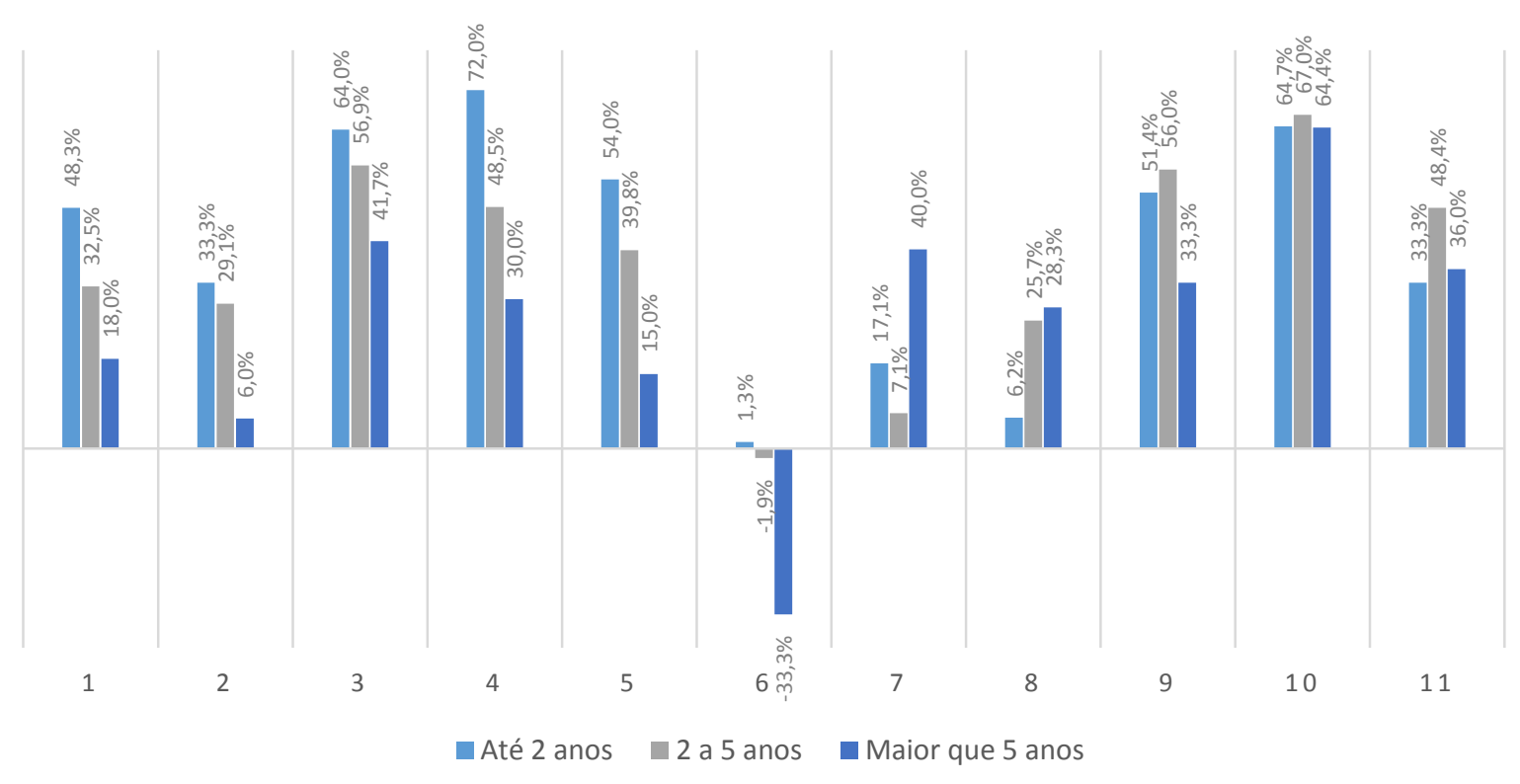

Figura 5: Percepção dos pais de crianças implantadas até aos 2 anos, de 2 aos 5 anos e com mais de 5 anos nas escalas do CCIPP

Das 40 crianças, 5 foram implantadas até aos 2 anos, 31 entre 2 e 5 anos e 4 com idade superior a 5 anos. Constatou-se que em 6 escalas:(1)Ansiedades sobre a decisão de implantar, (2)Atitudes ao processo de implante, (3)Uso do implante pela criança, (4)Comunicação atual, (5)Educação e (6)Funcionamento da criança antes do implante, os pais de crianças implantadas até aos 2 anos tiveram a percepção mais positiva que dos pais de crianças implantadas entre 2 e 5 anos, que também tiveram percepções melhores que os pais de crianças implantadas maiores de 5 anos. Contudo, o teste de Kruskal Wallis revelou que não existe diferença estatística significativa entre as idades de implantação na percepção dos pais em nenhuma das escalas. 


\section{3 - AVALIAÇÃO DAS CRIANÇAS USUÁRIAS DE IC DE ACORDO COM AS CATEGORIAS DE AUDIÇÃO E LINGUAGEM}

A Tabela 2 traz as categorias da audição e linguagem das 40 crianças segundo os critérios de Bevilacqua (1996) ${ }^{109}$ e Geers (1994) ${ }^{114}$.

Tabela 2: Avaliação fonoaudiológica da audição e linguagem

\begin{tabular}{lcc}
\hline Avaliação fonoaudiológica & Freq. & (\%) \\
\hline Audição & & \\
0-Não detecta sons de fala & 0 & $0,0 \%$ \\
1-Detecção dos sons da fala & 3 & $7,5 \%$ \\
2-Padrão de percepção de fala & 0 & $0,0 \%$ \\
3-Iniciando a identificação de palavras & 4 & $10,0 \%$ \\
4-Identificação de palavras (reconhecimento da vogal) & 4 & $10,0 \%$ \\
5-Identificação de palavras (reconhecimento da consoante) & 11 & $27,5 \%$ \\
6-Reconhecimento de palavras em conjunto aberto & 18 & $45,0 \%$ \\
Linguagem & & \\
1-Não fala & 1 & $2,5 \%$ \\
2-Emissão de palavras isoladas & 3 & $7,5 \%$ \\
3-Emissão de frases simples & 13 & $32,5 \%$ \\
4-Emissão de frases complexas & 9 & $22,5 \%$ \\
5-Fluência & 14 & $35,0 \%$ \\
\hline
\end{tabular}

Observa-se que a maioria das crianças encontra-se nos níveis mais elevados da audição $n=18$ (45\%) e da linguagem $n=14$ (35\%). 
A avaliação de linguagem e da audição realizada pelo fonoaudiólogo com tempo de uso do IC são apresentadas a seguir. Vemos que o maior tempo de uso do IC melhora os resultados da audição e da linguagem.

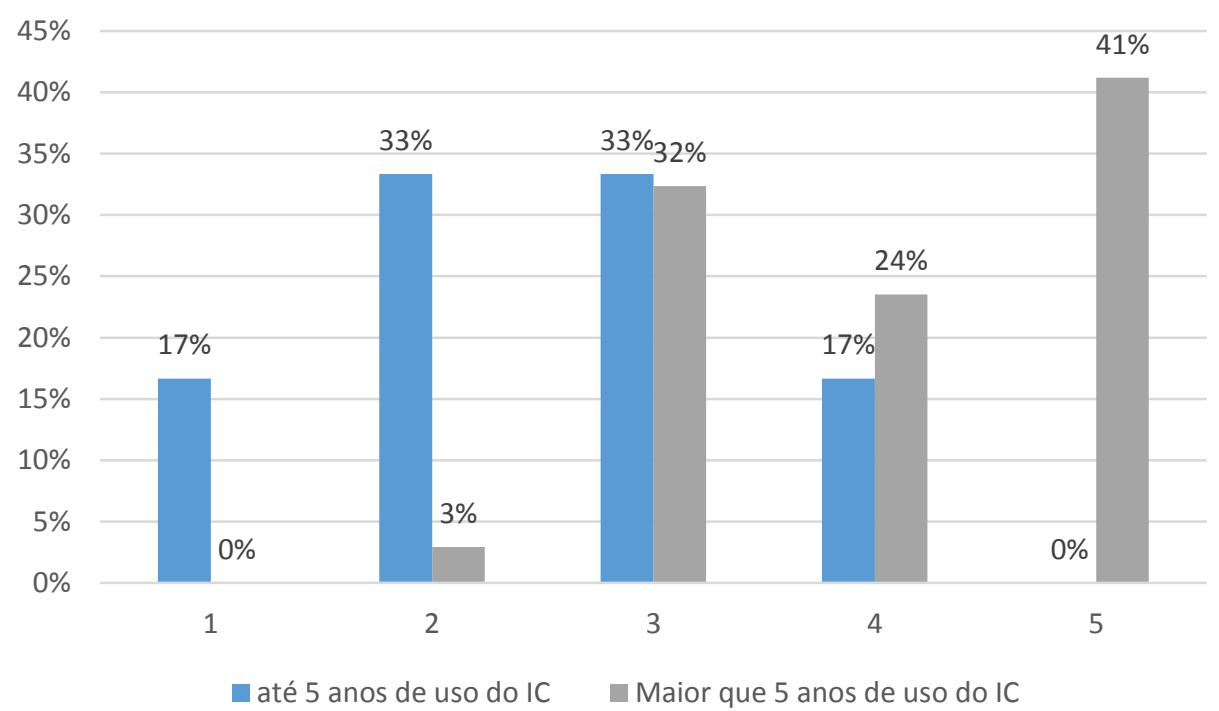

Figura 6: Proporção de classificação da linguagem por tempo de uso do IC

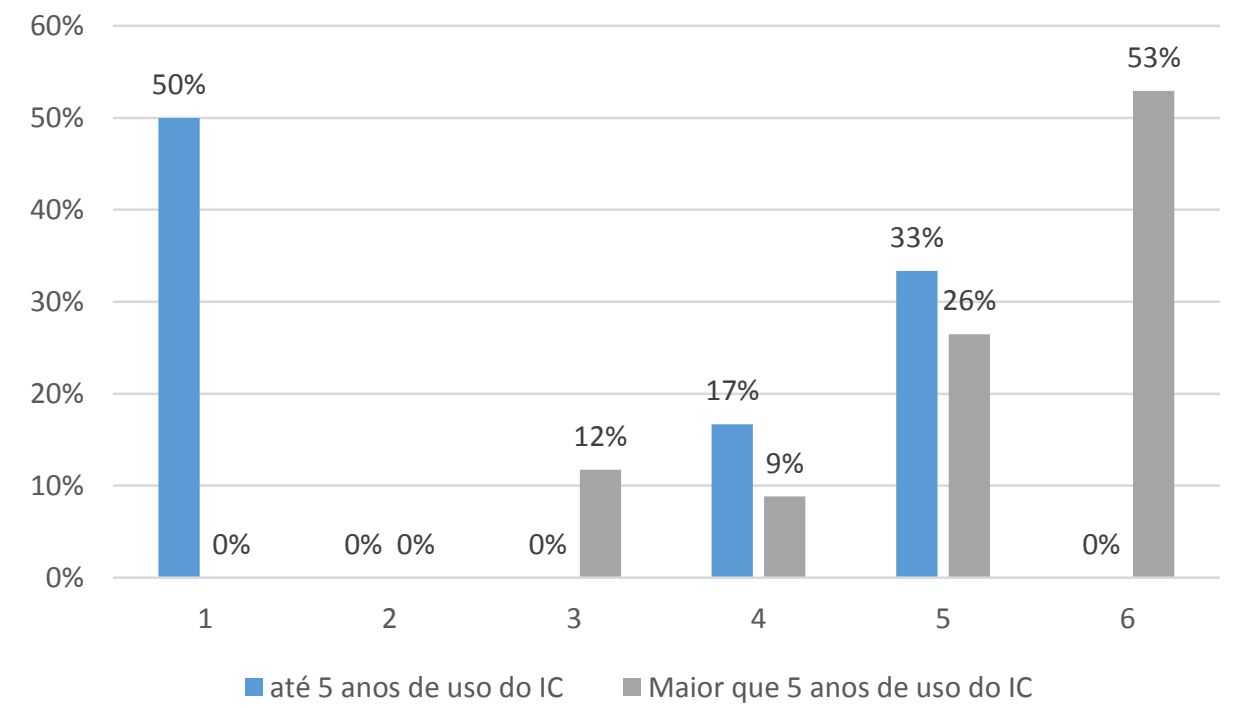

Figura 7: Proporção de classificação da audição por tempo de uso do IC 
A avaliação da linguagem e da audição do fonoaudiólogo com idade no implante apresentada revela que a implantação precoce também melhora os resultados da audição e da linguagem.

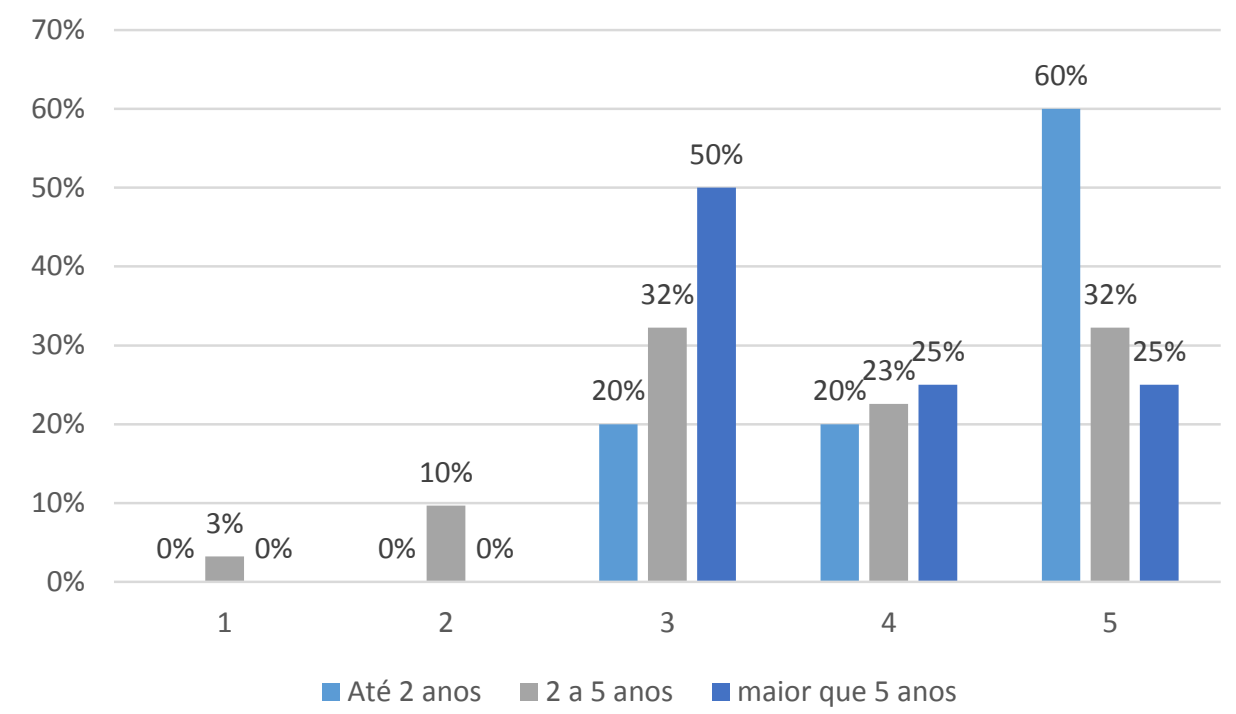

Figura 8: Proporção de classificação da linguagem por idade no implante

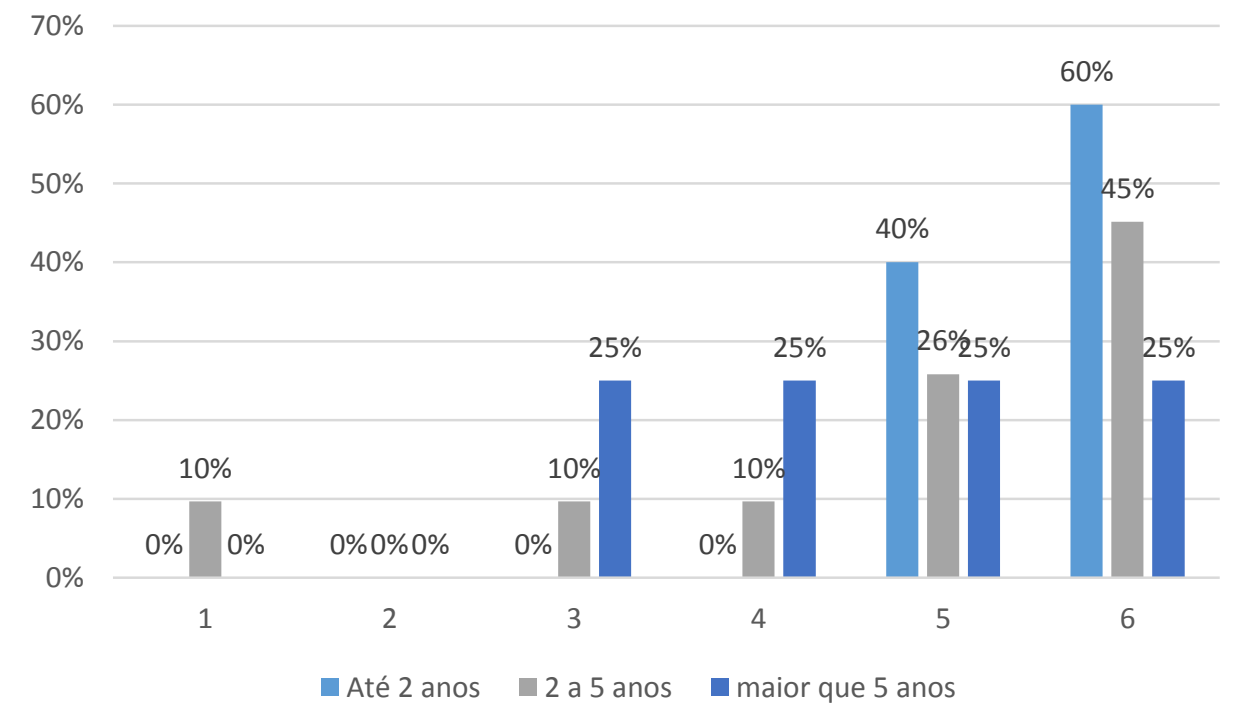

Figura 9: Proporção de classificação da audição por idade no implante 


\section{4 - ASSOCIAÇÃO ENTRE A AVALIAÇÃO DOS PAIS E DOS PROFESSORES}

Quanto ao desempenho escolar da criança implantada, referido pelo professor, temos que: 25 (64\%) referiram estar na média, 11 (28,5\%) abaixo da média e 3 (7,5\%) acima da média.

A Tabela 3 apresenta o resultado da análise das comparações das respostas às questões dirigidas a professores e pais das crianças implantadas baseados nas categorias de audição e linguagem propostas por Bevilacqua (1996) ${ }^{109}$ e Geers (1994) ${ }^{114}$.

Tabela 3: Questionário elaborado para pais e professores - Correlação tau-b de Kendall

\begin{tabular}{lcc}
\hline Cruzamentos professores e pais & Tau b & p-valor \\
\hline 1-Seu aluno/filho detecta a fala? & 0,167 & 0,292 \\
2- Seu aluno/filho diferencia uma palavra longa de uma curta? & 0,29 & 0,056 \\
3- Seu aluno/filho diferencia palavras que tem o mesmo número & & \\
de sílabas com pista visual (Ex.: gato x casa)? & 0,236 & 0,131 \\
4- Seu aluno/filho sabe diferenciar as palavras pelas vogais com & & \\
pista visual (Ex.: pé, pó, pá)? & 0,286 & 0,056 \\
5- Seu aluno/filho sabe diferenciar as palavras pelas consoantes & & \\
com pista visual (Ex.: mão, pão, cão)? & 0,199 & 0,155 \\
6-Seu aluno/filho consegue entender o que foi dito? & 0,492 & $<0,001^{\star *}$ \\
7-Seu aluno/filho emite algum som de fala? & 0,272 & 0,096 \\
8-Seu aluno/filho fala algumas palavras? & 0,405 & $0,019^{*}$ \\
9- Seu aluno/filho fala frases de 2 ou 3 palavras? & 0,339 & $0,028^{*}$ \\
10- Seu aluno/filho fala frases de 4 e 5 palavras? & 0,411 & $0,006^{\star *}$ \\
11- Você acha que seu aluno/filho fala bem? & 0,494 & $<0,001^{\star *}$ \\
\hline
\end{tabular}

${ }^{*} p<0.05$

Observou-se que em cinco questões há concordância entre a avaliação dos professores e pais $(p<0.05)$. São elas: (Questão 6$)$ você percebe que seu aluno/filho consegue entender o que foi dito?; (Questão 8) seu aluno/filho fala algumas palavras?; (Questão 9) seu aluno/filho fala frases de 2 ou 3 palavras?; (Questão 10) seu 
aluno/filho fala frases de 4 e 5 palavras?; e (Questão 11) você acha que seu aluno/filho fala bem? As seis primeiras questões se referem à audição e as demais à linguagem. Pode-se notar inicialmente que não há uma concordância completa nas percepções de professores principalmente nas questões relacionadas a audição, sendo que os pais e professores concordaram mais com as questões baseadas na linguagem (4/5) do que as questões de audição (1/6). 


\section{5 - CORRELAÇÃO ENTRE A PERSPECTIVA dOS PAIS E A AVALIAÇÃO FONOAUDIOLÓGICA DA AUDIÇÃO E DA LINGUAGEM}

A tabela 4 apresenta a correlação da avaliação fonoaudiológica da audição e da linguagem propostas por Bevilacqua (1996) ${ }^{109}$ e Geers (1994) ${ }^{114}$ e as escalas do CCIPP.

Tabela 4: Avaliação fonoaudiológica e escalas do CCIPP - Rho de Spearman e pvalor

\begin{tabular}{lcc}
\hline Matriz & Audição & Linguagem \\
\hline Audição & - & $0,91(0,001)^{\star *}$ \\
Linguagem & $0,91(0,001)^{\star *}$ & - \\
(1) Ansiedades sobre a decisão de implantar & $0,211(0,197)$ & $0,29(0,073)$ \\
(2) Atitudes ao processo de implante & $0,121(0,464)$ & $0,217(0,185)$ \\
(3) Uso do implante pela criança & $0,26(0,11)$ & $0,211(0,198)$ \\
(4) Comunicação atual & $0,549(0,001)^{\star *}$ & $0,512(0,001)^{\star *}$ \\
(5) Educação & $0,602(0,001)^{\star *}$ & $0,590(0,001)^{\star \star}$ \\
(6) Funcionamento da criança antes do implante & $0,209(0,202)$ & $0,174(0,29)$ \\
(7) Adaptação imediata & $0,278(0,086)$ & $0,302(0,062)$ \\
(8) O apoio dos pais para a criança & $-0,251(0,123)$ & $-0,213(0,193)$ \\
(9) Autoconfiança atual & $0,088(0,592)$ & $0,095(0,566)$ \\
(10) Relações sociais & $0,275(0,09)$ & $0,229(0,162)$ \\
(11) Bem-estar e felicidade & $0,102(0,536)$ & $0,131(0,427)$ \\
\hline
\end{tabular}

${ }^{* *} \mathrm{p}<0.05$

Constata-se, pela Tabela 4, que a avaliação do fonoaudiólogo para audição e linguagem correlacionaram significativamente apenas com as escalas (4)Comunicação atual e (5)Educação. Isso sugere que quanto maior a categoria de audição e linguagem avaliada pelo fonoaudiólogo melhor é a percepção dos pais com as questões abordadas nas escalas de comunicação e educação $(p<0.05$ Rho 0.54 e 0.60 respectivamente). Observou-se também, uma correlação positiva ( $p<0.05$ Rho 
$=0,91$ ) entre a avaliação de audição e linguagem ambas categorizadas pelos fonoaudiólogos, ou seja, quanto melhor a audição da criança melhor sua linguagem e vice versa do ponto de vista fonoaudiológico. Percebe-se pelos achados que as outras escalas não apresentam correlação estatisticamente significante com as categorias de audição e linguagem $(p>0.05)$. Vale ressaltar que as escalas de autoconfiança atual, relações sociais e bem estar e felicidade não estiveram correlacionadas com as categorias de audição e linguagem avaliadas pelos fonoaudiólogos. 


\section{6 - DISCUSSÃO}

\section{1 - PERCEPÇÃo dOS PAIS SOBRE OS RESULTADOS DO IC AVALIADAS PELO CCIPP}

O presente estudo mostrou que os pais avaliaram em 10 das 11 escalas do instrumento o resultado de maneira positiva com o uso do IC (Figura 3). As escalas de maior concordância foram a de (10) Relações sociais, (3)Uso do IC pela criança, (9)Autoconfiança atual e (4)Comunicação atual. Pesquisas que utilizaram o mesmo instrumento relataram percepções positivas mais direcionadas à comunicação, relações sociais e autoconfiança ${ }^{112 ; 115 ; 116 .}$

Quando avaliou-se as correlações entre as escalas do CCIPP (Tabela 1) verificou-se uma correlação positiva entre a escala relacionada à educação e comunicação e também uso do implante e relações sociais. Estas correlações também foram verificadas em outros estudos ${ }^{111 ; 112}$. Os benefícios do IC nos aspectos educacionais, assim como no aprimoramento das relações sociais ficam aparentes.

Embora este estudo mostrou que para os pais houve maior concordância para Relações sociais, BATTEN et al. (2014) discutiram que as crianças surdas apresentaram dificuldades sociais em comparação com os seus pares ouvintes e que o gênero feminino tem maior facilidade na interação entre pares ${ }^{117}$. MARTIN, et al. (2011) mostraram que os implantados apresentaram maior facilidade de socialização quando acompanhados do que quando estão sozinhos ${ }^{31}$. Também há evidência de que a interação entre pares aumenta a autoestima ${ }^{118}$. Tais percepções não são analisadas durante as avaliações clínicas e acadêmicas em geral, mas fundamentalmente no ambiente familiar sendo os pais importantes informantes.

Ainda que nosso estudo tenha correlacionado positivamente o uso do IC com as relações sociais, BAT-CHAVA \& DEIGNAN (2001) constataram que o IC tem o potencial de melhorar as relações das crianças surdas com os pares ouvintes, mas elas ainda enfrentavam obstáculos de comunicação que dificultavam muito suas relações sociais ${ }^{119}$. MAGALHÃES, et al. (2007) identificaram imaturidade, intenso egocentrismo, ansiedade e dificuldades no relacionamento especialmente com seus pais nas crianças usuárias de IC e que têm a fala pobremente desenvolvida ${ }^{120}$. Assim 
sendo, a avaliação global do paciente implantado é fundamental para se determinar os reais benefícios destes dispositivos na vida do paciente.

A escala Uso do IC pela criança trata da efetividade do uso e os ganhos auditivos obtidos. VIEIRA, et al. (2014) e COUTO \& CARVALHO (2013) mostram que quanto mais tempo de uso ao longo do dia maiores são os resultados auditivos conquistados, no entanto, em crianças é preciso treino para que isto aconteça e, por vezes, não é fácil melhorar o seu comportamento ${ }^{3 ;} 17$.

Embora esta escala (Uso do IC pela criança) tenha tido alta concordância, uma das limitações do nosso estudo foi não ter investigado a efetividade do uso em horas diárias do IC pela criança, os defeitos ocorridos no dispositivo ao longo do anos e o tempo para conserto do mesmo. Isto porque tais dados poderiam influenciar a discussão sobre tal escala.

COSTA (2011), FORTUNATO et al. (2009), SACH \& WHYNES (2005), NIKOLOPOULOS et al. (2005), INCESULU et al. (2003), têm mostrado que a inteligibilidade da fala se desenvolve ao longo de uma escala de tempo mais ampla, em torno de 5 a 10 anos de uso do IC 33;121 4; 122. Neste estudo verificou-se que a percepção do resultado dos pais com crianças implantadas há mais de 5 anos é melhor do que aquela dos pais de crianças implantadas há menos de 5 anos em 8 das 11 escalas (Figura 4). Este resultado aponta para melhora na percepção dos resultados do IC com o passar dos anos, proporcionando, uma percepção mais positiva nos pais. Contudo, a escala que sinaliza significância estatística diz respeito apenas à Ansiedade sobre a decisão de implantar $(\mathrm{p}=0,03)$. Ou seja, há questões emocionais angustiantes vivenciadas pelos genitores no transcorrer do processo de implantação para além das questões fonoaudiológicas da criança, pois são eles que gerenciam a vida de seus filhos ${ }^{96 ; 123 .}$

No que diz respeito a idade do implante, foi encontrado que em 6 escalas os pais de crianças implantadas até 2 anos de idade tiveram a percepção melhor que a dos pais de crianças implantadas em idades superiores. Esta diferença não foi considerada estatisticamente significante (Figura 5). SOUSA et al. (2014), KANDA et al.(2012) e ARTIERES et al. (2009), mostraram que a implantação precoce tem resultados mais rápidos e efetivos, mas estes resultados não se associam necessariamente com a melhor percepção dos pais, limitando-se aos achados audiológicos objetivos ${ }^{34 ; 83 ; 90}$. O menor tempo de privação auditiva associa-se aos melhores resultados da audição e da linguagem em crianças usuárias de IC 18; 192426 . 
Espera-se que estes melhores resultados sejam percebidos diretamente pelos pais. Contudo, o presente estudo mostrou que os ganhos de audição e linguagem dos usuários de IC implantados antes do dois anos não influenciam na avalição global dos resultados avaliados pelo instrumento CCIPP. Novamente os dados apontam para o fato de que a avaliação no contexto amplo das crianças trazem informações importantes.

\section{2 - AVALIAÇÃO FONOAUDIOLÓGICA DA AUDIÇÃO E DA LINGUAGEM DE CRIANÇAS USUÁRIAS DE IC}

De acordo com a avaliação fonoaudiológica da audição, vide tabela 2, vemos que $45 \%$ das crianças já reconhecem as palavras em conjunto aberto, sendo a média 4,85, o que representa que a maioria está identificando as palavras por reconhecimento da consoante. Mas temos 3 crianças $(7,5 \%)$ que apenas detectam sons de fala. Como o tempo mínimo de uso do IC neste estudo foi de 3 anos, constatase uma grande variação nos resultados e, evidentemente, uma frustração nas expectativas dos pais das crianças que não evoluem como esperado. Tais dados corroboram com a literatura que aponta a variabilidade de resultados auditivos no IC e o quanto tais aspectos influenciam a percepção dos pais ${ }^{15}$.

Em relação à linguagem, apenas 35\% das crianças apresentam fluência verbal e cerca de $32 \%$ formam frases simples, a média sendo de 3,80 . Uma criança não fala, $2,5 \%$. Nota-se que a idade mínima dos participantes do estudo é de 7 anos e que o tempo mínimo de uso do IC é de 3 anos, além de não terem outros comprometimentos agregados. Daí depreende-se a lentidão do processo, a variação nos resultados e a dificuldade de manejo com pacientes que não evoluem, como já postulado na literatura $24 ; 25$.

Esta variação nos resultados audiológicos pode também ser justificada por descoberta realizada por um estudo publicado este ano na revista The Lancet. A pesquisa concluiu que a privação auditiva tem efeitos generalizados sobre 0 desenvolvimento do cérebro, afetando a capacidade de processar informações para 
além do sistema auditivo. Após a perda sensorial auditiva, a conectividade efetiva do cérebro é alterada dentro do sistema auditivo, entre os sistemas sensoriais, e entre o sistema e os centros que servem as funções neurocognitivas. Como resultado, a surdez congênita pode ser pensada como uma doença conectoma (mapeamento das conexões entre os neurônios no cérebro), com a variabilidade interindividual na adaptação do cérebro à perda sensorial subjacente, o que justifica a maior parte da variação observada no resultado do implante coclear. Temos, então, que diferentes funções executivas, processamento sequencial e formação de conceitos estão particularmente em risco em crianças surdas. Também sinalizou que a abordagem deve ser personalizada para engendrar melhores resultados em cada usuário ${ }^{124}$.

Esses novos estudos podem elucidar outras variáveis que limitam ou potencializam os efeitos do IC em crianças pré-linguais. Podem também confirmar se as pesquisas até então realizadas são coerentes com essa variação de resultados e sinalizar ajustes que possam ser realizados para que o sucesso do IC seja, no mínimo, para incluir o usuário plenamente na sociedade.

\section{3 - ASSOCIAÇÃo ENTRE AVALIAÇÃo dE PAIS E PROFESSORES DE CRIANÇAS USUÁRIAS DE IC}

BRAZAROTTO (2008), CAMPOS (2015) e HUTTUNEN \& VALIMAA (2010) têm apontado as dificuldades escolares dos usuários de IC e mostram que 0 desempenho acadêmico está abaixo da média nas crianças implantadas quando comparadas com seus pares ouvintes ${ }^{20 ; 28 ; 125}$. Nossos resultados sugerem que a maioria dos professores pesquisados $(64 \%)$ referiram que seus alunos implantados estão na média, 28,5\% abaixo da média e 7,5\% acima da média, em comparação com a turma. Contudo, tal aspecto foi avaliado em duas questões. A avaliação objetiva poderia apontar um resultado mais fidedigno para este dado.

KRONENBERGER, et al. (2014) afirma que as crianças surdas pré-linguais, usuárias de IC, são 2 a 5 vezes mais propensas que as crianças ouvintes a terem problemas na maioria dos domínios das funções executivas, tais como: memória, 
atenção, processamento sequencial, resolução de problemas, memória de trabalho e aprendizagem conceitual. Os achados relatam associação entre privação auditiva, atraso de linguagem, e atraso nas funções executivas ${ }^{126}$. Tais fatores contribuem para um desempenho acadêmico difícil e frequentes atrasos na aprendizagem. Estes apontamentos também ocorrem nos pacientes que apresentam resultados fonoaudiológicos dentro do esperado (Tabela 2). Assim sendo, há a possibilidade de relatos do desenvolvimento da audição e linguagem dentro do esperado do ponto de vista fonoaudiológico e a percepção de resultados acadêmicos insuficientes referido por professores.

Nossos resultados demonstraram que a percepção dos pais torna-se mais positiva com o passar do tempo (Figura 4). HUTTUNEN \& VÄLIMAA (2010), em um estudo, ao longo de 5 anos, verificaram que os pais observaram alterações comportamentais positivas nos seus filhos usuários de IC, ficando mais calmos, autoconfiantes e com melhoras sociais com o passar do tempo. As maiores mudanças começaram a ocorrer um ano após a implantação. Após cinco anos de implantação, dois terços das crianças foram consideradas tão independentes quanto seus pares etários ${ }^{127}$. Estas observações não são vistas na análise clínica fonoaudiológica em geral ou durante as avaliações acadêmicas. Portanto, as impressões dos pais em ambiente familiar mostram importantes observações não percebidas em ambiente clínico voltado para avaliação da audição e linguagem ou escolar.

Outro ponto é sobre o rebaixamento das expectativas dos pais frente ao desempenho acadêmico de seus filhos ao longo do tempo. Isto foi visto num estudo que verificou que nos domínios de comunicação e realizações acadêmicas, as mães foram frustradas frente as suas altas expectativas. Ou seja, viram que embora haja progressos com o uso do IC, precisam reconhecer que a criança continua a ter problema de audição ${ }^{128}$. Em nossa pesquisa, todas as crianças estudavam em escola regular, no entanto, não verificamos adequadamente o seu desempenho acadêmico e como este dado poderia influenciar na percepção dos pais.

Outra limitação do nosso estudo foi não ter identificado as dificuldades enfrentadas pelo professor que tem aluno implantado em sala e avaliar formas de manejo de tais aspectos. CAMPOS \& PINHEIRO (2014), em pesquisa realizada sobre o ruído no ambiente escolar, verificaram a dificuldade do DA neste ambiente e sugeriram algumas intervenções para a diminuição do barulho: uso de feltro nos pés 
das cadeiras e carteiras escolares, uso de piso emborrachado e cortinas nas janelas para melhor absorção do som, posicionamento do aluno longe de janelas e portas, necessidade de aproximação do DA quando o professor for explicar o conteúdo, uso de aparelho de frequência modulada (FM), uso de salas mais afastadas da área de recreação escolar ${ }^{99}$.

BROZOROTTO (2008), mostrou que os professores tem poucas informações sobre o IC, expectativas acadêmicas na média ou abaixo da média sobre seus alunos implantados, mas uma visão positiva sobre os mesmos ${ }^{28}$. Tais aspectos não foram investigados no presente estudo, revelando outra limitação do mesmo.

Pondera-se também sobre as dificuldades na leitura e escrita dos implantados, que dependendo da faixa etária, ainda não é cobrado tal desempenho. Contudo, com o passar do tempo aumenta-se as exigências acadêmicas e as dificuldades acabam por aparecer ${ }^{129}$. Isto pode gerar uma clara preocupação frente ao desafio do ensino e cumprimento do currículo escolar, visto que nosso estudo mostrou que para os professores a audição e a linguagem interferem no desempenho acadêmico dos alunos.

CAMPOS (2015) constatou que o longo tempo de uso do IC possibilita a inserção dos usuários em escolas regulares e o desempenho acadêmico se apresenta regular, embora haja defasagens no desenvolvimento de habilidades necessárias para o sucesso acadêmico ${ }^{125}$. Nossos resultados se apresentam de forma semelhante, visto que os sujeitos pesquisados estudam em escolas regulares e em sua maioria (64\%) tiveram rendimento escolar na média de sua turma.

Cabe uma ressalva, independente da análise do sistema de ensino brasileiro, para que haja uma educação de qualidade é preciso haver preparação adequada dos professores. Eles precisam ser capazes de proporcionar instrução direta para os alunos, colaborar com outros profissionais e famílias, trabalhar com membros de outras equipes, tomar decisões dentro da instituição de ensino sobre alterações no tipo e no grau de serviços disponibilizados a cada estudante e, quando necessário, buscar ajustes no currículo ou outros serviços adicionais ${ }^{130}$. Pondera-se, de igual modo, que tais considerações sejam vislumbradas pela equipe de saúde que lida com os implantados.

Foi observado (Tabela 3 ) que os pais e professores concordaram mais com as questões baseadas na linguagem (4/5) do que com as questões de audição (1/6). Isto pode ser devido ao ambiente mais ruidoso da escola, pois os usuários de IC 
apresentam redução dos índices de reconhecimento de fala em tais ambientes ${ }^{100}$. Desta forma, não há uma concordância completa da percepção de resultados do IC nas crianças no ambiente escolar e familiar. A percepção do resultado global do IC deve levar em consideração o funcionamento da criança em várias situações.

Este estudo sinaliza a heterogeneidade dos resultados dos implantados, mas não abarca os diferentes tipos de surdez. Contudo, vemos que o estabelecimento de ambientes educacionais adequados para a população eclética de alunos implantados ou com algum grau de deficiência auditiva é complexo. Tais alunos variam de acordo com diversos fatores, tais como: tipo e grau de perda auditiva, habilidades cognitivas, apoio da família, principal modo de comunicação utilizada, background cultural, étnico e linguístico, uso de amplificação e seus benefícios. Diante de tantas vicissitudes, uma ponderação clara que precisa ser feita nos serviços de IC é que haja uma bandeira vermelha que sinalize o momento crucial para que a criança implantada seja alocada em Libras, quando necessário. Ou seja, diante do insucesso dos resultados, se haja uma orientação para que os pais também procurem o suporte de uma outra língua. Isto não deve, necessariamente, excluir o usuário da fonoterapia oral ou audiovisual, dos mapeamentos ou do atendimento do centro de IC. Mas ser um recurso a mais para o ajustamento da criança em termos acadêmicos, de aprendizagem da comunicação, da leitura e da escrita.

Não devemos ver o usuário apenas como ouvinte ou falante. A criança é um todo! É necessário ampliar a visão para compreender as mudanças comportamentais, afetivas, sociais, desenvolvimentais e escolares, especialmente nos infantes, pois estão se constituindo como pessoas. $E$ isto, infelizmente, não significa que estaremos acertando todos os ponteiros. Existe todo um amplo contexto que circunda a criança, para além dos ajustes auditivos e linguísticos. Ter audição e fala não representa sucesso cognitivo, social, financeiro, trabalhista, dentre outros. Assim como o implantado ter Libras não caracteriza insucesso. Pelo contrário, significa que uma equipe competente soube identificar as limitações do processo do implante e orientar adequadamente a família para a busca de outros recursos. 


\section{4 - Correlação entre a percepção dos pais e a avaliação da audição e da linguagem realizada pelos fonoaudiólogos}

Quando estudou-se a avaliação fonoaudiológica da audição e linguagem e a percepção dos pais foi constatado que quanto melhor a avaliação da audição e da linguagem mais positiva foi a percepção dos pais nas questões abordadas nas escalas de (4) Comunicação atual e (5) Educação (Tabela 4).

Vale ressaltar que as escalas de autoconfiança atual, relações sociais e bem estar e felicidade não estiveram correlacionadas com as categorias de audição e linguagem avaliadas pelos fonoaudiólogos, embora estes aspectos sejam vistos em estudos sobre crianças implantadas ${ }^{39 ; 120}$. Assim sendo, a percepção dos pais em ambiente de atividades cotidianas deve ser considerada pois outros elementos escalas - vistos fora do ambiente clínico não se correlacionam diretamente com a avaliação da linguagem e audição.

Observou-se também, uma correlação positiva $(R h o=0,91)$ entre a avaliação de audição e linguagem, ou seja, quanto melhor a audição da criança melhor sua linguagem e vice versa. Outras pesquisas têm mostrado que a aquisição da linguagem oral também é um preditor para o desenvolvimento ortográfico, da leitura e da escrita 34; 81 o que mostra a coesão dos resultados encontrados.

Ratificamos o que a literatura já tem consolidado sobre o aprimoramento dos resultados de audição e linguagem ao longo do tempo de uso do IC (Figuras 6 e 7) e o quanto a implantação precoce é benéfica para tais aspectos (Figuras 8 e 9) 22; 24 .

Vemos que a avaliação fonoaudiológica do implantado para averiguação do seu desempenho auditivo e linguístico é altamente relevante 15; 114 . Contudo, constatou-se neste estudo que na concepção dos pais os ganhos obtidos com o uso do IC em crianças vão além da avaliação clínica fonoaudiológica da audição e da linguagem, mas se desenvolve em vários outros aspectos, especialmente com a comunicação, educação e relações sociais do usuário. Já os professores conseguem perceber mais os ganhos de linguagem do que de audição nos seus alunos quando comparados com os pais das crianças implantadas dado o ambiente ruidoso de avaliação.

Temos, então, que a privação auditiva ocasiona danos globais ao desenvolvimento sócio educacional da criança ${ }^{124}$ e o IC é um recurso efetivo para a 
reabilitação auditiva, podendo diminuir os prejuízos causados pela surdez no que diz respeito a educação, comunicação e relações sociais da criança implantada ${ }^{105}$. Destarte, pode haver percalços no processo de reabilitação e, por isso, é necessário a estimulação não apenas fonoaudiológica, mas, também, social, educacional e familiar para o aumento dos ganhos que podem advir com o uso do IC em crianças. Afinal, as avaliações individuais de pais, professores e fonoaudiólogos realizadas sob prismas diferentes e em ambientes diversos contribuem para o aprimoramento das diversas redes que a criança frequenta. 


\section{7 - CONCLUSÃo}

Conclui-se que os pais avaliam positivamente, pelo CCIPP, os benefícios do IC neste grupo de crianças, esta percepção torna-se mais positiva com o passar dos anos. Na concepção dos pais a idade em que o IC ocorreu não se correlaciona de forma ainda mais positiva com os resultados, embora a avaliação da audição e linguagem possa ser diferente entre os pares implantados. Os pais e professores concordam mais com os resultados na esfera da linguagem que na audição. A avaliação clínica fonoaudiológica da audição e linguagem correlaciona-se fortemente entre si, mas esteve relacionada apenas às escalas de comunicação e educação na perspectiva da avaliação dos pais. Aspectos importantes cotidianos tais como relações sociais e bem estar e felicidade não estiveram correlacionadas com as categorias de audição e linguagem avaliadas pelos fonoaudiólogos.

Para se verificar o benefício real e global do implante coclear nas crianças usuárias recomenda-se que a avaliação fonoaudiológica da audição e linguagem, realizada em ambiente clínico, possa ser enriquecida com avaliações realizadas durante atividades da vida cotidiana com pais e professores, com o objetivo de detectar dificuldades precocemente e possibilitar intervenção pela equipe de profissionais envolvidos na reabilitação biopsicossocial destes usuários.

Também sinalizamos que pesquisas futuras possam investigar criteriosamente os desafios encontrados pelos professores de implantados e as possibilidades de manejos para melhor aprimoramento acadêmico dos usuários de IC. 


\section{REFERÊNCIAS BIBLIOGRÁFICAS}

LIN, F. R.; NIPARKO, J. K. Measuring health-related quality of life after pediatric cochlear implantation: A systematic review. International Journal of Pediatric Otorhinolaryngology, v. 70, n. 10, p. 1695-1706, Disponível em: < http://dx.doi.org/10.1016/j.ijporl.2006.05.009 >. Acesso em: 2015/09/17.

VIGOTSKY, L. S. A construção do pensamento e da linguagem. São Paulo: Martins Fontes, 2000.

VIEIRA, S. D. S. et al. Cochlear Implant: the complexity involved in the decision making process by the family. Revista Latino-Americana De Enfermagem, v. 22, n. 3, p. 415-424, May-Jun 2014. ISSN 0104-1169. Disponível em: <<Go to ISI>://WOS:000337334200010 >.

SACH, T. H.; WHYNES, D. K. Paediatric cochlear implantation: the views of parents. International Journal of Audiology, v. 44, n. 7, p. 400-407, Jul 2005. ISSN 1499-2027. Disponível em: <<Go to ISI>://WOS:000231368000003 >.

DALL'ASTRA, P. V. A importância da língua de sinais para o desenvolvimento da pessoa surda: a noção de inclusão associada ao sentimento de pertencimento no espaço escolar.: Rev. Educ. Especial. 28: 117-130 p. 2015.

CARDOSO, A. H. A.; RODRIGUES, K. G.; BACHION, M. M. Percepção da pessoa com surdez severa e/ou profunda acerca do processo de comunicação durante seu atendimento de saúde. Ribeirão Preto: Rev. Latino-am. Enfermagem. 14: 553-560 p. 2006.

CRISTOBAL, R.; OGHALAI, J. S. Hearing loss in children with very low birth weight: current review of epidemiology and pathophysiology. Archives of disease in childhood. Fetal and neonatal edition, v. 93, n. 6, p. F462-F468, 2008. ISSN 1359-29981468-2052. Disponível em: < http://www.ncbi.nlm.nih.gov/pmc/articles/PMC3597102/>.

UCHOA, N. T. et al. [Prevalence of hearing loss in very low birth weight neonates]. J Pediatr (Rio J), v. 79, n. 2, p. 123-8, Mar-Apr 2003. ISSN 0021-7557

SAÚDE, M. D. Diretrizes de atenção da triagem auditiva neonatal. Brasília: Secretaria de Atenção à Saúde. Departamento de Ações Programáticas 2012.

IBGE. Censo.: Instituto Brasileiro de Geografia e Estatística. http://www.ibge.gov.br/estadosat/temas.php?sigla=df\&tema=censodemog2010 defic 2010.

SAÚDE., M. D. Política Nacional de Saúde da Pessoa Portadora de Deficiência. Brasília: Secretaria de Atenção à Saúde. 2008. 

Relatório $n^{\circ}$ 99. Brasília: Departamento de Gestão e Incorporação de Tecnologias em Saúde da Secretaria de Ciência, Tecnologia e Insumos Estratégicos. http://conitec.gov.br/images/Incorporados/Implantes Cocleares-FINAL.pdf 2014. sobre Implante Coclear no período de 2000 a 2010. Revista CEFAC, v. 15, n. 6, p. 1583-1590, 2013-12 2013. ISSN 1982-0216. Disponível em: < <Go to ISI>://SCIELO:S1516$18462013000600021>$.

SANTANA, A. P. $O$ processo de aquisição da linguagem: estudo comparativo de duas crianças usuárias de implante coclear. São Paulo: Distúrb. Comun.: 233-243 p. 2005.

PERCY-SMITH, L. Associations between Auditory Capacity, Speech and Language, Level of Communication and Parental Assessment of Children with Cochlear Implant. Cochlear Implants International, v. 11, n. 1, p. 50-62, 2010/03/01 2010. ISSN 1467-0100. Disponível em: $<$ http://dx.doi.org/10.1002/cii.424 >.

LOY, B. et al. The children speak: An examination of the quality of life of pediatric cochlear implant users. Otolaryngology - Head and Neck Surgery, v. 142, n. 2, p. 247-253, 2// 2010. ISSN 0194-5998. Disponível em: < http://www.sciencedirect.com/science/article/pii/\$0194599809016659 >.

COUTO, M. I. V.; CARVALHO, A. C. M. Fatores que influenciam na participação dos pais de crianças usuárias de implante coclear na (re)habilitação oral: revisão sistemática. CoDAS, v. 25, p. 84-91, 2013. ISSN 2317-1782.

SHARMA, A.; CAMPBELL, J. A sensitive period for cochlear implantation in deaf children. The journal of maternal-fetal \& neonatal medicine : the official journal of the European Association of Perinatal Medicine, the Federation of Asia and Oceania Perinatal Societies, the International Society of Perinatal Obstetricians, v. 24, n. 01 , p. 151-153, 2011. ISSN 147670581476-4954. Disponível em: < http://www.ncbi.nlm.nih.gov/pmc/articles/PMC3743531/ $>$.

FAGAN, M. K. Cochlear implantation at 12 months: Limitations and benefits for vocabulary production. Cochlear Implants Int, v. 16, n. 1, p. 24-31, Jan 2015. ISSN 1467-0100.

GEERS, A. et al. Educational factors contributing to cochlear implant benefit in children. International Congress Series, v. 1254, p. 307-312, 11// 2003. ISSN 0531-5131. Disponível em: < http://www.sciencedirect.com/science/article/pii/S0531513103011142 >. use on bilateral auditory development in children who are deaf. Frontiers in Psychology, v. 4, 2013. ISSN 1664-1078. Disponível em: < http://www.frontiersin.org/Journal/Abstract.aspx?s=86\&name=auditory cognitive neurosci ence\&ART DOI=10.3389/fpsyg.2013.00719 >. 
MARTIN, D. et al. Peer Relationships of Deaf Children With Cochlear Implants: Predictors of Peer Entry and Peer Interaction Success. Journal of Deaf Studies and Deaf Education, v. 16, n. 1, p. 108-120, 2011. Disponível em: < http://idsde.oxfordjournals.org/content/16/1/108.abstractN2 -

SARANT, J. et al. Bilateral Versus Unilateral Cochlear Implants in Children: A Study of Spoken Language Outcomes. Ear and Hearing, v. 35, n. 4, p. 396-409, Jul-Aug 2014. ISSN 0196-0202. Disponível em: <<Go to ISI : //WOS:000338418200008 >.

NIPARKO, J. K. et al. SPoken language development in children following cochlear implantation. JAMA, v. 303, n. 15, p. 1498-1506, 2010. ISSN 0098-7484. Disponível em: < http://dx.doi.org/10.1001/jama.2010.451 >.

OSBERGER, M. J.; ZIMMERMAN-PHILLIPS, S.; KOCH, D. B. Cochlear implant candidacy and performance trends in children. Annals of Otology Rhinology and Laryngology, v. 111, n. 5, p. 62-65, May 2002. ISSN 0003-4894. Disponível em: <<Go to ISI :://WOS:000175585600013 >.

GEERS, A. E.; NICHOLAS, J. G. Enduring Advantages of Early Cochlear Implantation for Spoken Language Development. Journal of Speech, Language, and Hearing Research, v. 56, n. 2, p. 643-655, 2013. ISSN 1092-4388. Disponível em: < http://dx.doi.org/10.1044/10924388(2012/11-0347) $>$.

PINHEIRO, A. B. S. M. et al. Avaliação das habilidades escolares de crianças com implante coclear. Revista CEFAC, v. 14, n. 5, p. 826-835, 2012-10 2012. ISSN 1982-0216. Disponível em: $<<$ Go to ISI $>$ ://SCIELO:S1516-18462012000500008 >.

BRAZOROTTO, J. S. Crianças usuárias de implante coclear: desempenho acadêmico, expectativas dos pais e dos professores. COSTA., M. D. P. R. D. e BEVILACQUA., M. C. São Carlos: Universidade Federal de São Carlos. Programa de Pós Graduação em Educação Especial. Tese de Doutorado. 2008.

PUNCH, R.; HYDE, M. B. Communication, Psychosocial, and Educational Outcomes of Children with Cochlear Implants and Challenges Remaining for Professionals and Parents.: Hindawi Publishing Corporation. International Journal of Otolaryngology. 2011: 573280-1-573280-10 p. 2011.

PUNCH, R.; HYDE, M. Social Participation of Children and Adolescents With Cochlear Implants: A Qualitative Analysis of Parent, Teacher, and Child Interviews. Journal of Deaf Studies and Deaf Education, v. 16, n. 4, p. 474-493, 2011. Disponível em: < http://jdsde.oxfordjournals.org/content/16/4/474.abstract $>$.

VINCENTI, V. et al. Pediatric cochlear implantation: an update. Ital J Pediatr, v. 40, p. 72, 2014. ISSN 1720-8424. 
BAT-CHAVA, Y.; MARTIN, D.; IMPERATORE, L. Long-term improvements in oral communication skills and quality of peer relations in children with cochlear implants: parental testimony. Child: Care, Health and Development, v. 40, n. 6, p. 870-881, 2014. ISSN 1365-2214. Disponível em: < http://dx.doi.org/10.1111/cch.12102 >.

FORTUNATO, C. A. D. U.; BEVILACQUA, M. C.; COSTA, M. D. P. R. D. Análise comparativa da linguagem oral de crianças ouvintes e surdas usuárias de implante coclear. Revista CEFAC, $\mathrm{v}$. 11, p. 662-672, 2009. ISSN 1516-1846.

SOUSA, A. F. et al. Word acquisiton in children with cochlear implants.: Rev. CEFAC. 16: 15041511 p. Set-Out. 2014.

VLASTARAKOS, P. V. Profound deafness and the acquisition of spoken language in children. World J Clin Pediatr, v. 1, n. 4, p. 24-8, Dec 8 2012. ISSN 2219-2808.

ROWE, M. L.; RAUDENBUSH, S. W.; GOLDIN-MEADOW, S. The pace of vocabulary growth helps predict later vocabulary skill. Child Dev, v. 83, n. 2, p. 508-25, Mar-Apr 2012. ISSN 0009-3920.

SHALLOP, J. K. et al. Cochlear implants in five cases of auditory neuropathy: postoperative findings and progress. Laryngoscope, v. 111, n. 4 Pt 1, p. 555-62, Apr 2001.

YAMADA, M. O.; BEVILACQUA, M. C. O papel do psicólogo no programa de implante coclear do Hospital de Reabilitação de Anomalias Craniofaciais. Campinas: Estud. psicol. 222005.

YAMADA, M. O. Dimensão afetiva segundo a concepção de Emílio Romero da pessoa com surdez adquirida antes e após o uso de implante coclear. São Paulo: Catálogo USP 2002.

LEMES, J. P.; GOLDFELD, M. Análise da ortografia de crianças usuárias de implante coclear. Revista da Sociedade Brasileira de Fonoaudiologia, v. 13, p. 279-289, 2008. ISSN 1516-8034.

PUNCH, R.; HYDE, M. Social participation of children and adolescents with cochlear implants: a qualitative analysis of parent, teacher, and child interviews. J Deaf Stud Deaf Educ, v. 16, n. 4, p. 474-93, Fall 2011. ISSN 1081-4159.

BOAS, A. C. V. B. V.; RODRIGUES, O. M. P. R.; YAMADA, M. O. Promovendo a interação mãecriança com implante coclear: um estudo de caso. Brasília: Psic. Teor. Pesq. 22: 259-268 p. Set.-Dez. 2006.

GOFFMAN, E. Estigma: notas sobre a manipulação da identidade deteriorada. São Paulo: LTC 2003.

ARAÚJO, F. R. D. S. The severance of the cartesian approach and some legal consequence thereof. Brasília: Revista CEJ. XIII: 78-86 p. jul.-set. 2009. 
VELHO, O. De Bateson a Ingold: passos na constituição de um paradigma ecológico. Rio de Janeiro: Mana. 7 Out. 2001.

CARVALHO-FREITAS, M. N. D.; MARQUES, A. L. Formas de ver as pessoas com deficiência: um estudo empírico do construto de concepções de deficiência em situações de trabalho. RAM. Revista de Administração Mackenzie, v. 11, p. 100-129, 2010. ISSN 1678-6971.

SANTOS, W. R. D. Pessoas com deficiência: nossa maior minoria. Physis: Revista de Saúde Coletiva, v. 18, p. 501-519, 2008. ISSN 0103-7331.

SAÚDE, O. M. D. Classificação internacional de incapacidade, funcionalidade e saúde. Lisboa: Direção Geral da Saúde 2004.

MORETTIN, M. Classificação internacional de funcionalidade, incapacidade e saúde, versão crianças e jovens (CIF-CJ): elaboração de um checklist para avaliação da funcionalidade em usuários de implante coclear. 2012. Faculdade de Saúde Pública de São Paulo., São Paulo.

SAMPAIO, R. F.; LUZ, M. T. Funcionalidade e incapacidade humana: explorando o escopo da classificação internacional da Organização Mundial da Saúde. Cadernos de Saúde Pública, v. 25, p. 475-483, 2009. ISSN 0102-311X.

LEWIS, D. R. et al. Multiprofessional committee on auditory health - COMUSA.: Braz J Otorhinolaryngol. 76: 121-128 p. Jan.-Fev. 2010.

SAMPAIO, A. L.; ARAUJO, M. F.; OLIVEIRA, C. A. New criteria of indication and selection of patients to cochlear implant. Int J Otolaryngol, v. 2011, p. 573968, 2011. ISSN 1687-9201.

BATTAGLINI, M. P.; BeVILACQUA, M. C.; SOUZA, D. D. G. D. Desempenho de seleção e nomeação de figuras em crianças com deficiência auditiva com implante coclear. Temas em Psicologia, v. 20, p. 189-202, 2012. ISSN 1413-389X.

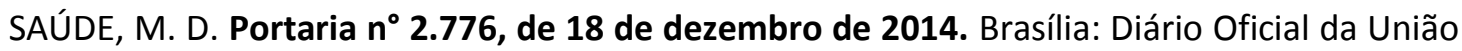
2014.

BOND, M. et al. The effectiveness and cost-effectiveness of cochlear implants for severe to profound deafness in children and adults: a systematic review and economic model. Health Technology Assessment, v. 13, n. 44, p. 1-+, Sep 2009. ISSN 1366-5278. Disponível em: <<Go to $|S|>: / /$ WOS:000272349300001 >.

ARCHBOLD, S.; O'DONOGHUE, G. M. Cochlear implantation in children: current status. Paediatrics and Child Health, v. 19, n. 10, p. 457-463, Disponível em: < http://dx.doi.org/10.1016/j.paed.2009.07.005 >. Acesso em: 2015/09/18. 
PEREIRA, A. M.; MELO, T. M. D. Falhas dos componentes externos do implante coclear: influência da idade e do tempo de uso. Revista CEFAC, v. 16, n. 5, p. 1419-1425, 2014-10 2014. ISSN 1982-0216. Disponível em: <<Go to ISI>://SCIELO:S1516-18462014000501419 >.

MOURA, M. L. S. D. O bebê do século XXI e a psicologia em desenvolvimento. Abordagem evolucionista sobre a relação entre filogênese e ontogênese no desenvolvimento infantil. VIEIRA, M. L. e PRADO, A. B. São Paulo: Casa do Psicólogo: 155-203 p. 2004.

ANGELO, T. C. S. D.; BEVILACQUA, M. C.; MORET, A. L. M. Percepção da fala em deficientes auditivos pré-linguais usuários de implante coclear. Pró-Fono Revista de Atualização Científica, v. 22, p. 275-280, 2010. ISSN 0104-5687.

MIZIARA, I. D. et al. Aspectos bioéticos e médico-legais do implante coclear em crianças. Brazilian Journal of Otorhinolaryngology, v. 78, p. 70-79, 2012. ISSN 1808-8694.

LESTER, E. B. et al. Barriers to the Early Cochlear Implantation of Deaf Children. Otology \& Neurotology, v. 32, n. 3, p. 406-412, Apr 2011. ISSN 1531-7129. Disponível em: <<Go to ISI>://WOS:000288239800014 >.

LANTOS, J. D. Ethics for the pediatrician: the evolving ethics of cochlear implants in children. Pediatrics in review / American Academy of Pediatrics, v. 33, n. 7, p. 323-326, 2012/07// 2012. ISSN 0191-9601. Disponível em: < http://europepmc.org/abstract/MED/22753791 $>$.Disponivel em: < http://dx.doi.org/10.1542/pir.33-7-323 $>$.

HYDE, M.; POWER, D. Some Ethical Dimensions of Cochlear Implantation for Deaf Children and Their Families. Journal of Deaf Studies and Deaf Education, v. 11, n. 1, p. 102-111, 2006. Disponivel em: < http://idsde.oxfordjournals.org/content/11/1/102.abstract $>$.

SUMMERFIELD, A. Q.; MARSHALL, D. H. Paediatric cochlear implantation and healthtechnology assessment. International Journal of Pediatric Otorhinolaryngology, v. 47, n. 2, p. 141-151, Disponível em: < http://dx.doi.org/10.1016/S0165-5876(98)00133-5 >. Acesso em: 2015/09/18.

BALKANY, T. J. et al. Cochlear implants in children. Otolaryngologic Clinics of North America, v. 34, n. 2, p. 455-467, 2001. ISSN 0030-6665.

O'NEILL, C. et al. Indirect costs, cost-utility variations and the funding of paediatric cochlear implantation. International Journal of Pediatric Otorhinolaryngology, v. 58, n. 1, p. 53-57, Apr 6 2001. ISSN 0165-5876. Disponível em: < <Go to ISI>://WOS:000167695900007 >.

MARTINI, A. et al. [Cochlear implant in children: rational, indications and cost/efficacy]. Minerva Pediatr, v. 65, n. 3, p. 325-39, Jun 2013. ISSN 0026-4946 

n. 1 , p. 29-44, 2002/01/01 2002. ISSN 1321-2753. Disponível em: < http://dx.doi.org/10.1007/BF03351265 >. comunicação e sinalização - surdez. Brasília: Secretaria de Educação Especial. Ministério da Educação e Cultura 2006.

Lei $\mathrm{n}^{\circ}$ 10.436, de 24 de abril de 2002. Brasília: Presidência da República - Subchefia para assuntos jurídicos. http://www.planalto.gov.br/CCIVIL 03/Leis/2002/L10436.htm 2002.

$\mathrm{CROUCH}, \mathrm{R}$. A. Letting the deaf be deaf. Reconsidering the use of cochlear implants in prelingually deaf children. Hastings Cent Rep, v. 27, n. 4, p. 14-21, Jul-Aug 1997. ISSN 00930334

KIM, L.-S. et al. Cochlear implantation in children. Auris Nasus Larynx, v. 37, n. 1, p. 6-17, 2// 2010. ISSN 0385-8146. Disponível em: < http://www.sciencedirect.com/science/article/pii/S0385814609002090 >.

BOONS, T. et al. Predictors of spoken language development following pediatric cochlear implantation. Ear Hear, v. 33, n. 5, p. 617-39, Sep-Oct 2012. ISSN 0196-0202.

LYNESS, C. R. et al. How does visual language affect crossmodal plasticity and cochlear implant success? Neurosci Biobehav Rev, v. 37, n. 10 Pt 2, p. 2621-30, Dec 2013. ISSN 0149-7634.

LEE, H. J. et al. Visual speech circuits in acquired profound deafness: a possible role for latent multimodal connectivity. Oxford University: Brain. 130: 2929-41 p. 2007.

MACSWEENEY, $M$. et al. Dissociating linguistic and nonlinguistic gestural communication in the brain. Neurolmage, v. 22, n. 4, p. 1605-1618, 8// 2004. ISSN 1053-8119. Disponível em: < http://www.sciencedirect.com/science/article/pii/S1053811904001697 >.

CAMPBELL, R.; MACSWEENEY, M.; WOLL, B. Cochlear implantation (CI) for prelingual deafness: the relevance of studies of brain organization and the role of first language acquisition in considering outcome success. Frontiers in Human Neuroscience, v. 8, Oct 17 2014. ISSN 16625161. Disponível em: <<Go to IS|>://WOS:000343402100001 >.

FITZPATRICK, E. M. et al. The effects of sign language on spoken language acquisition in children with hearing loss: a systematic review protocol. Syst Rev, v. 2, p. 108, 2013. ISSN 2046-4053. cérébrale du sujet sourd profond. Paris: Fondation Fyssen: 44-58 p. 2007. 
ORYADI ZANJANI, M. M. et al. Comparing the effect of auditory-only and auditory-visual modes in two groups of Persian children using cochlear implants: a randomized clinical trial. Int J Pediatr Otorhinolaryngol, v. 77, n. 9, p. 1545-50, Sep 2013. ISSN 0165-5876.

FRANÇA, M. P. et al. Aquisição da linguagem oral: relação e risco para a linguagem escrita. São Paulo: Arquivos de neuro-psiquiatria. 62: 469-472 p. 2004.

TOBEY, E. A. et al. Influence of implantation age on school-age language performance in pediatric cochlear implant users. Int J Audiol, v. 52, n. 4, p. 219-29, Apr 2013. ISSN 1499-2027.

KANDA, Y. et al. What Factors Are Associated with Good Performance in Children with Cochlear Implants? From the Outcome of Various Language Development Tests, Research on Sensory and Communicative Disorders Project in Japan: Nagasaki Experience. Clinical and Experimental Otorhinolaryngology, v. 5, p. S59-S64, Apr 2012. ISSN 1976-8710. Disponível em: $<<$ Go to $|S|>: / /$ WOS:000304433000014 >.

BRENNAN-JONES, C. G. et al. Auditory-verbal therapy for promoting spoken language development in children with permanent hearing impairments. Cochrane Database Syst Rev, v. 3, p. Cd010100, 2014. ISSN 1361-6137.

GEERS, A. E. et al. Effects of communication mode on skills of long-term cochlear implant users. Ann Otol Rhinol Laryngol Suppl, v. 185, p. 89-92, Dec 2000. ISSN 0096-8056

GEERS, A. E. Factors affecting the development of speech, language, and literacy in children with early cochlear implantation. Language Speech and Hearing Services in Schools, v. 33, n. 3, Jul 2002. ISSN 0161-1461. Disponível em: <<Go to ISI>://WOS:000176845900005 >.

ROBBINS, A. M. How does total communication affect cochlear implant performance in children? The impact of scientific advances on the education of deaf children. Paris: 4th ACFOS International Conference: 1-8 p. Nov. 2002.

BERGESON, T. R.; HOUSTON, D. M.; MIYAMOTO, R. T. Effects of congenital hearing loss and cochlear implantation on audiovisual speech perception in infants and children. Restor Neurol Neurosci, v. 28, n. 2, p. 157-65, 2010. ISSN 0922-6028.

GEERS, A. et al. Rehabilitation factors contributing to implant benefit in children. Annals of Otology Rhinology and Laryngology, v. 111, n. 5, p. 127-130, May 2002. ISSN 0003-4894. Disponível em: < <Go to ISI >://WOS:000175585600025 >.

ARTIERES, F. et al. Impact of early cochlear implantation on the linguistic development of the deaf child. Otol Neurotol, v. 30, n. 6, p. 736-42, Sep 2009. ISSN 1531-7129.

NELSON, H. D. et al. Screening for speech and language delay in preschool children: systematic evidence review for the US Preventive Services Task Force. Pediatrics, v. 117, n. 2, p. e298319, Feb 2006. ISSN 0031-4005. 
WILSON, B. S.; DORMAN, M. F. Cochlear implants: a remarkable past and a brilliant future. Hearing research, v. 242, n. 0, p. 3-21, 06/22 2008. ISSN 0378-5955 1878-5891. Disponível em: < http://www.ncbi.nlm.nih.gov/pmc/articles/PMC3707130/ >.

FIGUEIREDO, C. C.; GIL, D. Avaliação do grau de envolvimento familiar nos atendimentos de crianças com deficiência auditiva. Audiology - Communication Research, v. 18, n. 4, p. 303307, 2013-12 2013. ISSN 2317-6431. Disponível em: < <Go to ISI>://SCIELO:S2317$64312013000400011>$.

STEFANINI, M. R. et al. Parental perspectives of children using cochlear implant. CoDAS, v. 26, n. 6, p. 487-493, 2014-12 2014. ISSN 2317-1782. Disponível em: < <Go to ISI>://SCIELO:S2317$17822014000600487>$.

HYDE, M.; PUNCH, R.; KOMESAROFF, L. Coming to a Decision About Cochlear Implantation: Parents Making Choices for their Deaf Children. Journal of Deaf Studies and Deaf Education, v. $15, \quad$ n. 2 , p. 162-178, 2010 . Disponível em: < http://idsde.oxfordjournals.org/content/15/2/162.abstract $>$.

YAMANAKA, D. A. R. et al. Implante coclear em crianças: a visão dos pais. Psicologia: Teoria e Pesquisa, v. 26, p. 465-473, 2010. ISSN 0102-3772.

ALKHAMRA, R. A. Cochlear implants in children implanted in Jordan: A parental overview. Int J Pediatr Otorhinolaryngol, v. 79, n. 7, p. 1049-54, Jul 2015. ISSN 0165-5876.

ARCHBOLD, S. et al. Outcomes from cochlear implantation for child and family: parental perspectives. Deafness \& Education International, v. 10, n. 3, p. 120-142, 2008. ISSN 1557069X. Disponível em: < http://dx.doi.org/10.1002/dei.243 $>$.

CAMPOS, N. B. D.; DELGADO-PINHEIRO, E. M. C. Análise do ruído e intervenção fonoaudiológica em ambiente escolar: rede privada e pública de ensino regular. Revista CEFAC, v. 16, n. 1, p. 83-91, 2014-03 2014. ISSN 1982-0216. Disponível em: < <Go to ISI>://SCIELO:S1516-18462014000100083 >.

CALDWELL, A.; NITTROUER, S. Speech Perception in Noise by Children With Cochlear Implants. Journal of speech, language, and hearing research : JSLHR, v. 56, n. 1, p. 10.1044/10924388(2012/11-0338), 06/28 2013. ISSN 1092-43881558-9102. Disponível em: < http://www.ncbi.nlm.nih.gov/pmc/articles/PMC3810941/ >.

EBRAHIMI, H. et al. Stigma in mothers of deaf children. Iran J Otorhinolaryngol, v. 27, n. 79, p. 109-18, Mar 2015. ISSN 2251-7251

KOBOSKO, J.; GEREMEK-SAMSONOWICZ, A.; SKARZYNSKI, H. [Mental health problems of mothers and fathers of the deaf children with cochlear implants]. Otolaryngol Pol, v. 68, n. 3, p. 135-42, May-Jun 2014. ISSN 0030-6657 
NICHOLAS, J. G.; GEERS, A. E. Personal, social, and family adjustment in school-aged children with a cochlear implant. Ear Hear, v. 24, n. 1 Suppl, p. 69s-81s, Feb 2003. ISSN 0196-0202

LANGEREIS, M.; VERMEULEN, A. School performance and wellbeing of children with $\mathrm{Cl}$ in different communicative-educational environments. Int J Pediatr Otorhinolaryngol, v. 79, n. 6, p. 834-9, Jun 2015. ISSN 0165-5876.

DE GIACOMO, A. et al. Children with cochlear implants: Cognitive skills, adaptive behaviors, social and emotional skills. International Journal of Pediatric Otorhinolaryngology, v. 77, n. 12, p. 1975-1979, Disponível em: < http://dx.doi.org/10.1016/j.ijporl.2013.09.015 >. Acesso em: 2015/10/03.

TANAMATI, L. F.; BEVILACQUA, M. C.; COSTA, O. A. Cochlear implant in postlingual children: functional results 10 years after the surgery. Braz J Otorhinolaryngol, v. 78, n. 2, p. 103-10, Apr 2012. ISSN 1808-8686.

UZIEL, A. S. et al. Ten-year follow-up of a consecutive series of children with multichannel cochlear implants. Otol Neurotol, v. 28, n. 5, p. 615-28, Aug 2007. ISSN 1531-7129

BEADLE, E. A. et al. Long-term functional outcomes and academic-occupational status in implanted children after 10 to 14 years of cochlear implant use. Otol Neurotol, v. 26, n. 6, p. 1152-60, Nov 2005. ISSN 1531-7129

BEVILACQUA, M. C. et al. Elaboração de um procedimento de avaliação de percepção de fala em crianças deficientes auditivas profundas a partir de cinco anos de idade. Tópicos em Fonoaudiologia. São Paulo: Lovise, p. 411-433, 1996.

GEERS, A. E.; MOOG, J. S. Assessing the benefits of cochlear implants in an oral education program. In: UZIEL, A. S.;MONDAIN, M., et al (Ed.). Cochlear Implants in Children, v.50, 1995. p.119-124. (Advances in Oto-Rhino-Laryngology).

ARCHBOLD, S. M. et al. Parents and their deaf child: their perceptions three years after cochlear implantation. Deafness \& Education International, v. 4, n. 1, p. 12-40, 2002. ISSN 1557-069X. Disponível em: < http://dx.doi.org/10.1002/dei.114 >.

FORTUNATO-TAVARES, T. et al. Crianças com implante coclear: habilidades comunicativas e qualidade de vida. Brazilian Journal of Otorhinolaryngology, v. 78, p. 15-25, 2012. ISSN 18088694.

NUNES, T.; PRETZLIK, U.; ILICAK, S. Validation of a parent outcome questionnaire from pediatric cochlear implantation. J Deaf Stud Deaf Educ, v. 10, n. 4, p. 330-56, Fall 2005. ISSN 1081-4159 
GEERS, A. E. Techniques for assessing auditory speech perception and lipreading enhancement in young deaf children. Washington: Volta Review: 85-96 p. Nov.1994.

STEFANINI, M. R. et al. Parental perspectives of children using cochlear implant. Codas, v. 26, n. 6, p. 487-93, Nov-Dec 2014. ISSN 2317-1782.

ALMEIDA, R. P. D. et al. Quality of life evaluation in children with cochlear implants. CoDAS, v. 27, p. 29-36, 2015. ISSN 2317-1782.

BATTEN, G.; OAKES, P. M.; ALEXANDER, T. Factors Associated With Social Interactions Between Deaf Children and Their Hearing Peers: A Systematic Literature Review. Journal of Deaf Studies and Deaf Education, v. 19, n. 3, p. 285-302, Jul 2014. ISSN 1081-4159. Disponível em: <<Go to $\mid$ SI $>$ ://WOS:000338112000001 >.

BISHOP, J. A.; INDERBITZEN, H. M. Peer Acceptance and Friendship: An Investigation of their Relation to Self-Esteem. The Journal of Early Adolescence, v. 15, n. 4, p. 476-489, 1995. Disponível em: $<$ http://jea.sagepub.com/content/15/4/476.abstract $>$.

BAT-CHAVA, Y.; DEIGNAN, E. Peer Relationships of Children With Cochlear Implants. Journal of Deaf Studies and Deaf Education, v. 6, n. 3, p. 186-199, 2001. Disponível em: < http://jdsde.oxfordjournals.org/content/6/3/186.abstract >.

MAGALHÃES, A. M. M. et al. Desenvolvimento socioemocional de crianças surdas com implante coclear. Boletim - Academia Paulista de Psicologia, v. 27, p. 103-132, 2007. ISSN 1415-711X.

LF., T. Long-term results by using cochlear implants on children: systematic review. COSTA OA, B. M.: Int. Arch. Otorhinolaryngol. 15: 365-375 p. 2011.

NIKOLOPOULOS, T. P.; ARCHBOLD, S. M.; GREGORY, S. Young deaf children with hearing aids or cochlear implants: early assessment package for monitoring progress. Int J Pediatr Otorhinolaryngol, v. 69, n. 2, p. 175-86, Feb 2005. ISSN 0165-5876

HARDONK, S. et al. Pediatric Cochlear Implantation: A Qualitative Study of Parental DecisionMaking Processes in Flanders, Belgium. American Annals of the Deaf, v. 155, n. 3, p. 339-352, 2010. ISSN 1543-0375. Disponível em: < https://muse.jhu.edu/journals/american annals of the deaf/v155/155.3.hardonk.html >.

KRAL, A. et al. Neurocognitive factors in sensory restoration of early deafness: a connectome model. The Lancet Neurology, v. 15, n. 6, p. 610-621, ISSN 1474-4422. Disponível em: < http://dx.doi.org/10.1016/S1474-4422(16)00034-X >. Acesso em: 2016/04/15.

CAMPOS, P. D. Desempenho acadêmico de crianças e adolescentes usuários de implante coclear. São Paulo: Universidade de São Paulo 2015. 

Otolaryngology-Head \& Neck Surgery, v. 140, n. 7, p. 608-615, Jul 2014. ISSN 2168-6181. Disponível em: <<Go to ISI ://WOS:000340900900004 >.

HUTTUNEN, K.; VÄLIMAA, T. Parents' Views on Changes in Their Child's Communication and Linguistic and Socioemotional Development After Cochlear Implantation. Journal of Deaf Studies and Deaf Education, 2010. Disponível em: < http://idsde.oxfordjournals.org/content/early/2010/07/01/deafed.enq029.abstract >. Since Child's Cochlear Implantation. Journal of Deaf Studies and Deaf Education, v. 12, n. 1, p. 55-64, 2007. Disponível em: < http://idsde.oxfordjournals.org/content/12/1/55.abstract $>$.

GEERS, A. et al. Long-term outcomes of cochlear implantation in the preschool years: From elementary grades to high school. International Journal of Audiology, v. 47, p. S21-S30, 2008 2008. ISSN 1499-2027. Disponível em: <<Go to ISI>://WOS:000260909000005 >. 


\title{
APÊNDICE A \\ Termo de Consentimento Livre e Esclarecido - Pais
}

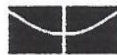 \\ UnB \\ UNIVERSIDADE DE BRASÍLIA \\ PROGRAMA DE PÓS-GRADUAÇĀO EM CIÊNCIAS DA SAÚDE \\ FACULDADE DE CIÉNCIAS DA SAÚDE
}

Termo de Consentimento Livre e Esclarecido - TCLE

Convidamos o(a) Senhor(a) a participar do projeto de pesquisa O CONSTRUTO DE SUCESSO DO IMPLANTE COCLEAR NA CONCEPÇÃO DE PAIS E PROFESSORES, sob a responsabilidade da pesquisadora Tânis Moreira Rodrigues de Moura. O projeto visa pesquisar as situações bem sucedidas relacionadas à reabilitação através do Implante Coclear, bem como, as questões problemáticas para possíveis ajustes futuros, no sentido de diminuir os pontos negativos e potencializar os positivos deste processo.

O objetivo é investigar a noção de sucesso do implante coclear na visão dos pais e professores de crianças usuárias deste dispositivo no DF e que fazem reabilitação fonoterápica no CEAL - Centro Educacional de Audição e Linguagem Ludovico Pavoni. Por isso, solicitamos a sua autorização para ter acesso aos relatórios fonoterápicos, prontuários clínicos e menções escolares do seu filho(a).

Eis algumas informações para sua participação na pesquisa:

- O Senhor(a) responderá a dois questionários autoaplicáveis e gastará de 30-60 minutos de seu tempo para isto.

- Seu nome será mantido em sigilo e nenhuma informação que lhe identifique aparecerá;

- Caso tenha alguma dúvida antes ou no decorrer da pesquisa, entre em contato com a pesquisadora;

- O pequeno risco decorrente de sua participação na pesquisa pode acontecer no sentido de levá-lo(a) a pensar sobre questões que estavam adormecidas em relação ao processo de reabilitação pelo implante coclear;

- A sua participação estará contribuindo para melhorar os ajustes necessários ao aprimoramento da reabilitação do implantado junto à família e professores;

- $O(a)$ Senhor(a) pode se recusar a responder qualquer questão que the traga constrangimento, podendo desistir de participar da pesquisa em qualquer momento sem nenhum prejuízo para o(a) senhor(a).

- Sua participação é voluntária, isto é, não há pagamento por sua colaboração, bem como, não terá nenhuma despesa com a sua participação.

Caso haja algum problema direto resultante dos procedimentos de pesquisa, você poderá ser indenizado, obedecendo-se as disposições legais vigentes no Brasil.

Os resultados da pesquisa serão mostrados na Universidade de Brasília podendo ser publicados posteriormente. Os dados e questionários utilizados na pesquisa ficarão sob a guarda do pesquisador por um período de no mínimo cinco anos, após isso serão destruídos ou mantidos na instituição.

Se o(a) Senhor(a) tiver qualquer dúvida em relação à pesquisa, por favor telefone para: Tânis -Moreira Rodrigues de Moura, na Fundação Universidade de Brasília nos telefones: 34485580 ou 8484 2307, no horário matutino.

Este projeto foi Aprovado pelo Comitê de Ética em Pesquisa da Faculdade de Ciências da Saúde (CEP/FS) da Universidade de Brasília. O CEP é composto por profissionais de diferentes áreas cuja função é defender os interesses dos participantes da pesquisa em sua integridade e dignidade e contribuir no desenvolvimento da pesquisa dentro de padrões éticos. As dúvidas com relação à assinatura do TCLE ou os direitos do participante da pesquisa podem ser obtidos através do telefone: (61) 3107-1947 ou do e-mail cepfs@unb.br ou cepfsunb@gmail.com, horário de atendimento de 10hs às 12hs e de 14hs às 17hs, de segunda a sexta-feira.

Este documento foi elaborado em duas vias, uma ficará com a pesquisadora responsável e a outra com o Senhor(a).

Nome/assinatura

Pai/Responsável

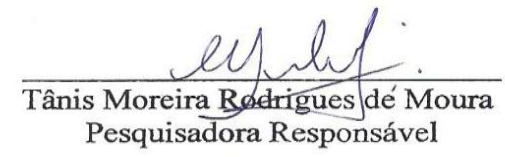

Brasília, de de 


\section{APÊNDICE B \\ Termo de Consentimento Livre e Esclarecido - Professores}

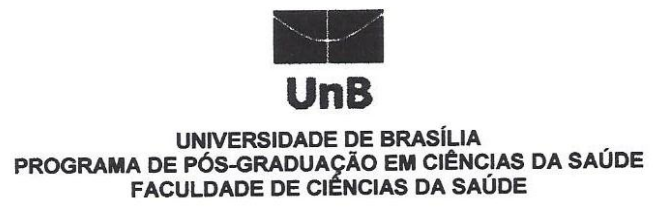

Termo de Consentimento Livre e Esclarecido - TCLE

Convidamos o(a) Senhor(a) a participar do projeto de pesquisa O CONSTRUTO DE SUCESSO DO IMPLANTE COCLEAR NA CONCEPÇÃO DE PAIS E PROFESSORES, sob a responsabilidade da pesquisadora Tânis Moreira Rodrigues de Moura. O projeto visa pesquisar as situações bem sucedidas relacionadas à reabilitação através do Implante Coclear, bem como, as questões problemáticas para possíveis ajustes futuros, no sentido de diminuir os pontos negativos e potencializar os positivos deste processo.

O objetivo é investigar a noção de sucesso do implante coclear na visão dos pais e professores de crianças usuárias deste dispositivo no DF e que fazem reabilitação fonoterápica no CEAL - Centro Educacional de Audição e Linguagem Ludovico Pavoni.

$\mathrm{O}$ (a) senhor(a) receberá todos os esclarecimentos necessários antes e no decorrer da pesquisa e lhe asseguramos que seu nome não aparecerá sendo mantido o mais rigoroso sigilo pela omissão total de quaisquer informações que permitam identificá-lo(a)

A sua participação se dará por meio de preenchimento de questionários autoaplicáveis na data combinada com um tempo estimado de 30-60 minutos para sua realização e divulgação das menções do aluno implantado, quando autorizado pelo seu responsável.

O pequeno risco decorrente de sua participação na pesquisa pode acontecer no sentido de levá-lo(a) a pensar sobre questões que estavam adormecidas em relação ao processo de reabilitação pelo implante voclear. Se você aceitar participar, estará contribuindo para melhorar os ajustes necessários ao aprimoramento da reabilitação do implantado junto à família e professores.

$O$ (a) Senhor(a) pode se recusar a responder qualquer questão que lhe traga constrangimento, podendo desistir de participar da pesquisa em qualquer momento sem nenhum prejuízo para o(a) senhor(a). Sua participação é voluntária, isto é, não há pagamento por sua colaboração, bem como, não terá nenhuma despesa com a sua participação.

Caso haja algum problema direto resultante dos procedimentos de pesquisa, você poderá ser indenizado, obedecendo-se as disposições legais vigentes no Brasil.

Os resultados da pesquisa serão mostrados na Universidade de Brasília podendo ser publicados posteriormente. Os dados e questionários utilizados na pesquisa ficarão sob a guarda do pesquisador por um período de no mínimo cinco anos, após isso serão destruídos ou mantidos na instituição.

Se o(a) Senhor(a) tiver qualquer dúvida em relação à pesquisa, por favor telefone para: Tânis Moreira Rodrigues de Moura, na Fundação Universidade de Brasília nos telefones: 34485580 ou 8484 2307, no horário matutino.

Este projeto foi Aprovado pelo Comitê de Ética em Pesquisa da Faculdade de Ciências da Saúde (CEP/FS) da Universidade de Brasília. O CEP é composto por profissionais de diferentes áreas cuja função é defender os interesses dos participantes da pesquisa em sua integridade e dignidade e contribuir no desenvolvimento da pesquisa dentro de padrões éticos. As dúvidas com relação à assinatura do TCLE ou os direitos do participante da pesquisa podem ser obtidos através do telefone: (61) 3107-1947 ou do e-mail cepfs@unb.br ou cepfsunb@gmail.com, horário de atendimento de $10 \mathrm{hs}$ às $12 \mathrm{hs}$ e de $14 \mathrm{hs}$ às $17 \mathrm{hs}$, de segunda a sexta-feira.

Este documento foi elaborạdo em duas vias, uma ficará com a pesquisadora responsável e a outra com o Senhor(a).

Nome/assinatura

Professor(a)
Tânis Moreira Rodrigues de Moura

Pesquisadora Responsável 


\section{APÊNDICE C - Questionário dos professores}

Prezado professor (a),

Estou realizando uma pesquisa com crianças usuárias de implante coclear. Por isso, gostaria de saber qual a sua opinião sobre seu aluno (a) implantado (a). Posso contar com 20 minutos do seu tempo para o preenchimento das respostas?

Você está recebendo esta folha com umas questões, um questionário de marcar $\mathrm{X}$ e dois termos de livre esclarecimento. Preciso que você assine e me devolva um dos termos (o outro fica com você). Quando acabar os questionários, dobre os papéis para que não vejam suas respostas, coloque todo o material dentro do saco plástico e grampeie-o para que não haja violação na devolução.

Por gentileza, responda a todas as questões da forma que mais se adeque à sua opinião.

1- Há diferenças entre o desempenho acadêmico do implantado e a sua classe escolar? ( ) $\operatorname{Sim}$ ( )Não

2- Em comparação com os demais alunos da turma o aluno(a) implantado(a) se encontra:
( )Na média
( )Acima da média
( )Abaixo da média

3- Você entende o que seu aluno(a) implantado(a) fala?

()nunca ()as vezes ()quase sempre ()sempre

4- Cite 3 dificuldades encontradas em seu dia-a-dia no contato pedagógico com a criança implantada:

5- Cite 3 qualidades observadas por você em relação ao seu aluno(a) implantado(a):

Agradeço imensamente a sua colaboração e ajuda!

Agora só falta o outro questionário de marcar $\mathrm{X}$.

Atenciosamente,

Tânis Moreira. 


\section{QUESTIONÁRIO DIRECIONADO AOS PROFESSORES}

1- Você percebe que seu aluno detecta a fala?
()nunca
()as vezes
( )quase sempre
()sempre

2- Você percebe que seu aluno diferencia uma palavra longa de uma curta?
()nunca
()as vezes
( )quase sempre
( )sempre

3- Você percebe que seu aluno diferencia palavras que tem o mesmo número de sílabas com pista visual (exemplo: gato $\mathrm{x}$ casa)?

()nunca ()as vezes ()quase sempre $\quad$ ()sempre

4- Você percebe que seu aluno sabe diferenciar as palavras pelas vogais com pista visual (exemplo: pé, pó, pá)?
()nunca
( )as vezes
( )quase sempre
()sempre

5- Você percebe que seu aluno sabe diferenciar as palavras pelas consoantes com pista visual (exemplo: mão, pão, cão, chão)?

$\begin{array}{llll}\text { ()nunca ()as vezes } \quad \text { ()quase sempre } & \text { ()sempre }\end{array}$

6- Você percebe que seu aluno consegue entender o que foi dito?

( )nunca ()as vezes ()quase sempre ()sempre

7- Seu aluno emite algum som de fala?
( )nunca
( )as vezes
( )quase sempre
( )sempre 
8- Seu aluno fala algumas palavras?
()nenhuma
()algumas
( )muitas
()todas

9- Seu aluno fala frases de 2 ou 3 palavras (exemplo: Quero água. Mamãe, quero dormir.)?

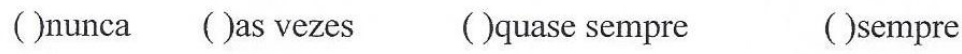

10-Seu aluno fala frases de 4 ou 5 palavras (exemplo: Já coloquei meu pijama. Mamãe, me dá um copo?)?
( )nunca
( )as vezes
( )quase sempre
()sempre

11- Você acha que seu aluno fala bem?

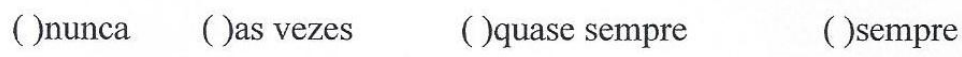




\section{APÊNDICE D - Questionário direcionado aos pais}

1-Seu filho detecta a fala?
( )nunca
( )as vezes
( )quase sempre
( )sempre

2- Seu filho diferencia uma palavra longa de uma curta?
( )nunca
( )as vezes
( )quase sempre
( )sempre

3- Seu filho diferencia palavras que tem o mesmo número de sílabas com pista visual (Ex.: gato $x$ casa)?
( )nunca
( )as vezes
( )quase sempre
( )sempre

4- Seu filho sabe diferenciar as palavras pelas vogais com pista visual (Ex.: pé, pó, pá)?
( )nunca
( )as vezes
( )quase sempre
( )sempre

5- Seu filho sabe diferenciar as palavras pelas consoantes com pista visual (Ex.: mão, pão, cão)?
( )nunca
( )as vezes
( )quase sempre
( )sempre

6-Seu filho consegue entender o que foi dito?
( )nunca
( )as vezes
( )quase sempre
( )sempre

7-Seu filho emite algum som de fala?
( )nunca
( )as vezes
( )quase sempre
( )sempre

8-Seu filho fala algumas palavras?
( )nenhuma
( )as vezes
( )quase sempre
( )sempre

9- Seu filho fala frases de 2 ou 3 palavras?
( )nunca
( )algumas
( )muitas
()todas

10- Seu filho fala frases de 4 e 5 palavras?
( )nunca
( )as vezes
( )quase sempre
( )sempre 
11- Você acha que seu filho fala bem?
( )nunca
( )as vezes
( )quase sempre
( )sempre 


\title{
ANEXO I - Termo de Concordância da Instituição Co-participante
}

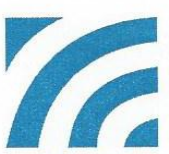

\author{
Associação das Obras Pavonianas de Assistência \\ CNPJ 62.382.395/0006-04 \\ CENTRO EDUCACIONAL DA AUDIÇÃO E LINGUAGEM \\ "LUDOVICO PAVONI" - CEAL/LP
}

\section{TERMO DE CONCORDÂNCIA}

GIUSEPPE RINALDI, Diretor do Centro Educacional da Audição e Linguagem "Ludovico Pavoni" - CEAL-LP está de acordo com a realização, nesta instituição, da pesquisa O CONSTRUTO DE SUCESSO DO IMPLANTE COCLEAR EM CRIANÇAS NA CONCEPÇÃO DOS PROFISSIONAIS DE SAÚDE, PAIS E PROFESSORES, de responsabilidade da pesquisadora Tânis Moreira Rodrigues de Moura, para investigar sobre a temática do implante coclear em crianças, após aprovação pelo Comitê de Ética em Pesquisa com Seres Humanos da Faculdade de Ciências da Saúde da Universidade de Brasília.

O estudo envolve realização de entrevistas aplicadas aos pais e professores de crianças usuárias de implante. Tem duração de dois anos, com previsão de início para outubro de 2013.

Brasília - DF, 12 de agosto de 2013.

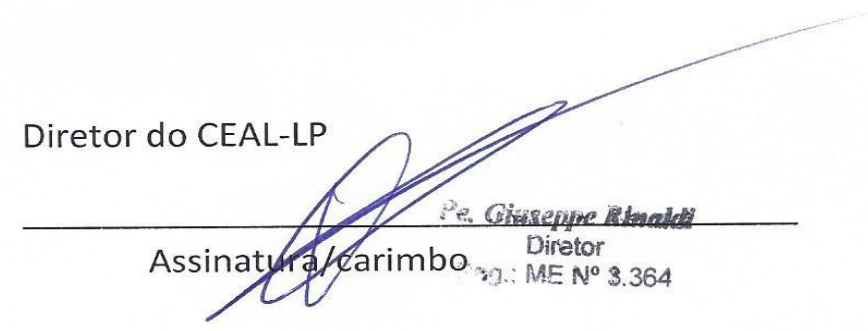

Chefia responsável pela Unidade Clínica / Acadêmica:

Assinatura/carimbo

Pesquisador Responsável pelo protocolo de pesquisa:

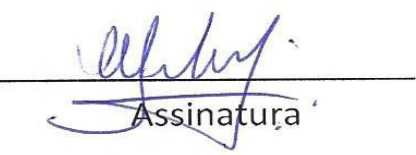

SGAN 909/B - CEP 70790-090 - BRASÍLIA-DF - CAIXA POSTAL 6172 - CEP 70749-970

FONE: (61) 33499944 - FAX: (61) 33471307

E-MAIL: secretaria@ceallp.org.br / centroaudiologico@ceallp.org.br 


\section{ANEXO II - Parecer do Comitê de Ética em Pesquisa}
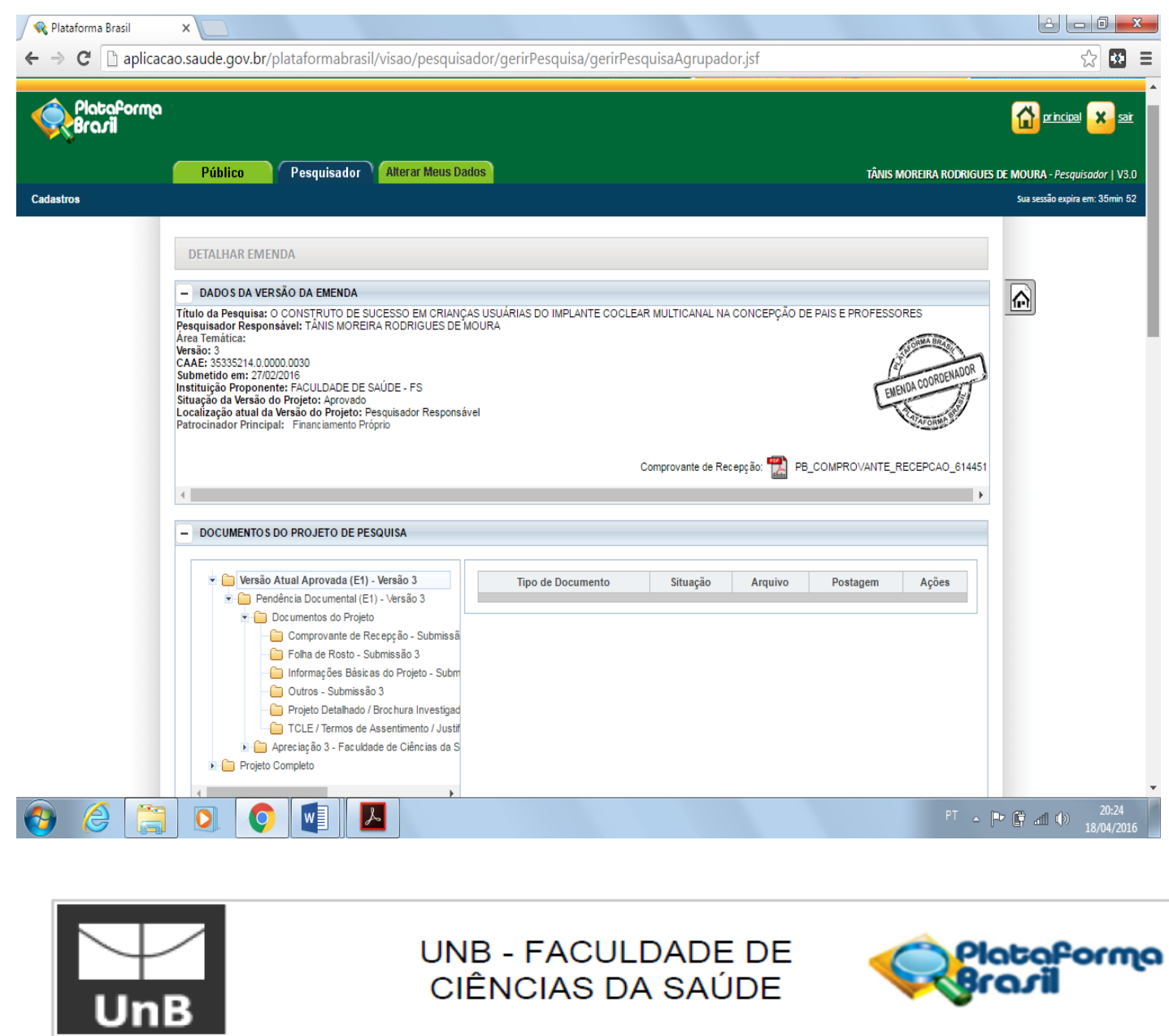

\section{UNB - FACULDADE DE CIÊNCIAS DA SAÚDE}

\section{COMPROVANTE DE ENVIO DO PROJETO}

\section{DADOS DO PROJETO DE PESQUISA}

Título da Pesquisa: $\quad$ O CONSTRUTO DE SUCESSO DO IMPLANTE COCLEAR EM CRIANÇAS NA CONCEPÇÃO DE PAIS E PROFESSORES

Pesquisador: TÂNIS MOREIRA RODRIGUES DE MOURA

Versão: 2

CAAE: 35335214.0 .0000 .0030

Instituição Proponente:

FACULDADE DE SAÚDE - FS

DADOS DO COMPROVANTE

Número do Comprovante:

$074343 / 2014$

Patrocionador Principal:

Financiamento Próprio

Informamos que o projeto O CONSTRUTO DE SUCESSO DO IMPLANTE COCLEAR EM CRIANÇAS NA CONCEPÇÃO DE PAIS E PROFESSORES que tem como pesquisador responsável TÂNIS MOREIRA RODRIGUES DE MOURA, foi recebido para análise ética no CEP UnB - Faculdade de Ciências da Saúde em 28/08/2014 às 10:46. 
Plotcoforna MINISTÉRIO DA SAÚDE - Conselho Nacional de Saúde - Comissăo Nacional de Ética em Pesquisa - CONEP Groril

FOLHA DE ROSTO PARA PESQUISA ENVOLVENDO SERES HUMANOS

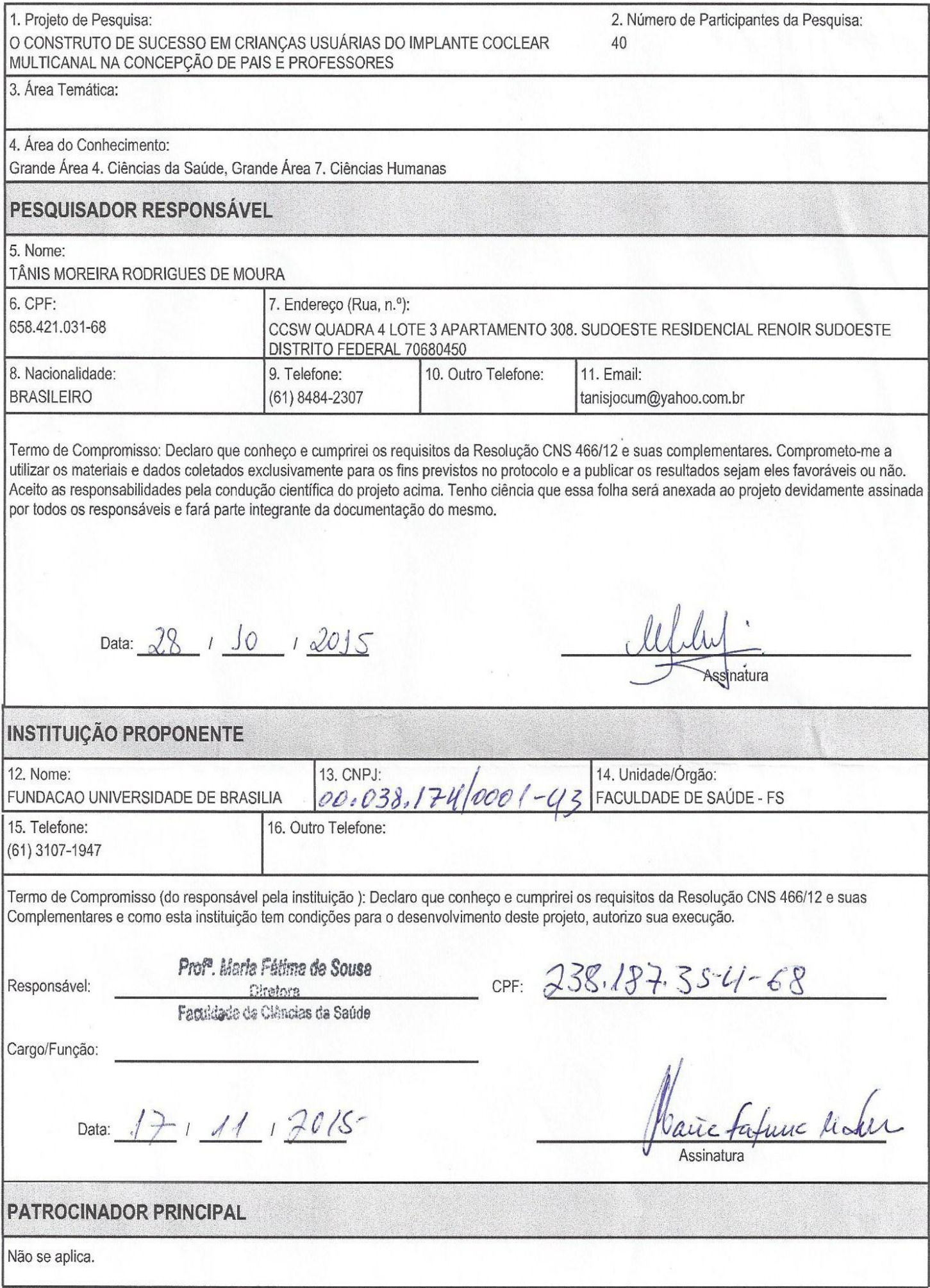




\title{
ANEXO III - Questionário "Crianças com implante coclear: perspectivas dos pais"
}

\section{Crianças com implante coclear: perspectivas dos pais}

\author{
Desenvolvido por Sue Archibold e Mark Lutman. \\ Development support by The Royal National Institute for Deaf People. \\ Traduzido e adaptado para o Português Brasileiro por Talita Fortunato- Tavares, Debora Befi-Lopes, Ricardo F. \\ Bento e Claudia R. F. Andrade.
}

\section{Nome da Criança:}

Gostaríamos de ajudar a responder este questionário.

Reconhecemos que você está na melhor posição para descrever o que o implante coclear significa para sua criança e para sua família.

Este questionário é direcionado para os pais. Ele deve ser respondido após pelo menos um ano de uso do implante coclear.

Ele consiste de frases com as quais você pode concordar ou discordar.

Você deve marcar uma das cinco caixas para indicar sua opinião: concordo plenamente, concordo, nem concordo nem discordo, discordo, discordo plenamente.

As frases foram baseadas em entrevistas com pais que possuem filhos com implante coclear.

Por favor, forneça sua resposta inicial ao invés de ficar pensando por um longo período.

Por favor, marque somente uma caixa por frase e não deixe nenhuma sem responder.

Se alguma frase não se aplicar à sua situação como, por exemplo, se não houver irmãos, por favor, escreva ' $N / A^{\prime}$ (significando não aplicável) para sabermos que você não se esqueceu de respondê-la.

Muito obrigado por usar seu tempo para responder ao questionário.

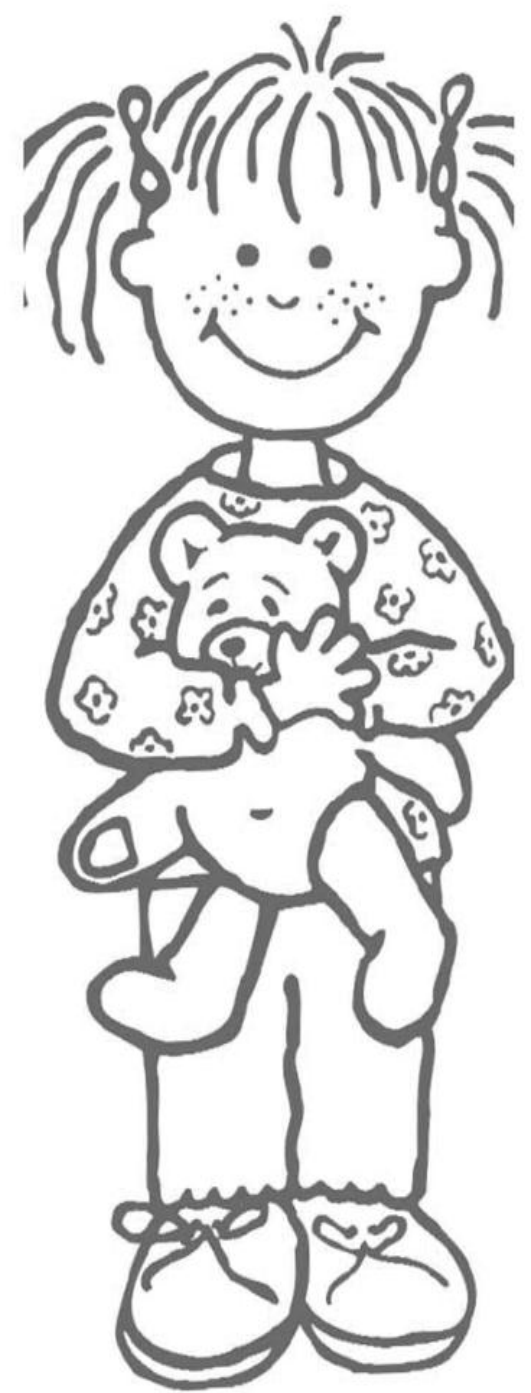




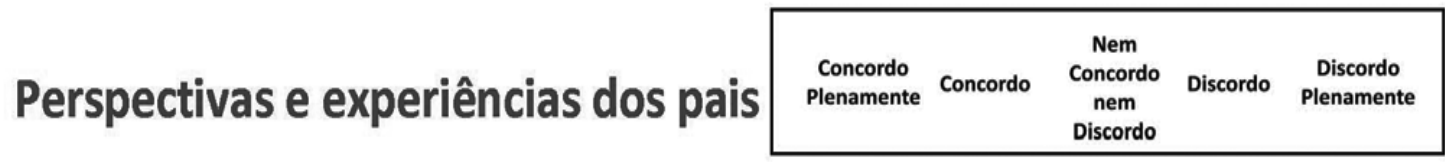

1. A comunicação é difícil mesmo com pessoas que ela conhece bem.

2. Imediatamente após a cirurgia a habilidade de minha filha de se comunicar era pior que agora.

3. A ajuda que eu forneço a ela se tornou mais produtiva agora que ela tem o implante.

4. Antes da cirurgia ela não apresentava benefício nenhum com as próteses auditivas.

5. Ela não tem uma relação próxima com os avôs.

6. Ela é totalmente dependente do implante o tempo todo.

7. Ela sabe quando eu quero chamar sua atenção porque ela consegue me ouvir chamá-la.

8. Eu me preocupo que o implante quebre.

9. Ela não está apta para a escola regular.

10. Tem sido um problema conseguir alguém para cuidar da família quando vamos ao Centro de Implante.

11. $\overline{0 \text { progresso durante os primeiros meses pareceu muito }}$ devagar.

12. Quase nunca eu posso deixá-la fazer alguma coisa sozinha.

13. O programa no Centro de Implante deveria enfatizar fala e audição.

14. Eu me preocupo que ela irá me culpar pela decisão de implantar.

15. Ela tem precisado de mais ajuda minha desde que recebeu o implante.

16. Ela ainda demonstra sinais de frustração em seu comportamento.

17. Eu me preocupo que minha filha será rejeitada pela Comunidade Surda por causa do implante.

18. A qualidade da fala dela me preocupa.

19. Muita ajuda no começo do tratamento significa que a criança precisará de menos ajuda mais tarde.

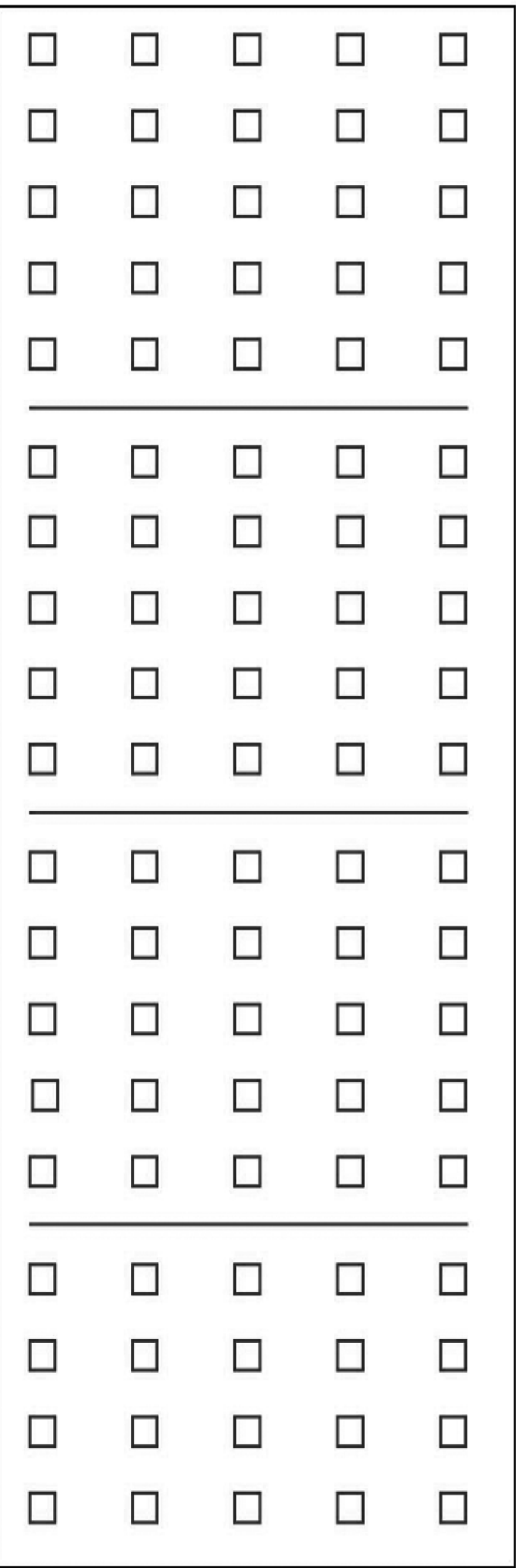


Perspectivas e experiências dos pais $\begin{gathered}\text { Nem } \\ \begin{array}{c}\text { concordo } \\ \text { Plenamente }\end{array} \text { concordo } \begin{array}{c}\text { nerdo } \\ \text { nem }\end{array}\end{gathered}$ Discordo $\begin{gathered}\text { Discordo } \\ \text { Plenamente }\end{gathered}$

20. Eu tenho mais tempo para mim devido ao aumento da independência de minha filha.

21. Somente equipes experientes devem realizar cirurgias de implante coclear.

22. Os custos para se locomover até o Centro de Implante são um problema.

23. Na escola ela está acompanhando bem as crianças da sua idade.

24. $O$ apoio em Libras ou sinais é útil por um período considerável após o implante.

25. Eu gostaria de participar de encontros com outras famílias que tem criança implantada.

26. 0 progresso após o implante tem excedido minhas expectativas.

27. Agora nós podemos conversar mesmo que ela não consiga ver meu rosto (por exemplo, no carro ou no escuro).

28. Tomar a decisão de realizar a cirurgia foi a parte mais difícil para mim.

29. A espera pelos resultados da avaliação antes da cirurgia foi um período difícil para mim.

30. Antes do implante ela estava socialmente isolada.

31. A escola local e os serviços de apoio supriram adequadamente todas as nossas necessidades relacionadas ao uso do implante na escola.

32. Uma mudança significativa tem sido a melhora na autoconfiança de minha filha.

33. Ela era muito dependente de nós antes do implante.

34. Nós sentimos necessidade de apoio do Centro de Implante com relação ao futuro de minha filha.

35. Agora ela se diverte ouvindo música, assistindo TV, ou jogando vídeo-game.

36. Nós somos dependentes do Centro de Implante para apoio técnico do implante.

37. Eu me preocupo com o futuro de minha filha relativo à escola.

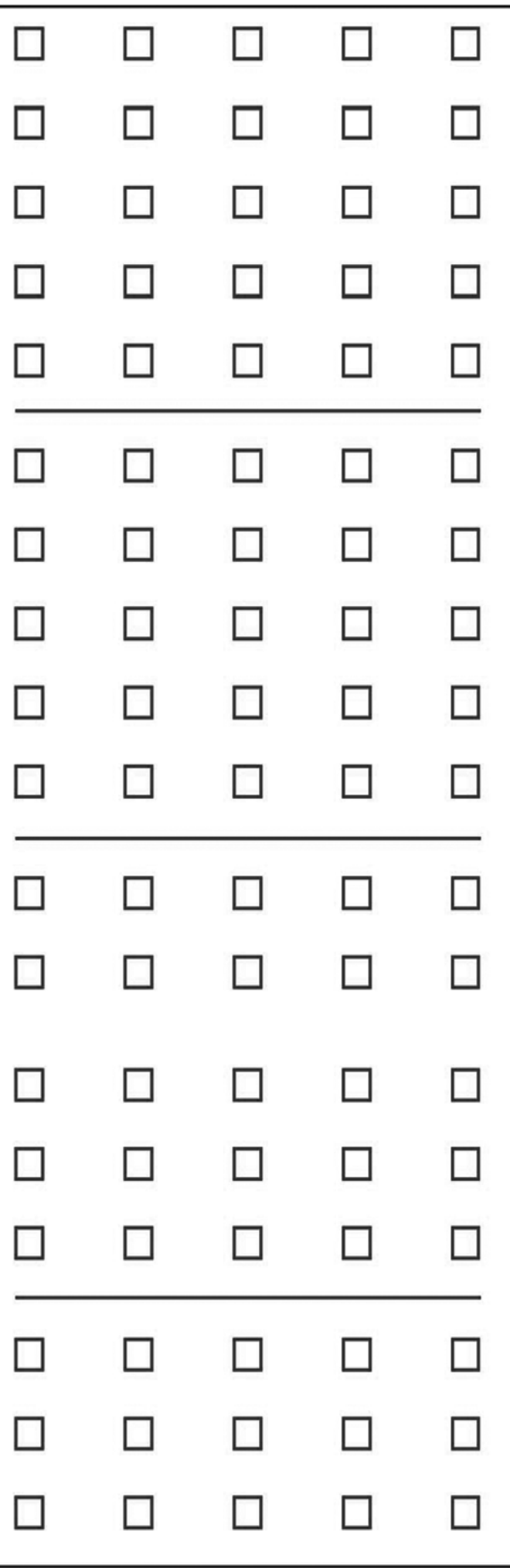


Perspectivas e experiências dos pais

38. O processo de cirurgia não foi mais invasivo do que eu esperava.

39. Ela não faz amigos fora da família facilmente.

40. É essencial que minha filha esteja encorajada a usar o processador o tempo todo.

41. Ela é sociável dentro da família.

42. Uma atitude positiva é de grande ajuda para o sucesso com o uso do implante.

43. Ajustes e checagens regulares do sistema de implante são essenciais.

44. Pelo menos uma visita por ano de funcionários do Centro de Implante na casa/escola é essencial.

45. Ela compartilha situações em família mais frequentemente agora do que antes do implante.

46. Antes de proceder à cirurgia pais deveriam obter o maior número de informações possível sobre o dispositivo.

47. Ela é tão independente quanto a maioria das crianças da idade dela.

48. Pais deveriam ter a opção de usar língua de sinais na escola.

49. Foi útil conhecer outra família com criança implantada antes de decidir implantar.

50. Eu estou feliz com o progresso dela na escola.

51. Agora eu posso deixá-la brincar fora porque ela está ciente dos sons do trânsito.

52. O fator mais importante em escolher um dispositivo de implante é a confiabilidade.

53. Ela ainda está inapta a lidar com situações novas.

54. Eu estou confiante que estimulação elétrica a longo prazo não ser um problema.

55. Todo o processo de implantação ainda é estressante.

56. Eu esperava que ela falasse assim que colocasse o implante.

\begin{tabular}{|ccc|}
\hline $\begin{array}{c}\text { Concordo } \\
\text { Plenamente }\end{array}$ Concordo & $\begin{array}{c}\text { Nem } \\
\text { Concordo } \\
\text { nem } \\
\text { Discordo }\end{array}$ & Discordo \\
\hline
\end{tabular}
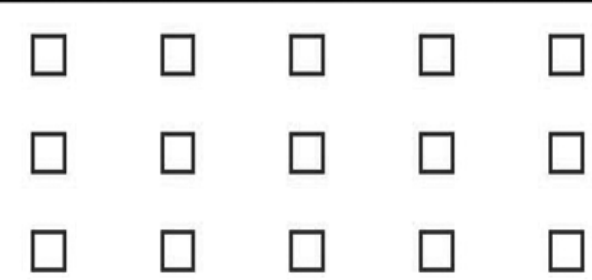

$\square \quad \square \quad \square \quad \square$
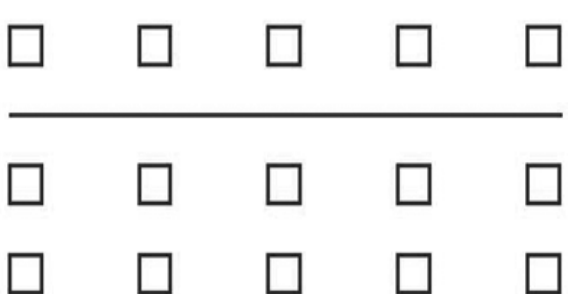

$\square \square \square \square \square$
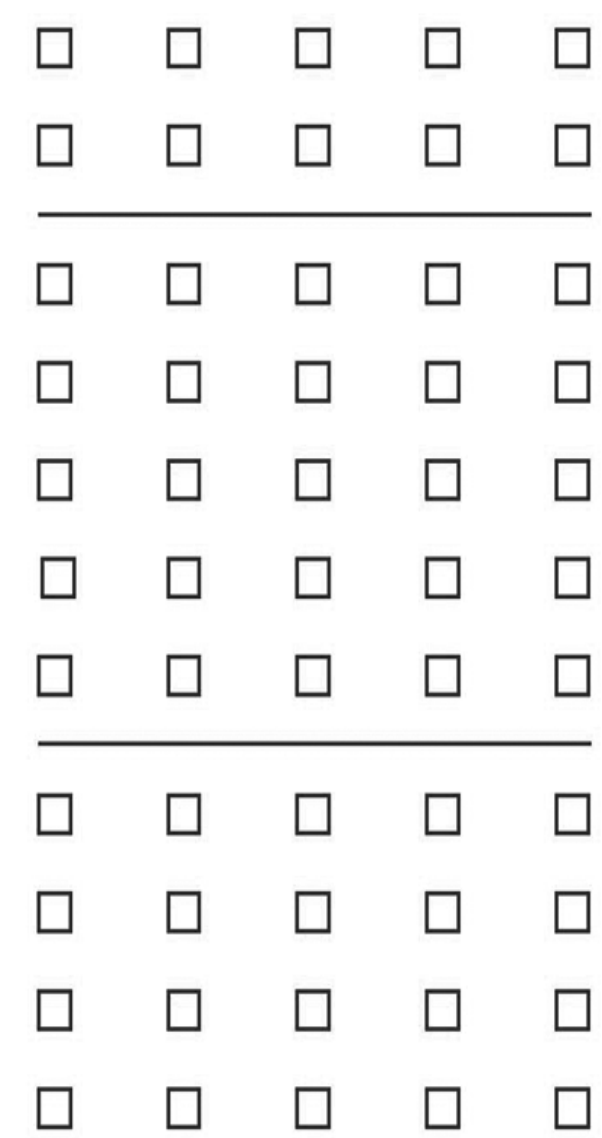
Perspectivas e experiências dos pais

\begin{tabular}{|c|c|c|c|c|}
\hline $\begin{array}{l}\text { Concordo } \\
\text { Plenamente }\end{array}$ & Concordo & $\begin{array}{c}\text { Nem } \\
\text { Concordo } \\
\text { nem } \\
\text { Discordo }\end{array}$ & Discordo & $\begin{array}{l}\text { Discordo } \\
\text { Plenamente }\end{array}$ \\
\hline
\end{tabular}

57. Eu me preocupo que agora ela não faça parte nem do mundo surdo nem do mundo ouvinte.

58. Foi importante para mim que minha filha pudesse ouvir os sons do trânsito por motivos de segurança.

59. O comportamento dela melhorou depois do implante.

60. Agora eu acredito que minha filha terá perspectivas de emprego razoáveis.

61. Ela se tornou argumentadora desde que recebeu o implante.

62. Os pais de uma criança com implante precisam ser pacientes já que os benefícios podem demorar a aparecer.

63. Tem sido difícil sair do trabalho para as consultas no Centro de Implante.

64. Ela é menos frustrada agora do que antes do implante.

65. Ela faz parte de relações familiares do mesmo modo que outros membros da família.

66. Eu acho mais fácil me comunicar com ela pela fala do que por sinais.

67. Eu dou a mesma quantidade de ajuda agora do que antes do implante.

68. Eu optei pelo implante para que minha filha pudesse ter a chance de fazer parte do mundo ouvinte.

69. Ela é totalmente dependente do implante na escola.

70. Ela continua sendo uma criança feliz e é muito agradável e feliz de estar perto dela.

71. O desenvolvimento de linguagem oral (fala) tem se desenvolvido otimamente.

72. Agora ela é falante e envolve outros em conversas.

73. Outras crianças da família ficam ressentidas, incomodadas com o tempo e a atenção tomados pelo implante.

(Marque aqui se não há outras crianças na família)

74. A relação dela com irmãos ou irmãs tem melhorado.

(Marque aqui se não há irmãos ou irmãs.)

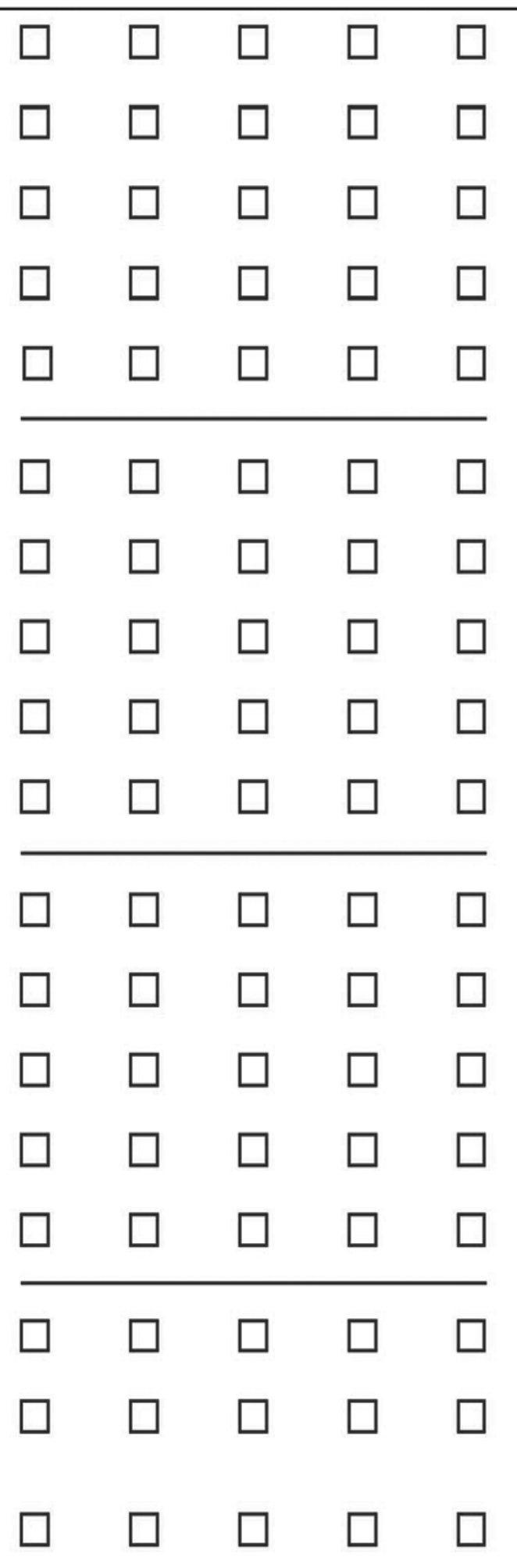




\section{Muito obrigado por preencher o questionário!}

Data de nascimento da criança

Seu nome

Sua relação com a criança

(pai, mãe, responsável pela criança etc.)

Mês e ano da cirurgia

Data de hoje

Por favor, use este espaço para fazer comentários sobre observações não abordadas neste questionário. 
